\title{
Model Based Evaluation of the Differences between Full and Partial Flow Particulate Matter Sampling Systems
}

\author{
Nathan Kimble \\ West Virginia University
}

Follow this and additional works at: https://researchrepository.wvu.edu/etd

\section{Recommended Citation}

Kimble, Nathan, "Model Based Evaluation of the Differences between Full and Partial Flow Particulate Matter Sampling Systems" (2011). Graduate Theses, Dissertations, and Problem Reports. 2256.

https://researchrepository.wvu.edu/etd/2256

This Thesis is protected by copyright and/or related rights. It has been brought to you by the The Research Repository @ WVU with permission from the rights-holder(s). You are free to use this Thesis in any way that is permitted by the copyright and related rights legislation that applies to your use. For other uses you must obtain permission from the rights-holder(s) directly, unless additional rights are indicated by a Creative Commons license in the record and/ or on the work itself. This Thesis has been accepted for inclusion in WVU Graduate Theses, Dissertations, and Problem Reports collection by an authorized administrator of The Research Repository @ WVU. For more information, please contact researchrepository@mail.wvu.edu. 
Model Based Evaluation of the Differences between Full and Partial Flow Particulate Matter Sampling Systems

\author{
Nathan Kimble \\ Thesis submitted to the \\ College of Engineering and Mineral Resources \\ at West Virginia University \\ in partial fulfillment of the requirements \\ for the degree of
}

Master of Science

in

Mechanical Engineering

Dr. John Nuszkowski, Chair

Dr. Benjamin Shade

Dr. Hailin Li

Department of Mechanical and Aerospace Engineering

Morgantown, West Virginia

2011

Keywords: Diesel Emissions, Particulate Matter, Error Propagation, Particulate Loss Copyright 2011 Nathan Kimble 


\section{ABSTRACT \\ Model Based Evaluation of the Differences between Full and Partial Flow Particulate Matter Sampling Systems}

\section{Nathan Kimble}

PM has been shown to be harmful to people, animals, and the environment. For this reason PM is a regulated emission. As federal regulation of particulate matter (PM) becomes tighter, the need to accurately measure it becomes paramount. As the limit decreases, it becomes more difficult to measure PM due to the inaccuracies in the measurement equipment, and the nature of the particles to be lost in the sampling system.

This study investigated the error propagation and particle loss in two common PM mass measurement systems, the full flow sampling system, also called the constant volume sampling (CVS), and the partial flow sampling (PFS) systems. Computer models were created to simulate the propagation of inaccuracies in the components to total error, and to simulate how many and why particles get lost in the systems. The data that the models used came from transient testing of a 2004 model year heavy-duty diesel engine from which both a CVS and PFS system were used to measure the emissions of PM. Particle spectrometer data were also collected and used in the particle loss model. The models produced batch error results and integrated mass loss results. The models also produced continuous error propagation and continuous particle loss to give more insight as to when in the transient test the largest errors and particle losses were occurring. Another useful result from the particle loss model was showing which types of losses affect which size of particle. Four types of particle loss were considered: diffusion, thermophoretic, isokinetic, and bend. Each of the loss types affected the particle distribution differently.

The CVS system had less error in its measurement, but more particles were lost therein. The PFS system had much more error than the CVS, but fewer particles were lost. The relative error in the CVS system was minimal at approximately $10 \%$, whereas the PFS system had a relative error of approximately $36 \%$. The losses in the CVS system lowered the mass result by approximately $11 \%$, and the losses in the PFS system lowered the mass result by approximately $5 \%$. 


\section{Acknowledgements and Dedication}

I would like to acknowledge and thank a few people that have helped me in completing this thesis. Thank you, Dr. Nuszkowski, for pointing me in the right direction and motivating me to put away distractions and finish this paper. Thank you, Dr. Shade, for hiring me as a graduate student and being my first advisor. Thank you, Dr. Li, for agreeing to be on my committee on such late notice and for being a great first Thermodynamics teacher. Thank you, everyone that was a part of the 2008 BG-3 testing, for collecting good data that I gladly used in this thesis. Thank you, everyone else at WVU CAFEE, for all the help and friendship that I received. Thank you, Pat and Jane, for all the great food and support that you afforded me during this process. Thank you, Dad and Mom, for always knowing what the future holds for me better than I do. Thank you, Emily, for being the best wife I ever had. Thank you, Roxann, for sleeping well at night and being my best cheerleader.

This work is dedicated to Roxann. 


\section{Table of Contents}

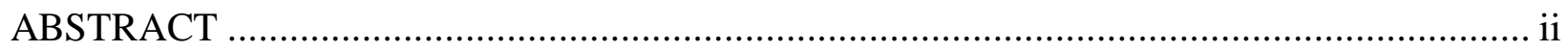

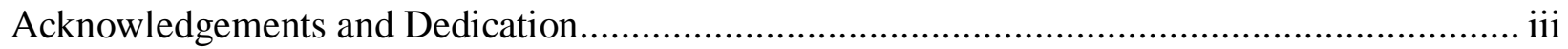

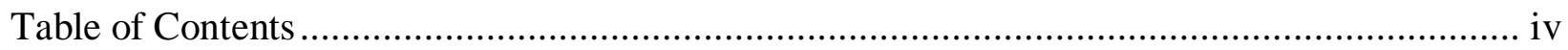

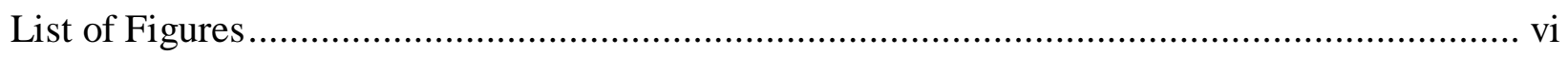

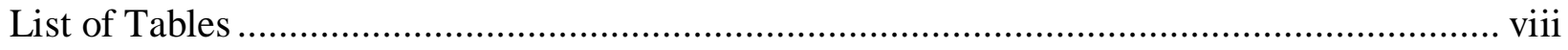

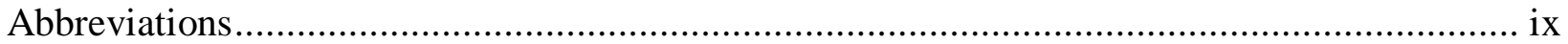

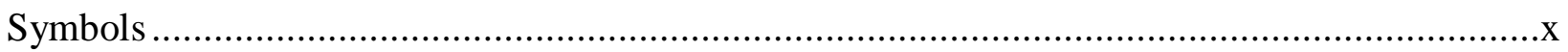

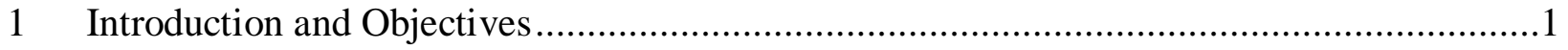

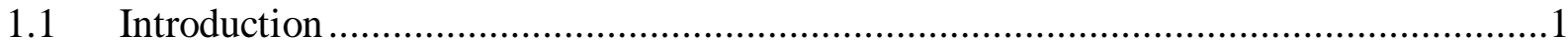

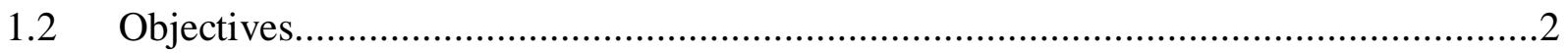

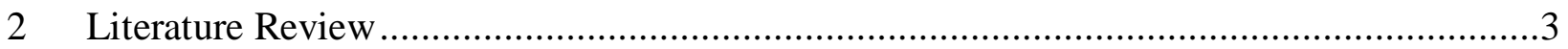

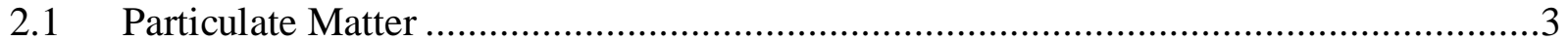

2.1.1 Health and Environmental Effects Related to Particulate Matter..............................3

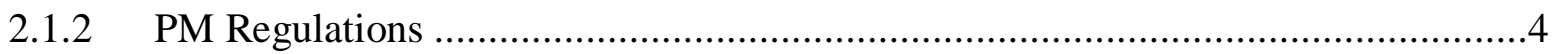

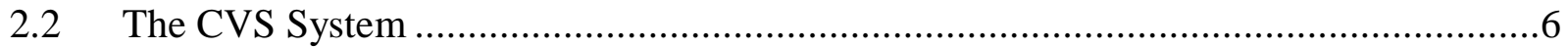

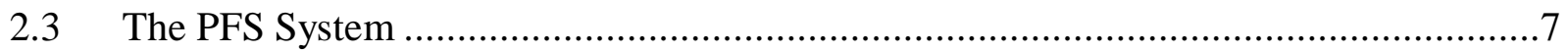

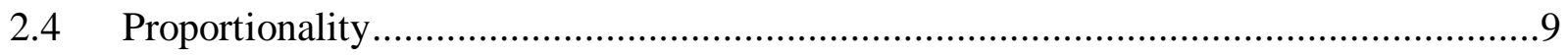

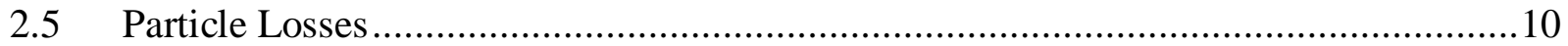

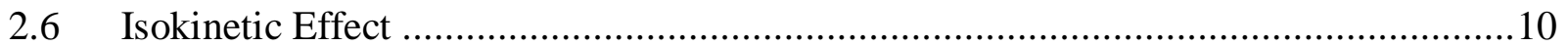

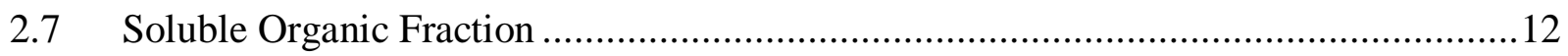

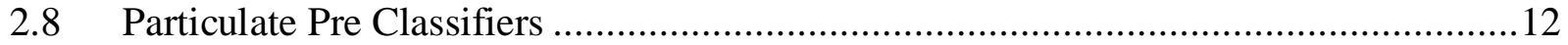

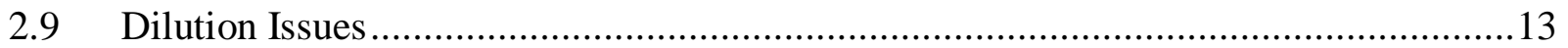

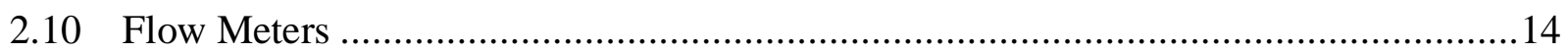

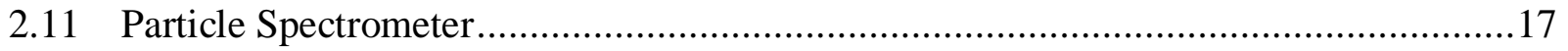

2.12 Error Propagation in Emissions Measurement Systems ……………………..............18

2.13 Previous Studies about Experimental Differences between PM Systems .....................19

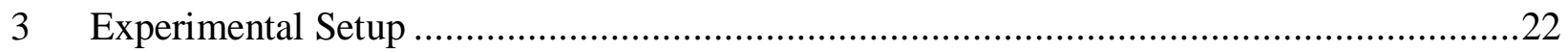

$3.1 \quad$ Test Engine

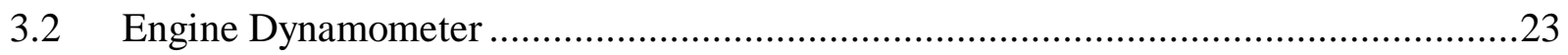


3.3 Heavy-Duty Federal Test Procedure (FTP) ...............................................23

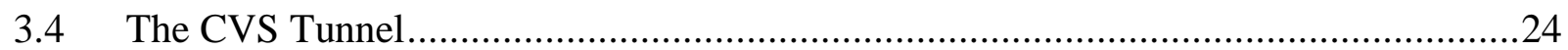

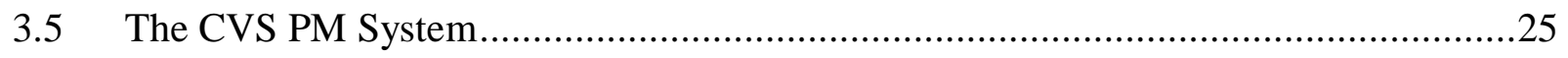

3.6 The Class 1000 Clean Room ..........................................................................22

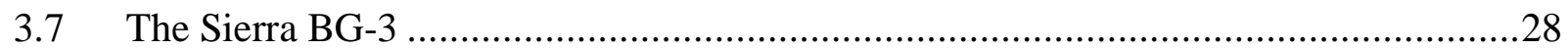

3.8 Engine Exhaust Particle Sizer Spectrometer................................................30

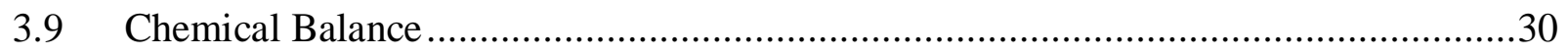

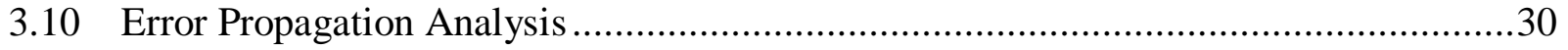

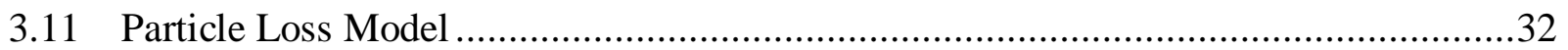

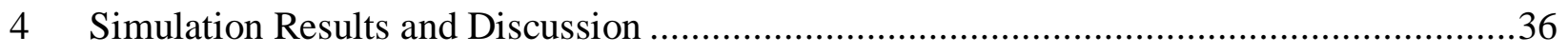

4.1 Batch Error Propagation Analysis ................................................................36

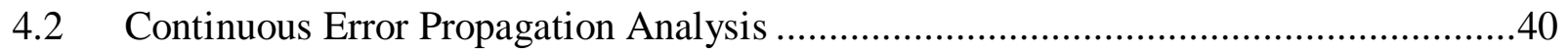

4.3 Validation of Loss Model ..........................................................................43

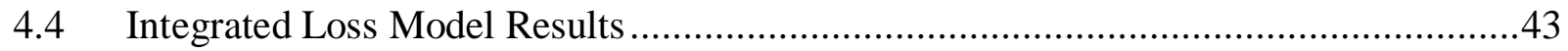

4.4.1 CVS Integrated Loss Results .................................................................44

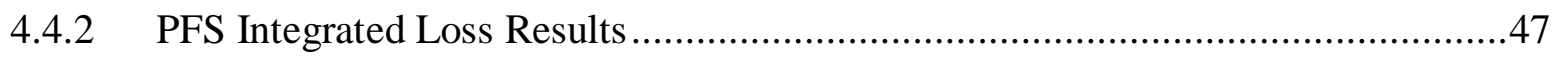

4.5 Continuous Loss Model Results ...................................................................50

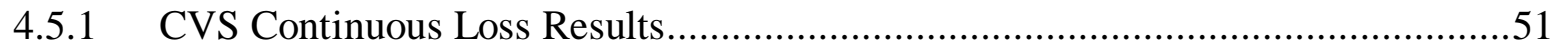

4.5.2 PFS Continuous Loss Results................................................................58

5 Conclusions and Recommendations ...................................................................65

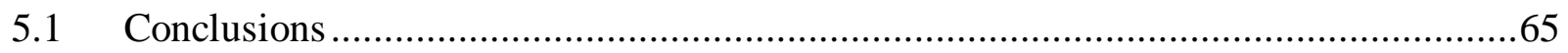

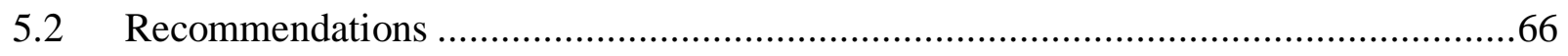

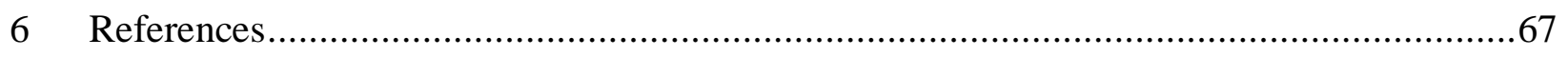

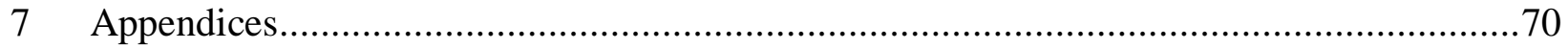

7.1 Code for CVS Error Propagation Analysis Model ..............................................70

7.2 Code for PFS Error Propagation Analysis Model ................................................73

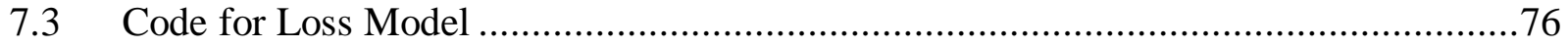




\section{List of Figures}

Figure 2-1: Heavy Duty Diesel Emissions Standards [2].......................................................

Figure 2-2: Constant Volume Sampling and Partial Flow Sampling Diagrams [6] .......................

Figure 2-3: Sampling Probe Facing into Flow with Probe Velocity Less than Isokinetic..............11

Figure 2-4: Sampling Probe Facing Backwards to Flow ..........................................................11

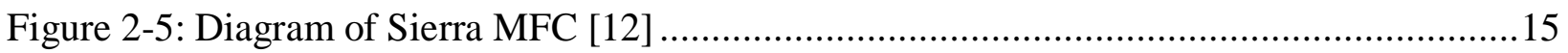

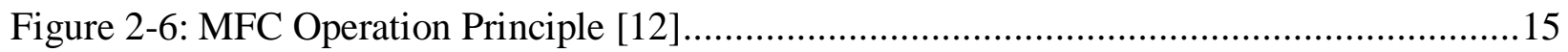

Figure 2-7: Diagram of a Roots Type Positive Displacement Pump..........................................16

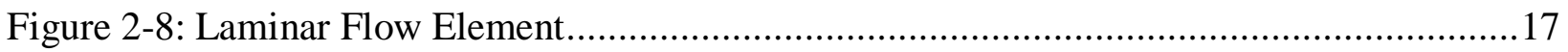

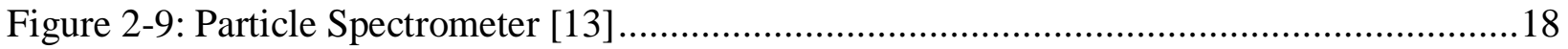

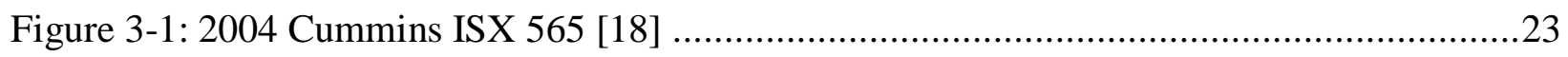

Figure 3-2: Federal Test Procedure [19] ………………..............................................24

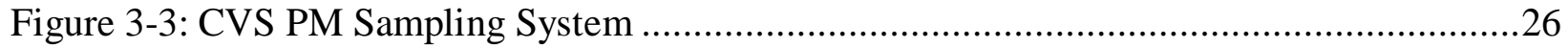

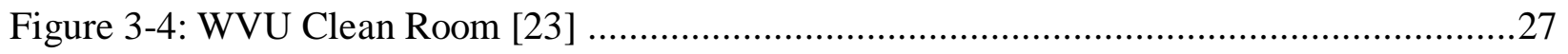

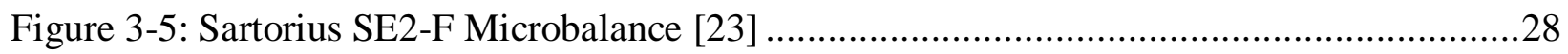

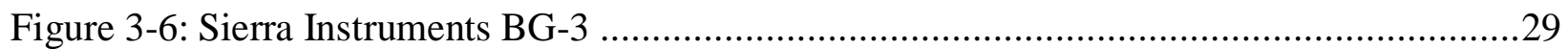

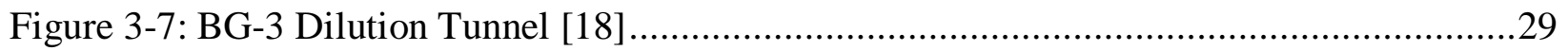

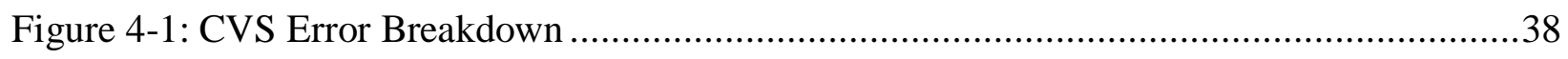

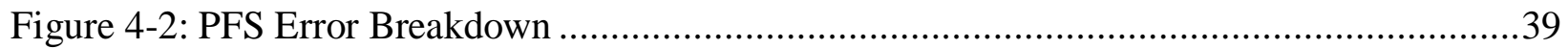

Figure 4-3: Calculated PM Mass Rate ................................................................................

Figure 4-4: Continuous Error Analysis of the CVS System.....................................................41

Figure 4-5: Continuous Error Analysis of the PFS System.................................................42

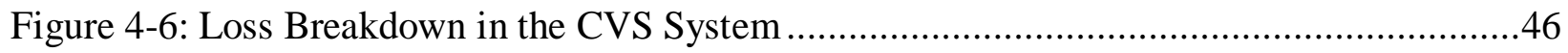

Figure 4-7: Loss Breakdown in the PFS System ………..................................................50

Figure 4-8: Continuous Particle Distribution ........................................................................51

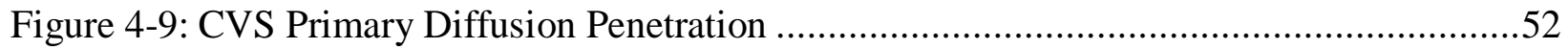

Figure 4-10: CVS Primary Dilution Tunnel Thermophoretic Penetration...................................53

Figure 4-11: CVS PM Probe Isokinetic Penetration ................................................................5

Figure 4-12: CVS Secondary Dilution Tunnel Diffusion Penetration ........................................55

Figure 4-13: CVS Secondary Dilution Tunnel Thermophoretic Penetration.................................55 


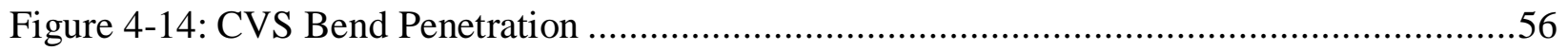

Figure 4-15: CVS Combined Particle Penetration................................................................57

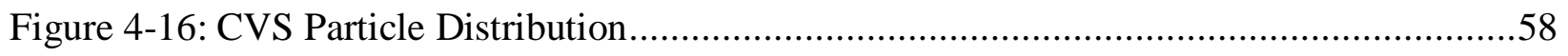

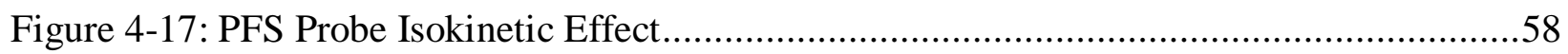

Figure 4-18: PFS Diffusion Particle Penetration ................................................................59

Figure 4-19: Diffusion Penetration Comparison .....................................................60

Figure 4-20: PFS Thermophoretic Particle Penetration .................................................61

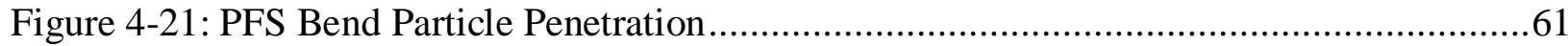

Figure 4-22: PFS Combined Particle Penetration .........................................................62

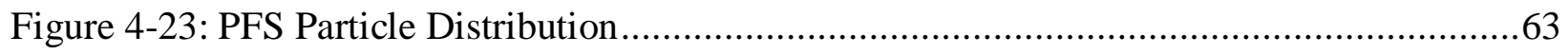

Figure 4-24: Difference between PFS and CVS Particle Penetration....................................64 


\section{List of Tables}

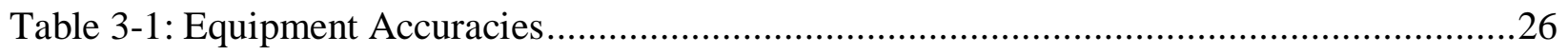

Table 4-1: CVS Error Propagation Analysis Results .................................................................

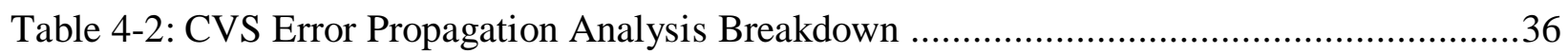

Table 4-3: PFS Error Propagation Analysis Results ..................................................................

Table 4-4: PFS Error Propagation Analysis Breakdown ............................................................... 37

Table 4-5: Adjusted PFS Error Propagation Analysis Results ......................................................39

Table 4-6: Adjusted PFS Error Propagation Analysis Breakdown.............................................40

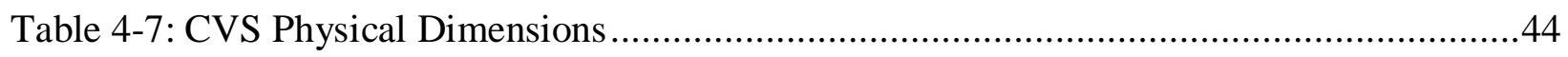

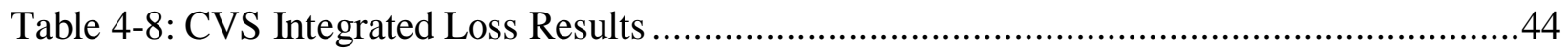

Table 4-9: CVS Integrated Loss Breakdown........................................................................4

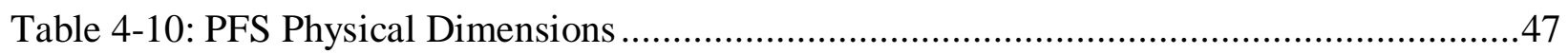

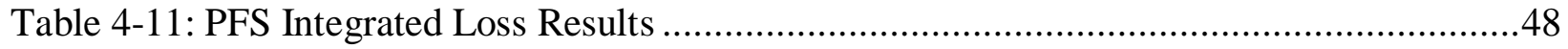

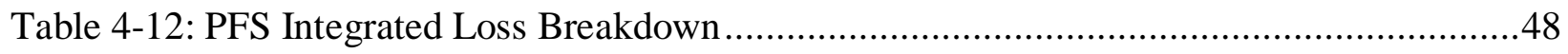




$\begin{array}{ll}\text { Abbreviations } & \\ \mathrm{CFR} & \text { Code of Federal Regulations } \\ \mathrm{CO} & \text { Carbon Monoxide } \\ \mathrm{CO}_{2} & \text { Carbon Dioxide } \\ \mathrm{CVS} & \text { Constant Volume Sampling } \\ \text { DPF } & \text { Diesel Particulate Filter } \\ \text { EC } & \text { Elemental Carbon } \\ \text { EGR } & \text { Exhaust Gas Recirculation } \\ \text { EPA } & \text { Environmental Protection Agency } \\ \text { FTP } & \text { Federal Test Procedure } \\ \mathrm{HC} & \text { Hydrocarbons } \\ \text { HEPA } & \text { High Efficiency Particulate Air } \\ \text { LFE } & \text { Laminar Flow Element } \\ \text { MFC } & \text { Mass Flow Controller } \\ \text { NOx } & \text { Oxides of Nitrogen } \\ \text { PDP } & \text { Positive Displacement Pump } \\ \text { PFS } & \text { Partial Flow Sampling } \\ \text { PM } & \text { Particulate Matter } \\ \text { SOF } & \text { Soluble Organic Fraction } \\ \text { SSV } & \text { Subsonic Venturi } \\ \text { VGT } & \text { Variable Geometry Turbocharger }\end{array}$




\section{Symbols}

\begin{tabular}{|c|c|}
\hline $\mathrm{C}_{\mathrm{c}}$ & Cunningham Slip Correction \\
\hline $\mathrm{D}$ & Particle Diffusion Coefficient \\
\hline $\mathrm{Dp}$ & Particle Diameter \\
\hline $\mathrm{d}$ & Tube Diameter \\
\hline $\mathrm{d}_{\text {probe }}$ & Probe Diameter \\
\hline $\mathrm{K}$ & Boltzmann Constant \\
\hline $\mathrm{L}$ & Tube Length \\
\hline $\mathrm{M}_{\text {background }}$ & PM Mass Collected on the Background Filter \\
\hline $\mathrm{M}_{\mathrm{PM}}$ & PM Mass Emitted \\
\hline $\mathrm{M}_{\text {sample }}$ & PM Mass Collected on Test Filter \\
\hline $\mathrm{P}$ & Pressure \\
\hline $\mathrm{V}$ & Volumetric Flow Rate \\
\hline $\operatorname{Re}$ & Reynolds Number \\
\hline $\mathrm{Sc}$ & Schmidt Number \\
\hline $\mathrm{Sh}$ & Sherwood Number \\
\hline Stk & Stokes Number \\
\hline $\mathrm{T}$ & Temperature \\
\hline $\mathrm{T}_{\mathrm{in}}$ & Initial Temperature \\
\hline $\mathrm{T}_{\text {out }}$ & Final Temperature \\
\hline $\mathrm{V}_{\mathrm{s} \text {, dilution }}$ & Standard Volumetric Flow of Dilution Air during Test \\
\hline $\mathrm{V}_{\mathrm{s} \text {, dilutionback }}$ & Standard Volumetric Flow of Dilution Air during Background Test \\
\hline $\mathrm{V}_{\mathrm{s}, \mathrm{exh}}$ & Standard Volumetric Exhaust Flow \\
\hline $\mathrm{V}_{\mathrm{s} \text {,filter }}$ & Standard Volumetric Flow through PM Test Filter \\
\hline $\mathrm{V}_{\mathrm{s}, \text { filterback }}$ & Standard Volumetric Flow through PM Background Filter \\
\hline $\mathrm{v}$ & Flow Velocity \\
\hline $\mathrm{v}_{\mathrm{p}}$ & Probe Flow Velocity \\
\hline $\mathrm{v}_{\mathrm{s}}$ & Surrounding Flow Velocity \\
\hline$v_{\text {tunnel }}$ & CVS Primary Tunnel Flow \\
\hline
\end{tabular}


$\mathrm{X}_{\text {dilute }}$

$\theta$

$\mu$

$\rho_{\mathrm{p}}$

$\tau$
Fraction of Dilution Air in Primary Dilution Tunnel

Bend Angle

Air Viscosity

Particle Density

Relaxation Time 


\section{Introduction and Objectives}

Diesel engines are used extensively and affect our lives in myriad ways. Planes, trains, trucks, and ships utilize these powerful and efficient engines to transport people and goods and literally, drive the world economy. However, the high emission levels are a constant concern of the U.S. Environmental Protection Agency (EPA) and environmental agencies of other countries. Government regulation is truly a reason for constant evaluation and testing of emission control systems, however, even more important is the effect on human beings, animals, and the environment in which they live. Also, the free market and the economy rely on the manufacture and sale of engines that are safe, environmentally friendly, and legal for their intended purposes.

\subsection{Introduction}

As government regulations of diesel emissions become increasingly stringent, the ability to precisely measure the emissions becomes more important. Of the harmful diesel emissions, particulate matter (PM) is one that is fairly difficult to measure and even more so due to the increasingly strict regulatory parameters. PM has been found to be harmful to public health, especially so to the weakest members of society and just as harmful to animals and the environment [1].

There are several ways to measure emissions. One common method is called constant volume sampling (CVS) and is extremely expensive, which makes it less desirable for those involved in emission testing. A less expensive method is called partial flow sampling (PFS). Both methods were chosen in this study and evaluation of the emission of PM produced by diesel engines because they are both accepted methods for measuring PM. The CVS takes in all the exhaust, dilutes it to a constant tunnel flow, and then collects a PM sample. The PFS takes only a small proportion of the exhaust, dilutes it to a constant tunnel flow, and then collects a PM sample. Both systems are shown in Figure 2-2. 


\subsection{Objectives}

In this study, both a PFS and CVS were tested and modeled. The PFS system used was the BG-3, manufactured by Sierra Instruments Inc. The CVS used was the 40 Code of Federal Regulations (CFR) 1065 compliant unit at the West Virginia University Engine Research Center. The objective of this study was to investigate each system's method of measuring PM. The tasks to reach this objective were as follows:

1. To examine the differences between CVS and PFS systems using error propagation analysis.

2. To investigate the differences between CVS and PFS systems using a model of particle loss. 


\section{Literature Review}

When studying the theory and practice of PM sampling systems, some background knowledge in the areas of PM and sampling is necessary. The following section describes basic information about PM, different systems used to characterize PM emissions from engines, and previous studies conducted regarding experimental differences between PM sampling systems.

\subsection{Particulate Matter}

PM is defined by the EPA as "a mixture of solid particles and liquid droplets found in the air [2]." In heavy duty diesel engine emission testing, PM is defined as anything that is collected on the PM filter. PM is made up of different types of particles such as elemental carbon (EC), hydrocarbons (HC), some sulfur compounds, and other species including some acids. PM is classified into different size classes. The EPA classifies particles between 2.5 and 10 micrometers as "inhalable coarse particles" and particles smaller than 2.5 micrometers as "fine particles." As a point of reference, a human hair is around 70 micrometers in diameter, so "inhalable coarse particles" are 14\% of the width of a human hair or smaller, and "fine particles" are $3.5 \%$ of the width of a human hair or smaller $[2,3]$.

\subsubsection{Health and Environmental Effects Related to Particulate Matter}

PM in the atmosphere affects human and animal health as well the environment. PM causes health problems because the particles are so small that they can travel deep into the lungs and become trapped there. Once the particles are in the lungs, they can cause irritation and inflammation. According to the EPA the following problems have been associated with PM exposure:

- Coughing and difficulty breathing

- Decreased lung function

- Aggravated Asthma

- Development of chronic bronchitis

- Irregular heartbeat 
- Nonfatal heart attacks

- Premature death of people with lung or heart disease

PM affects the weakest in the population the most. Those with lung or heart disease, those with asthma, the elderly, and children are generally the most susceptible to elevated levels of PM [1].

The environment is also affected by PM pollution. Since the pollution is in the air, its effects can become widespread by the air currents. The EPA has linked the following environmental problems to PM pollution:

- Visibility reduction

- Lake and stream acidification

- Changes in the nutrient balance in coastal waters and rivers

- Depletion of soil nutrients

- Damages to forests and crops

- Stains or damage to materials, particularly statues and monuments

These environmental and health related problems are the reason that the EPA has placed regulations on PM and many other pollutants [1].

\subsubsection{PM Regulations}

Repeatable PM measurement is important for the characterization and certification of engines. As the regulated limits of PM decreased from 1988 to 2007 for heavy-duty diesel engines, the methods of measuring PM stayed roughly the same. This means that the same amount of absolute error would make the relative error increase. The PM limit in 1988 was $0.6 \mathrm{~g} / \mathrm{bhp}-\mathrm{hr}$ and in 2007 was $0.01 \mathrm{~g} / \mathrm{bhp}-\mathrm{hr}$, which is a 98.3 percent reduction in PM limit in just 19 years. Figure 2-1 shows the reduction in heavy duty diesel emissions through the years. Also with the introduction of catalyzed Diesel Particulate Filters (DPFs) and in-cylinder techniques such as higher injection pressure and different injection timing strategies necessary to meet the standards, PM had a different composition in a 2007 and later model year engine than it once did in a 1988-1998 model year engine. The strategies to reduce PM targeted the EC, but many volatile hydrocarbons from unburned fuel and oil were still emitted. When the PM limit was higher, PM was mostly EC, but new technologies have virtually eliminated all EC leaving mostly 
volatiles. To minimize variations in PM measurement for 2007 and later model years, the filter face temperature range was made stricter, as well as secondary dilution air specifications, filter size and media, weighing environment specifications, and general filter handling methods [4].

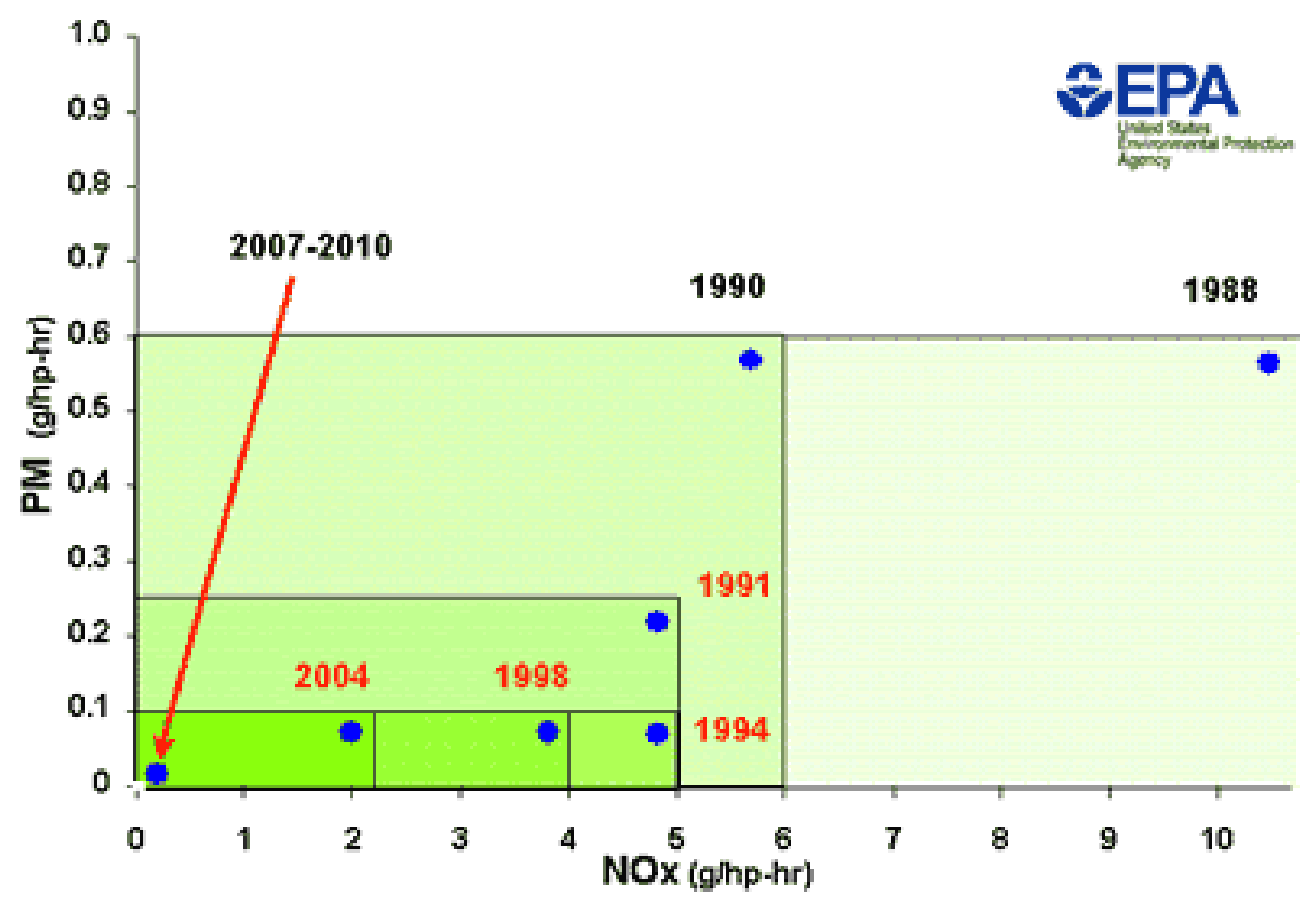

Figure 2-1: Heavy Duty Diesel Emissions Standards [2]

In the United States, EPA regulations state that PM from heavy duty diesel engines is to be measured gravimetrically. A gravimetric measurement is accomplished by weighing the mass of a filter before and after testing, and taking the difference to be the PM mass. A gravimetric measurement gives the total mass of PM collected but gives no insight into the sizes of the particles collected. In Europe as part of the Euro IV standard, PM measurement is regulated in terms of mass and particle number [5]. Particle number measurement systems show a particle size distribution emitted by the engine. With this type of measurement the user can see how much of each certain size of PM is emitted, and possibly target the elimination of the most harmful particle sizes [1]. 


\subsection{The CVS System}

The CVS system is the system that has been used for emissions testing since the 1980s. It is still the most widely used system for the certification of heavy duty diesel engines. The CVS system features a transfer tube that carries all the exhaust from the engine to the main dilution tunnel where it is mixed with dilution air that has been cleaned by a high efficiency particulate air (HEPA) filter. The dilution tunnel has a mixing orifice that facilitates the mixing of dilution air and engine exhaust gas. After the exhaust and dilution air have been well mixed, they enter the sample plane. The sample plane has many probes that take samples to different analyzers to measure gaseous emissions. The probe for the PM system is also at the sample plane. The PM probe takes a sample that then goes to the secondary dilution tunnel. The secondary dilution tunnel is much smaller than the main dilution tunnel and serves to further dilute the PM sample to the desired overall dilution ratio. After the secondary dilution tunnel, the sample moves through a pre-classifier and then through the sample filter. The filter can then be weighed in a clean room. The sample is pulled through the system by a vacuum pump. The secondary dilution air and total filter face flow are regulated by mass flow controllers. The system measures brake specific emissions according to 40 CFR Part 1065. The system is called constant volume sampling because the air pump that pulls air and exhaust through the main dilution tunnel is set to a constant mass flow rate. Even if the engine exhaust volume varies, the same amount of air flows through the main dilution tunnel. That means the dilution ratio is changing depending on engine exhaust flow. To account for any impurities that are related to the sampling system itself, a background filter may be used. A background test is conducted without the engine operating. The result of the background is then subtracted using the equations in $40 \mathrm{CFR}$ 1065. A diagram of the CVS system is shown in Figure 2-2. 


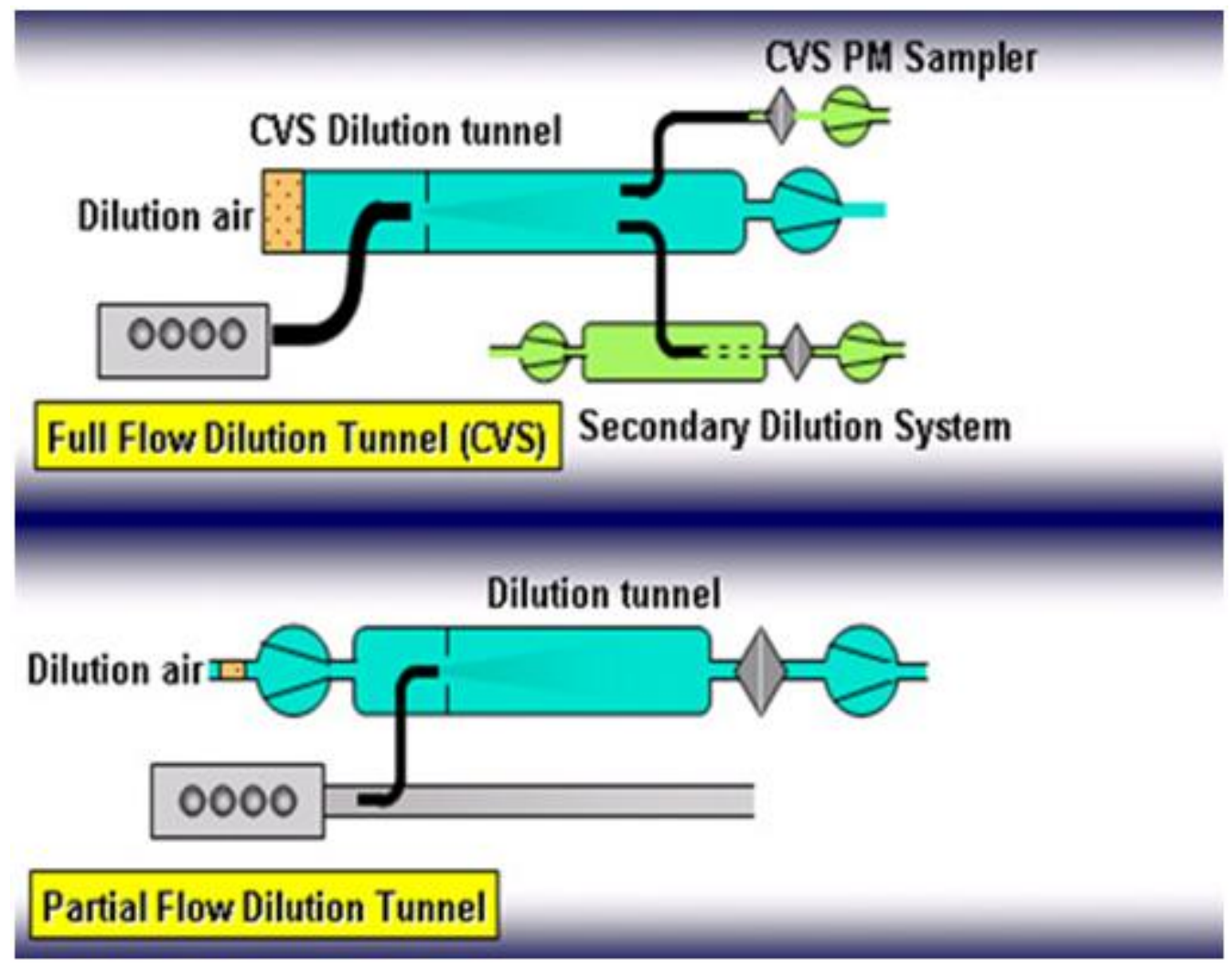

Figure 2-2: Constant Volume Sampling and Partial Flow Sampling Diagrams [6]

\subsection{The PFS System}

PFS systems are desirable for their lower cost and size than a CVS system. At this time, CVS systems are the standard when it comes to results in terms of precision and repeatability for PM measurement. A CVS system works by taking all the exhaust from the engine, diluting it at some rate, then taking a sample that is proportional to exhaust and dilution flow, and sending it through a filter. A PFS system works by taking a sample that is proportional to the exhaust, diluting the sample, and then sending the sample through a filter. Proportional sampling is a very important and difficult aspect of PFS systems because of the very transient nature of the exhaust flow [7].

The PFS system connects to the exhaust pipe carrying the raw exhaust. The system uses a probe in the pipe to extract a sample. The probe is usually a stainless steel tube that either points upstream or downstream, but the probe could have any design. The transfer line connects the 
probe to the system. These can be heated or unheated, rigid or flexible. The next item in the flow of the sample is the dilution tunnel. The dilution tunnel in a PFS system is much smaller than in a CVS system. The dilution air is cleaned by a HEPA filter and controlled by some type of mass flow meter or controller. It is then mixed with the sample in the dilution tunnel. Once diluted, the sample goes through a PM preclassifier which removes large particles which are not necessarily exhaust particles. After moving through the preclassifier, the diluted exhaust moves through the filter. The filter is usually a $47 \mathrm{~mm}$ filter, comparable to the ones used in CVS systems. The filter is also normally heated by a heated enclosure to the temperature of $47{ }^{\circ} \mathrm{C}$ since $40 \mathrm{CFR} 1065$ has a filter face temperature requirement of $47 \pm 5{ }^{\circ} \mathrm{C}$. Using the same filter type, size, temperature, and face velocity generally leads to more congruent results. After passing through the filter, the sample goes through a mass flow meter or controller and a vacuum pump. The vacuum pressure is what causes the sample and dilution air to go through the system. Another way to meter the filter flow is with a positive displacement pump (PDP) such as a roots blower. If the PDP is used, then it has the role of flow meter and vacuum pump. A flow meter is also needed to measure exhaust flow. The meter tells the PFS system the flow rate so that the system can remain at a proportional flow rate through the probe. The probe flow rate is set by the system through modulating the mass flow controllers. If proportionality is not kept, the final result can have significant error.

After a test the filter is removed, conditioned for at least an hour, and weighed in a clean room. The mass emission result is calculated by multiplying the PM mass by the proportionality constant. The result can be corrected for background PM and divided by the cycle work to get the brake specific emissions.

Some of the benefits of PFS systems are that they are less costly, smaller, less energy intensive, and use much less cleaned dilution air. Cost is an important aspect of every piece of equipment, and when a system costs tens of thousands of dollars less it is very important to buyers. Size is also a factor because PFS systems can be used as on-board systems for mobile emissions testing and be used in engine test bed applications where there might not be enough space for a CVS system. Energy usage is becoming more and more important in today's world and therefore energy efficiency is desirable. A PFS system uses much less energy because the amount of air 
that it has to move can be $90 \%$ less than a CVS system has to move. Lastly, dilution cleaning in a PFS system is miniscule compared to a CVS system. The HEPA filters that are needed for a CVS system are very large and expensive, whereas PFS systems use HEPA filters that are small and less expensive because of the minimal amount of dilution air demand. The attractions of PFS systems are all linked to cost, but the CVS system is still the most accepted system based on results. If PFS systems become more precise in their measurement, they may become more accepted. A diagram of the PFS system is shown in Figure 2-2.

\subsection{Proportionality}

To achieve proportionality in a PFS system under transient conditions, the sample flow controller must adjust the flow rate to be a constant proportion of the total exhaust flow in real time. This requires very accurate flow meters and controllers and fast response time in the control system. In order to get accurate measurements, the exhaust flow measurement and the sample flow must be proportional at all times during the test. If the sample flow is based on a delayed exhaust flow measurement, then the sample will be proportional to what the exhaust flow was at the beginning of the delay and not proportional to the exhaust flow at the current time. There are several factors that attribute to a delayed measurement, such as time responses of control circuits, dilution mass flow controllers, exhaust flow meters, and the pneumatics of the PFS system. A method for combating time alignment issues associated with response delays is a "look ahead" control. This uses the exhaust flow data from previous tests to control the sample flow so that delays in signal do not affect proportionality. The exhaust flow from the current test is then used for the calculation of brake specific or mile specific emissions $[7,8,9]$.

Proportionality according to 40 CFR 1065 is defined for batch sampling in $\S 1065.545$. The standard error of estimate should be less than $3.5 \%$ for the sample flow rate vs. the total flow rate. Also up to $5 \%$ of the data points may be removed to aid in passing the validation. The validation criteria for proportionality vary slightly with the type of flow meters used, but the flow meter must demonstrate that it can control the flow within $2.5 \%$ of the target flow rate. 


\subsection{Particle Losses}

Diffusion losses occur because of the tendency of particulates in air to go from areas of high concentration to areas of low concentration. The areas of low concentration are generally near the pipe walls, so the particles go to the pipe walls and cannot bounce back off like the air molecules. The diffusion losses are dependent on flow velocity and tube length. There is less diffusion loss when the flow velocity is higher, and when the tube length is shorter. Diffusion losses affect small particles more than large ones because small particles have a greater ability to slip between the other flowing particles. The small particles also have less momentum keeping them in the flow [9].

Inertial and gravitational losses occur mainly with the larger particles. Inertial loss is caused by sharp bends in the sampling system. The large particles have inertia to continue going straight, so sharp bends cause them to miss the turn and impinge on the wall. Gravitational loss also affects the largest particles. The particles will tend to settle in the bottom of the pipe because of gravity if the transfer line is too long. Because the inertial and gravitational losses affect the largest particles, the PM mass could be greatly affected if these factors are not taken into consideration [3].

Thermophoretic losses occur when there is a temperature gradient in the flow of the gas. The particulate is shoved to the colder areas close to the wall of the pipe by the warmer part of the gas in the center of the pipe. This action causes the particle to stick to the wall and make the gas have an artificially lower concentration of particles. Thermophoretic losses are similar to diffusion losses but are caused by temperature gradients instead of concentration gradients. Short transfer tubes that are heated or insulated would reduce thermophoretic losses compared to longer and/or uninsulated tubes. If a long transfer tube is needed then it should be heated [3, 9].

\subsection{Isokinetic Effect}

Some losses are due to the geometry of the sampling system itself. At a given velocity, heavier PM particles have more momentum than lighter particles such as air, so particulates have a higher tendency to deviate from flow streamlines if the streamlines change abruptly. If a sample 
probe is facing into the stream and pulling at a velocity less than the exhaust velocity, the PM measurement would be greater because the heavier particles would not be diverted around the probe (Figure 2-3). If the probe is facing into flow and pulling a sample at a velocity higher than exhaust velocity, the measurement will be underestimated because the particles would not be diverted into the probe. If the probe is facing backwards to the flow, the PM measurement would be underestimated because, again, the heavier particles would not be able to make the sharp turn back into the probe because of their momentum (Figure 2-4). Empirical relationships exist for correcting for these losses. Isokinetic sampling can be used to reduce losses due to the momentum of particles. During isokinetic sampling, the sample probe pulls a sample at the same velocity as the source velocity. This keeps the streamlines straight so that there are less momentum-related errors [9].

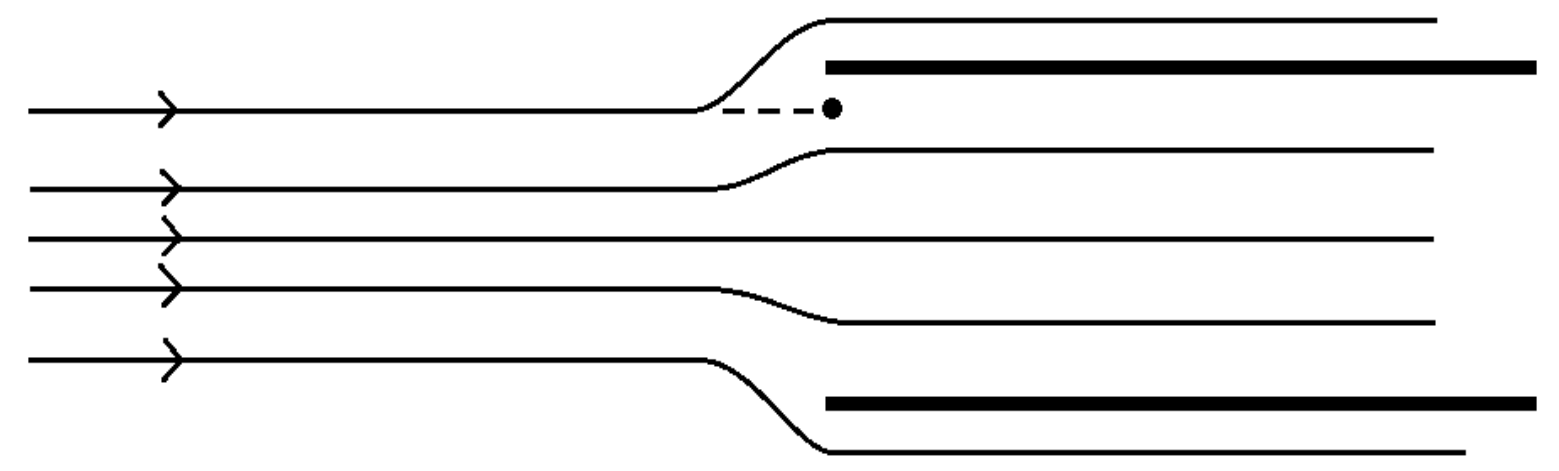

Figure 2-3: Sampling Probe Facing into Flow with Probe Velocity Less than Isokinetic

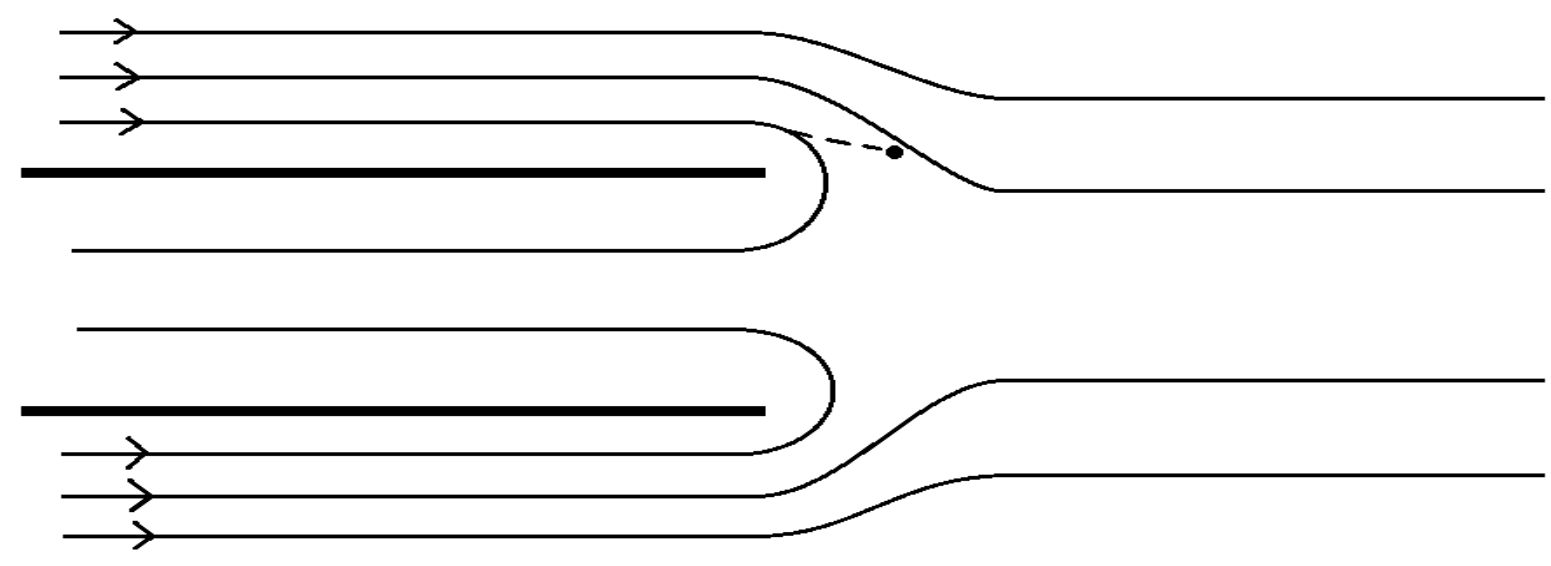

Figure 2-4: Sampling Probe Facing Backwards to Flow 


\subsection{Soluble Organic Fraction}

The soluble organic fraction (SOF) is the part of PM that is made up mainly of HC and sulfate. SOF condenses on the particles or on the PM filter and can also evaporate. This can make PM measurements have high variability. SOF content will be higher when the dilution temperature is lower because SOF will be more likely to condense onto particles. Lower dilution factors cause SOF content to be higher because the HC concentration will be higher and more likely to condense onto particles. These factors can lead to major differences between in-laboratory PM and real-world PM because of the differences in the dilution. In order to get repeatable SOF results, the dilution temperature and dilution factor must be the same for each test [9].

The SOF content can vary the PM mass captured on the filter up to 20 micrograms or about $2 \%$ over a 20 minute test for a 2007 model year engine [10]. The SOF content is highly dependent on filter face velocity. Higher filter face velocity will give lower SOF and vice versa. When the filter face velocity is higher, the SOF will be more likely to evaporate into the fast moving air. When the filter face velocity is low, the evaporation of the SOF to the air will happen at a lower rate.

DPFs are now used for PM reduction of heavy duty diesel engines. These DPFs trap the solid particles very well, but let through hot, gas phase volatile material. After passing through the $\mathrm{DPF}$, the volatile material nucleates or condenses into the liquid phase where some of it is then caught on a test filter. In DPF filtered engines the volatile SOF content has a much higher percentage than non DPF filtered engines. This increase in SOF percentage leads to higher uncertainty based on the issues mentioned in the above paragraphs [3].

\subsection{Particulate Pre Classifiers}

In many PM measurement systems there is a pre classifier to remove large particles from the sample stream before it goes through the filter. This step is mainly to remove particles that may have been stuck to the wall of the sampling system and became dislodged during the test. These large particles are an artifact of the measurement system rather than a part of the PM emission of the engine. Two accepted choices for particulate pre classification are a cyclone or an impactor. 
A cyclone will generally allow more of the large particles to pass than an impactor. This can lead to differences in PM mass of up to 5 micrograms or about $0.5 \%$ in a 20 minute test [10]. A cyclone was used as the pre classifier in both of the sampling systems used in this study.

\subsection{Dilution Issues}

Dilution ratio, dilution air quality, and dilution air temperature affect the PM mass result. Particles form differently with different dilution ratios. The dilution ratio normally used in PM measurement is between 5 to 1 and 7 to 1 . In the real world, the exhaust gas mixes with a near infinite amount of dilution air which makes the dilution ratio effectively infinite. This difference between real-life dilution ratio and in-laboratory dilution ratio means that what is measured as PM could be different compared to what is emitted to the atmosphere. In his study about dilution affects on PM, Swanson [10] shows that dilution ratio does have an effect on PM mass. The study concludes that using a lower dilution ratio would give a lower PM result because the full particle forming potential is not realized.

Dilution air quality is another important aspect of PM measurement. Getting the dilution air perfectly clean is a difficult process because of the large amount of air needed in a CVS tunnel. Swanson [10] concludes that dilution air contamination can attribute more than 10 micrograms or about $1 \%$ to the filter mass on a 20 minute test. PFS PM systems use much less air to dilute the sample, so the smaller amount of dilution air could be cleaned more thoroughly without as much difficulty as a CVS system.

Dilution air temperature, as mentioned earlier in the SOF section, can affect PM mass. With colder dilution air, more $\mathrm{HC}$ condenses onto the particulates to increase the PM mass, whereas hotter dilution air causes $\mathrm{HC}$ to stay in vapor form or even evaporate from particulates that it may have been on; thus decreasing PM mass collected at the filter $[9,10]$.

Residence time in the dilution tunnel also affects PM mass measurement. Usually the residence time in a PFS system is less than in a CVS system. The residence time is a major factor in particle size. Generally, when the residence time is longer, the particles are larger. This is 
because the particles collide and stick together to make larger particles. Large particles are more likely to be lost in the losses associated with sampling than are smaller particles. The large particles have more momentum, so they will more likely cause probe flow errors due to anisokinetic sampling. The pre-classifier, which removes the largest particles, could remove particles that became large by residence time effects. When there are more losses, the PM mass is lower, so the residence time affects the PM mass measurement in an indirect way. The exact amount that the residence time affects the PM mass is difficult to know because the mass difference also depends on the all of the losses mentioned earlier. 40 CFR 1065 specifies the residence time after dilution to be between 1 and 5 seconds. Both the CVS and PFS systems meet this requirement [11].

\subsection{Flow Meters}

Mass air flow meters are important for PFS PM measurement systems because they ensure accurate proportionality. Without proportionality PFS systems cannot give credible results. There are several types of flow meters that are used with these systems, including thermal mass air flow meters, positive displacement pumps, laminar flow elements, or other types.

Thermal mass air flow meters are used in the CVS PM system to measure the secondary dilution flow and the total PM filter flow at West Virginia University (WVU). These are Sierra Mass Flow Controllers (MFC) manufactured by Sierra Instruments Inc. The principle of operation for a MFC is the flow enters the meter and is split into one flow going through a laminar flow element and one flow going through a measuring tube. (Figure 2-5) In the measuring tube there are two resistance temperature device (RTD) coils that supply heat and measure temperature. Based on the temperature difference the flow is found. (Figure 2-6) The flow meter in the Sierra MFC also has a solenoid to control the flow passing through the meter. A set point is given to the controller and it modulates the solenoid opening to match the set point. [12] 


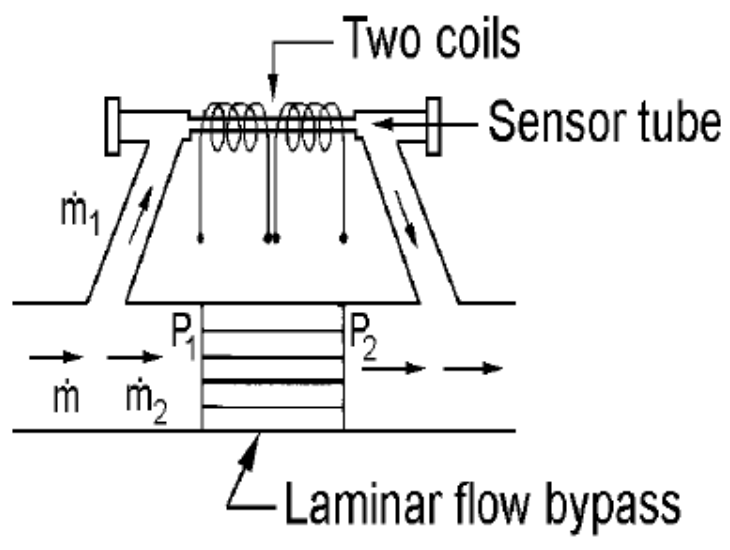

$$
\begin{aligned}
& \dot{\mathrm{m}}=\dot{\mathrm{m}}_{1}+\dot{\mathrm{m}}_{2} \\
& \dot{\mathrm{m}}=\dot{\mathrm{m}}_{1}\left(1+\dot{\mathrm{m}}_{2} / \dot{\mathrm{m}}_{1}\right)=k \dot{\mathrm{m}}_{1}
\end{aligned}
$$

Figure 2-5: Diagram of Sierra MFC [12]

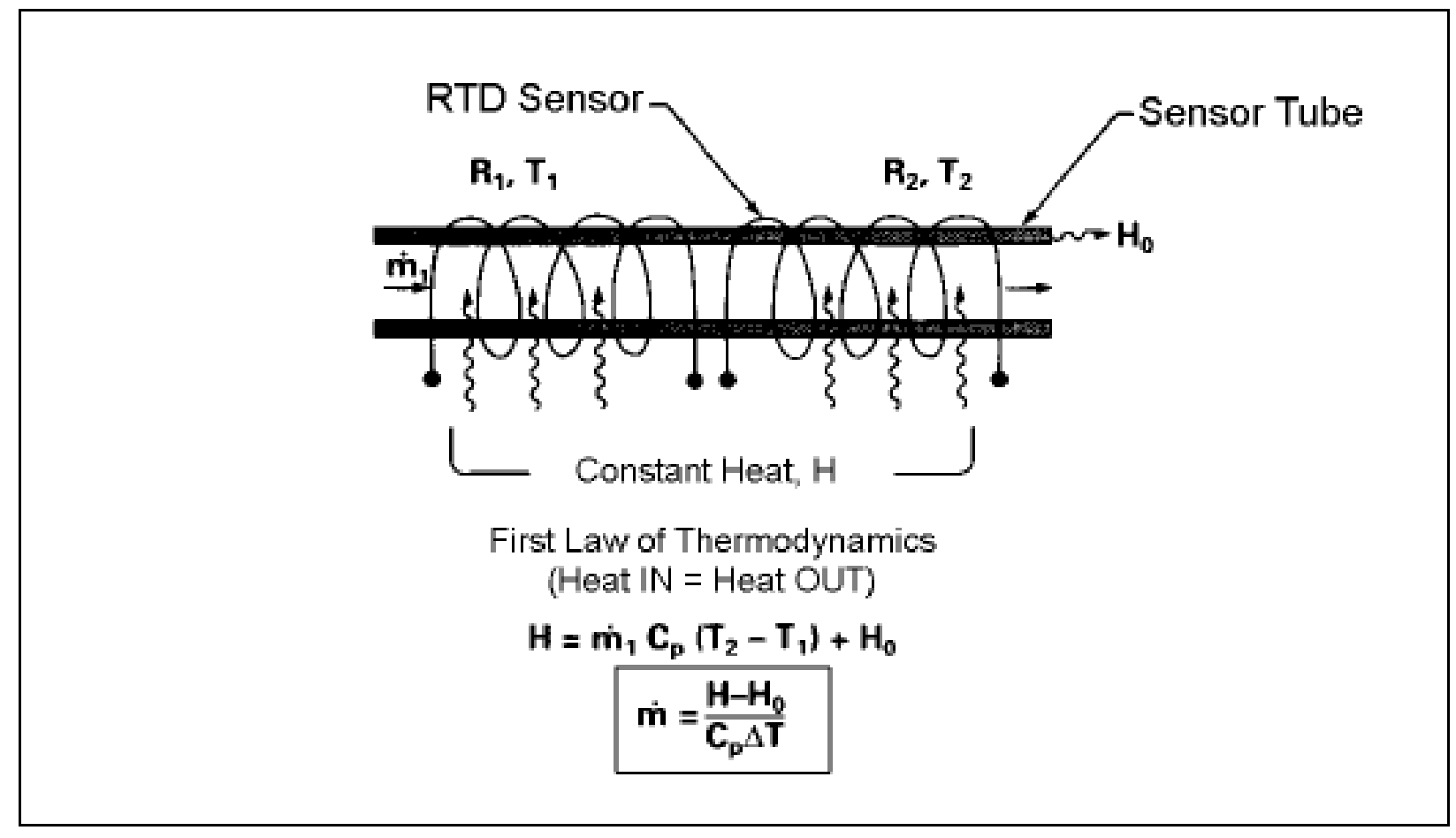

Figure 2-6: MFC Operation Principle [12]

The composition of the exhaust is constantly changing, therefore the density and heat capacity of the exhaust is also changing. With a thermal mass flow controller such as a MFC, these changes 
will affect the accuracy of the measurement because the calculations of the flow depend on both heat capacity and density. A correction factor can be applied to account for these changes in thermodynamic properties so the result will still be accurate [7, 9].

A PDP is another type of flow meter that is used in PFS systems. A positive displacement pump meters air flow by taking in a volume of air and pushing it through the pump. With these devices the air flow is proportional to the rotational speed of the pump. A large PDP may be used in the main dilution tunnel of a CVS emissions system according to 40 CFR 1065. Some PDPs are roots type (Figure 2-7) in which elongated gears mesh together perfectly so that there is a seal against any leaking back flow.

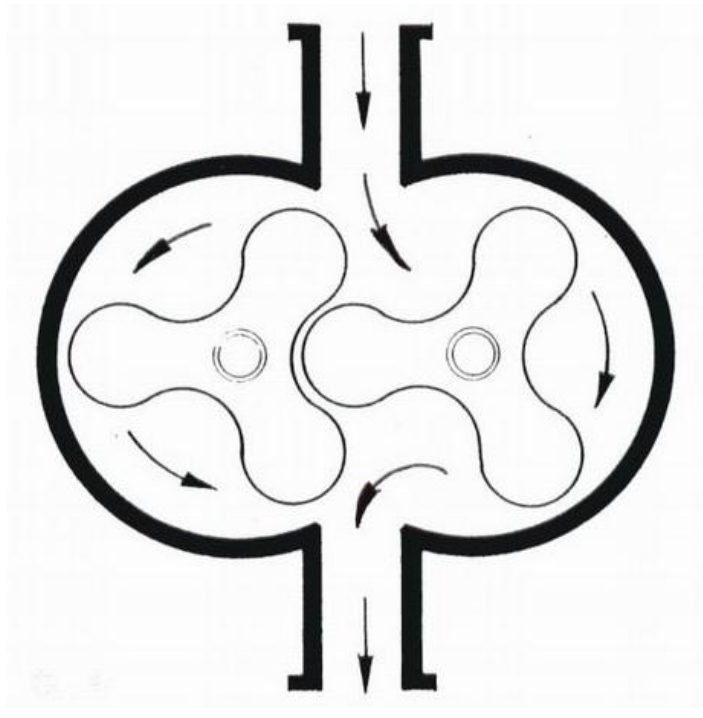

Figure 2-7: Diagram of a Roots Type Positive Displacement Pump

A laminar flow element (LFE) is another type of flow meter for gases. A LFE is a device that has an inlet and an outlet with a section between that has flow straighteners (Figure 2-8). The flow straighteners cause a pressure drop across them. If the differential pressure, absolute pressure at the inlet, and temperature at the inlet are known, then the mass flow is known based on the equation for flow in a laminar region. If the flow needs to be modulated to a certain set point, then a valve can be actuated to control the flow through the LFE. LFEs are typically only used for clean air flow measurement such as intake and dilution air. Changes in density are compensated by taking the temperature measurement. 


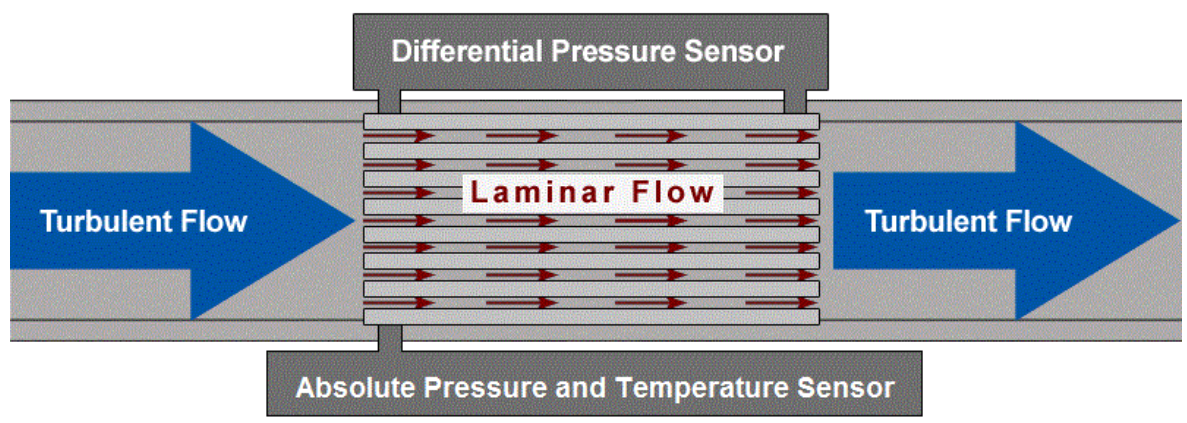

Figure 2-8: Laminar Flow Element

\subsection{Particle Spectrometer}

To measure PM in terms of size distribution, a spectrometer can be used. A spectrometer works by charging the particles that come into the system and streaming through an electric field. The smallest particles will be affected the soonest, whereas the larger particles travel farther through the field before being affected because of their momentum. When the particle collides with an electrometer the charge gets counted as a particle in the corresponding bin size. This gives a distribution of particle sizes that the engine is emitting. Figure 2-9 is a diagram that shows how particles act in a particle spectrometer [13]. 


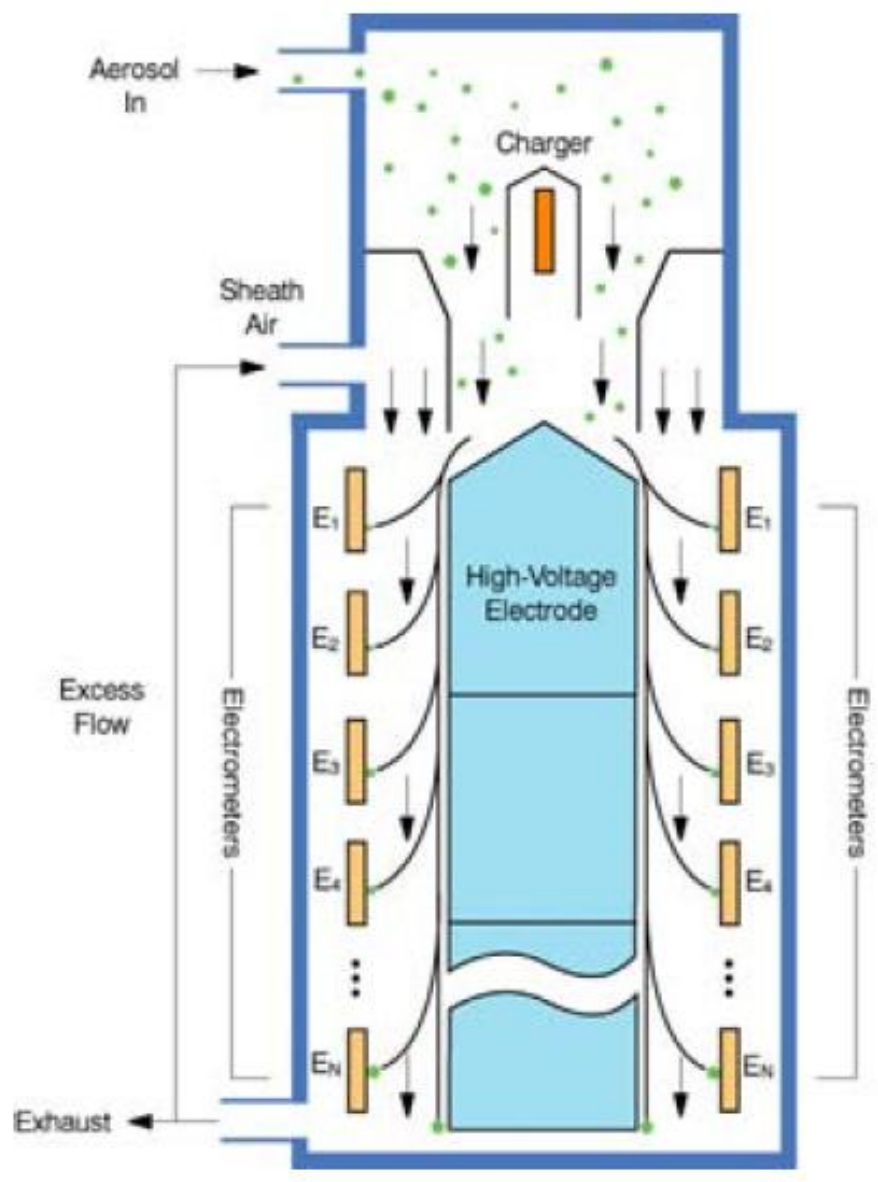

Figure 2-9: Particle Spectrometer [13]

\subsection{Error Propagation in Emissions Measurement Systems}

In a study by Bielaczyc and Szczotka [14], error propagation analysis was done in the measurement of gaseous emissions for light duty vehicles. The analysis used the uncertainties from the different components of the measuring system as inputs into the uncertainty analysis equation. The study concluded that the light duty CVS system was not adequate for measuring emissions at the very low Euro 5 limits. The study also concluded that the most important problem was to increase the accuracy of the components of the system.

A study by Velosa [15] also dealt with error propagation analysis in gaseous emissions for light duty vehicles. It modeled the error propagation from the analyzers to the distance specific result. The study concluded that a CFR part 86 compliant CVS measuring emissions at the ultra low 
emission vehicle standard, the $\mathrm{CO}$ result had an acceptable level of error, while the $\mathrm{HC}$ and $\mathrm{NOx}$ results had an unacceptable level of error.

\subsection{Previous Studies about Experimental Differences between PM Systems}

In a study by AVL [9], the designers at AVL applied many new designs to their existing PFS PM system. The new design experimented in this study was optimized to reduce diffusion and thermophoretic losses by shortening the transfer tube as much as possible and making the tube walls thin so they would reach the exhaust temperature quickly. Changes were also made to the mixing zone to reduce diffusion losses. The new design was tested against the old design at modes of $100 \%$ engine load, $25 \%$ engine load, and idle. The new design showed a higher mass at each mode which indicated less loss of PM due to diffusion and thermophoretic losses. The test engine was run through several steady state and transient tests including some modes from the ISO 8-mode test, Federal Test Procedure (FTP), European Transient Cycle, and Non-road Transient Cycle. With the steady state modes, the PFS system measured within 10\% of the CVS on all six modes, and within 5\% on four modes. For the transient tests, the PFS system showed agreement with the CVS within 5\% and had variability equal to the CVS system [9].

In a study performed by CRC [4], four different PFS PM systems were tested. The four systems were Cummins AEI/CUM, AVL SPC, Horiba MDLT, and the Sierra BG-3. The systems were tested based on response time and proportionality under transient conditions. It was found that all of the systems had a response time of less than 200 milliseconds. The proportionality of the sample flow to the exhaust flow had a correlation coefficient of better than 99 percent for all the systems, and the standard error based on the average was less than 5 percent for all the systems.

The systems were then used to test the PM emissions of an engine equipped with a DPF. The results of the systems were averaged at $0.0006 \mathrm{~g} / \mathrm{bhp}-\mathrm{hr}$. The variability from system to system was $0.00025 \mathrm{~g} / \mathrm{bhp}-\mathrm{hr}$, which fell within the CVS variability from test to test. The PFS systems had results that varied compared to the CVS system from 70 percent low to 400 percent high. This high relative variability and low average caused the tests to be redone with the PM at a higher level. The higher PM level was achieved by using a bypass that allowed some exhaust 
flow past the DPF and some to go through the DPF. When the new test was done, the relative variability fell to 30 percent when the average result was around $0.007 \mathrm{~g} / \mathrm{bhp}-\mathrm{hr}$. The study concluded that measuring PM at levels significantly lower than the regulated limit of $0.01 \mathrm{~g} / \mathrm{bhp}$ hr was very difficult. An additional experiment was done to see how other factors such as residence time, dilution ratio, and dilution temperature affected PM results. The AVL SPC was set up to have the same dilution criteria as the CVS and the results between them became significantly closer [4].

Horiba Instruments Inc. conducted a study [8] where they attempted to show correlation of their OBS-PM PFS system to a CVS at Southwest Research Institute. The OBS-PM is a PM measurement system designed to be used for on-board emissions measurement. The engine and test setup was the same as the setup for the CRC study [4]. Since the test setup was the same, the DPF and bypass were present for this study and used in the same way as in the CRC study. The following tests were run: FTP with all exhaust going through the DPF, FTP with some exhaust bypassing the DPF, two steady state tests (SS1 and SS2) with all exhaust going through the DPF. The OBS-PM was tested for proportionality with the result of a correlation coefficient of 99.6 percent, a standard error of 1.7 percent, and intercept of 0.02 percent of maximum sample flow. All of those specifications are within the ISO 16183 restrictions [8].

The results of the study show that the OBS-PM measured 15.2 percent lower than the CVS for the FTP, 21.9 percent lower than the CVS for the FTP with DPF bypass, 14.1 percent lower than the CVS for SS1, and 10.6 percent higher than the CVS for SS2. The study concluded that there was a possibility that the CVS was measuring too high because of CVS background levels that were 60 percent of the average FTP test, where OBS-PM backgrounds were 31.4 percent of the average FTP test. The author's conclusion that the CVS was measuring too high would mean that the OBS-PM measurement was more accurate than the CVS in this study [8].

There was also a study done at Southwest Research in 2002 [16] that tested the performance of PFS PM systems. The AVL SPC, Horiba MDLT, and the Sierra BG-2 were the systems tested. The engine used for the testing was a 1999 Cummins QSL9 designed for non road use. The proportionality was tested using the carbon dioxide $\left(\mathrm{CO}_{2}\right)$ concentration in the raw exhaust 
stream and the partial flow streams. The response time of each of the systems was found using a computer generated signal sent to the system. Then the response was timed to measure the response delay. The PFS systems had response times of around one second. The transient cycles were run using a "look ahead" strategy of the PFS systems. Look ahead uses pre-recorded exhaust flow from previous tests to control proportionality. Then the actual exhaust flow from the current run is used for calculation purposes. This strategy negates the negative effects of a system lag. For transient testing, the FTP, SATC, and ETC cycles were used. Some of the tests were done with the probe pointing upstream and some were done with the probe pointing downstream. For the tests with the probe pointing upstream the results were higher than when the probe was pointing downstream. When isokinetic sampling was approximated, the result was around 5\% closer to the CVS result, and variability in the measurement stayed the same [16].

The study concluded that one of the systems, the AVL SPC, could correlate with the CVS within 5 percent. This was encouraging to the authors. The study also concluded that PFS systems for PM measurement could work as a replacement of the CVS system, but the systems still showed room for improvement. Key issues that needed to be addressed by further studies were issues with the volatile portion of PM and validation criteria for each system. The PFS systems in the study all had different criteria such as dilution and filter face conditions, so a unifying standard was necessary. This unifying standard came in 40 CFR 1065 [16]. 


\section{Experimental Setup}

All of the experiments done in this research were conducted at the Engine Research Center (ERC) of the Center for Alternative Fuels Engines and Emissions (CAFEE) on the Evansdale campus of West Virginia University. Data were collected from CVS, PFS, and particle number systems. The test engine was a 2004 Cummins ISX 565 (Figure 3-1), and the FTP test cycle was used. When weighing the PM filters, a microbalance inside of a clean room was used. The different parts in this configuration are explained in more detail below.

\subsection{Test Engine}

The 2004 Cummins ISX 565 is a 15 liter displacement engine used for on road heavy duty trucks and other similar vocations. The engine meets the 2004 EPA emissions standards of $2.5 \mathrm{~g} / \mathrm{bhp}-\mathrm{hr}$ oxides of nitrogen (NOx) and $0.1 \mathrm{~g} / \mathrm{bhp}$-hr PM. The 565 at the end of the name denotes the rated horsepower that the engine can output. Some technologies that the 2004 Cummins ISX uses to meet emissions standards and increase performance are cooled exhaust gas recirculation (EGR) and a variable geometry turbocharger (VGT). Cooled EGR is taking some of the exhaust gas, cooling it through a heat exchanger and mixing it with the intake air. The re-circulated exhaust gas serves to decrease in cylinder bulk mixing temperatures to reduce NOx. A VGT serves to increase the engine differential pressure to drive EGR and to reduce the boost pressure lag associated with a normal turbocharger. With less boost lag, acceleration is improved, and the increased air-to-fuel ratio during acceleration events reduces smoke emission. Smoke is primarily the black carbon portion of total PM. Figure 3-1 shows the Cummins ISX in the test cell with the dynamometer. [17] 


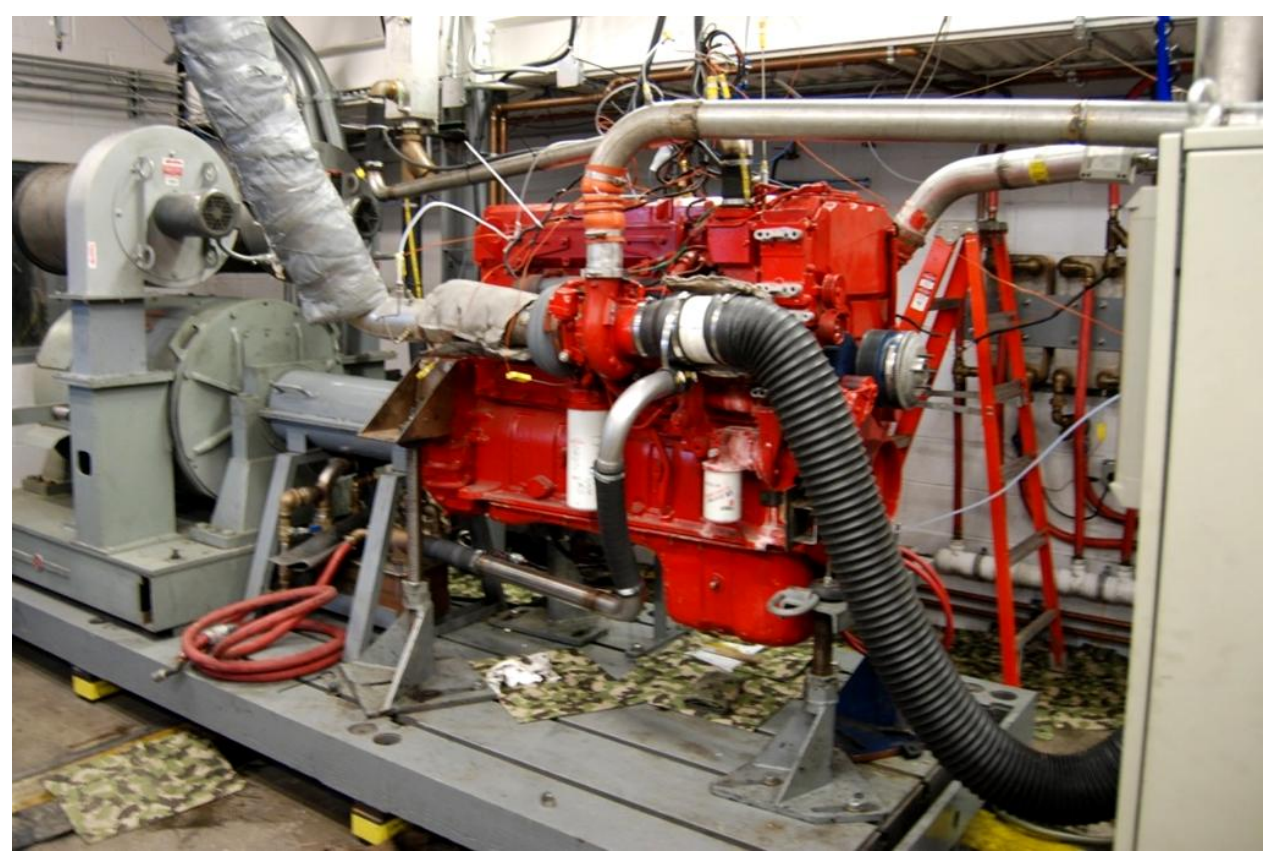

Figure 3-1: 2004 Cummins ISX 565 [18]

\subsection{Engine Dynamometer}

During the engine tests, a dynamometer was used to simulate a load on the engine according to the test procedure. The dynamometer used was manufactured by General Electric. It runs on direct current electricity and is cooled by two blowers that supply cooling air. The dynamometer measures and controls the rotational speed of the engine and the torque set point is reached by modulating the throttle signal to the engine. The torque is measured by a load cell connected to a lever arm on the stator of the dynamometer. The dynamometer has a capacity of up to 800 horsepower of load on the engine. The engine connects directly to the dynamometer by a shaft from the flywheel of the engine to the rotor of the dynamometer. Using the data provided from the dynamometer, the total work done by the engine over a test cycle can be found and used to find the brake power and brake specific emissions of PM and other species.

\subsection{Heavy-Duty Federal Test Procedure (FTP)}

The FTP is a test cycle for engine dynamometer testing. It consists of a list of speeds and torques as a proportion of the engines rated speed and maximum torque at that given engine speed. The 
FTP is the test cycle that is used in the US to certify the emissions from heavy-duty diesel engines. The FTP is 20 minutes long and consists of four parts. New York non-freeway is the first part and it simulates heavy traffic city driving situations with a high amount of idle time and several sharp acceleration and deceleration events. The second part is Los Angeles non-freeway and it represents city driving with sharp transients but less idle time than the New York nonfreeway. The third part is Los Angeles freeway which represents high speed driving without much change in speed but still transients in torque. The fourth part is another New York nonfreeway. The traces of torque and speed for the FTP are shown in Figure 3-2.

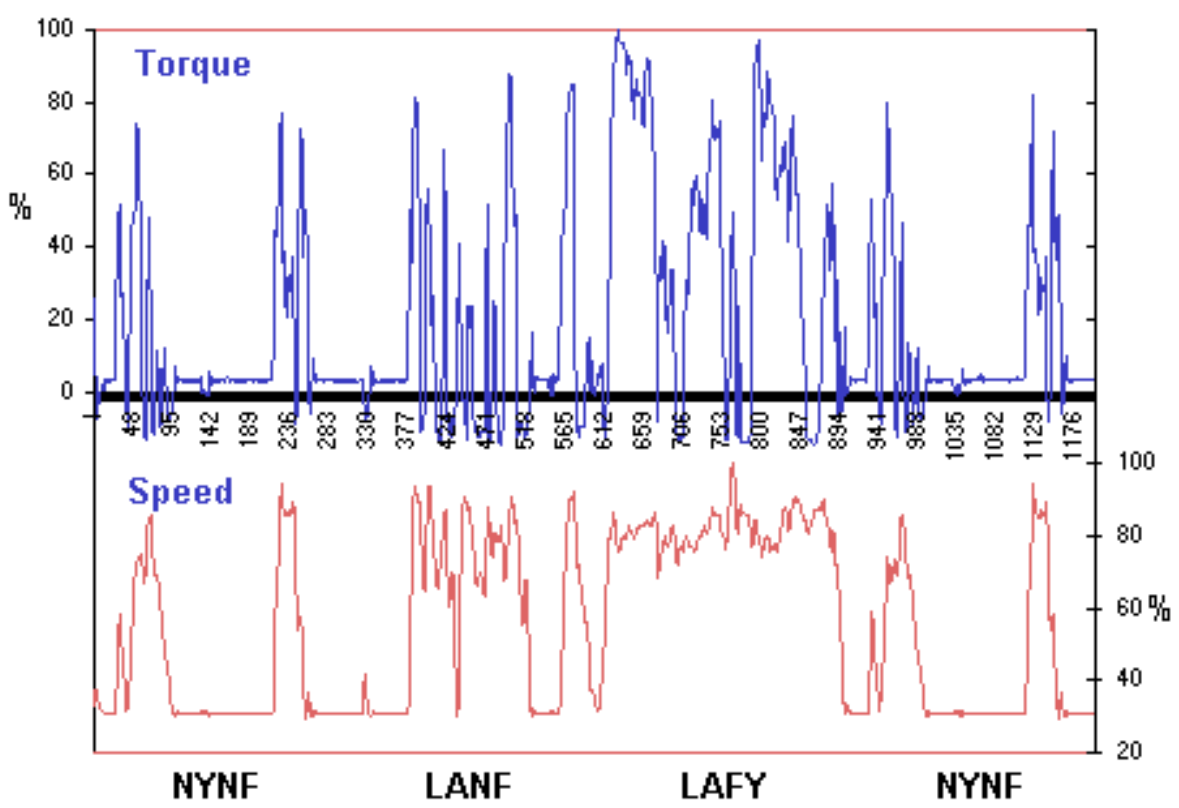

Figure 3-2: Federal Test Procedure [19]

\subsection{The CVS Tunnel}

The CVS tunnel at the ERC was built to abide within the specifications of 40 CFR 1065. The CVS tunnel mixes the exhaust with dilution air that is conditioned to the specified temperature and humidity. The tunnel is 20 inches in diameter and 200 inches downstream from the area where the exhaust enters the tunnel is the sample plane. This long length allows for good mixing and some residence time. At the sample plane there are several probes that extract samples to be analyzed or sent through a filter. There are probes that lead to analyzers of HC, carbon 
monoxide $(\mathrm{CO}), \mathrm{NOx}$, and $\mathrm{CO}_{2}$. There is also a probe that leads to the PM sampling system. Beyond the sample plane, the tunnel has a subsonic venturi (SSV) that measures the total flow through the tunnel. Past the SSV, there is a variable speed blower that keeps the blower flow rate at the set point. The SSV and variable speed blower use closed loop control to keep the flow rate steady. Finally, the tunnel vents to the ambient air.

\subsection{The CVS PM System}

When the sample is taken from the CVS tunnel it is then diluted again in a secondary dilution tunnel to dilute the sample down to the desired total dilution ratio. The reason for further dilution is to have another degree of freedom in the system so that the researcher may change filter face velocity and overall dilution ratio independently, while keeping the exhaust gas concentrations high in the primary tunnel. After the secondary dilution, the sample travels through a cyclone separator that removes the largest particles that are generally associated with re-entrainment from the sampling system itself. Then the sample goes through the PM filter that traps PM to be measured after the test. After the PM filter, the sample goes through a MFC and then is exhausted by a vacuum pump to the outside. The secondary dilution air is also controlled by a MFC and the following equation defines the sample flow.

$\dot{m}_{\text {sample }}=\dot{m}_{\text {probe }}+\dot{m}_{\text {secdil }}$

The flow through the PM filter is represented by $\dot{m}_{\text {sample }}, \dot{m}_{\text {probe }}$ is the flow from the CVS tunnel into the probe, and $\dot{m}_{\text {secdil }}$ is the flow of secondary dilution air into the secondary dilution tunnel. All of the PM system is housed in an enclosure that is heated to $47^{\circ} \mathrm{C}$ according to the regulation in the CFR for filter face temperature. The CVS PM system is featured in Figure 3-3. The accuracy of the mass flow controllers is listed in Table 3-1. 


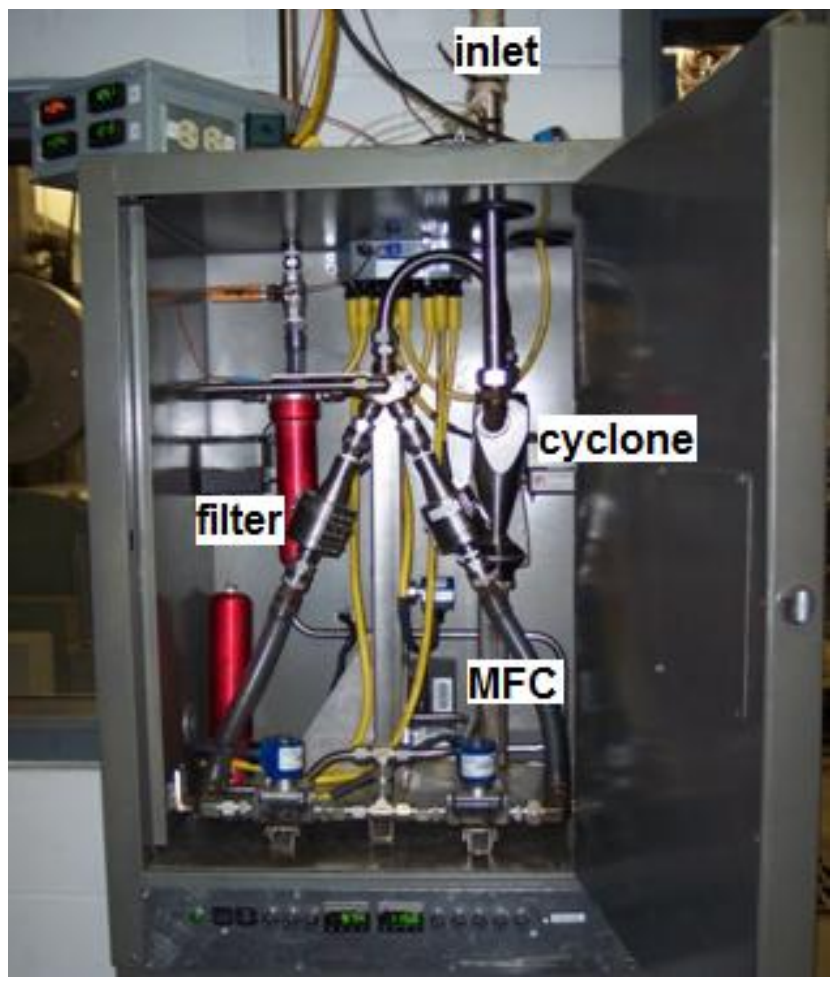

Figure 3-3: CVS PM Sampling System

Table 3-1: Equipment Accuracies

\begin{tabular}{|l|l|l|l|}
\hline Measured Parameter & Equipment & Accuracy & Reference \\
\hline Intake Air Flow Rate & $\begin{array}{l}\text { Laminar Flow } \\
\text { Element }\end{array}$ & $\begin{array}{l} \pm 0.72 \% \text { to } \pm 0.86 \% \text { of } \\
\text { Reading }\end{array}$ & {$[20]$} \\
\hline $\begin{array}{l}\text { CVS Primary Tunnel } \\
\text { Flow Rate }\end{array}$ & Subsonic Venturi & $\pm 2 \%$ of reading & $\begin{array}{l}40 \text { CFR } \\
1065.205\end{array}$ \\
\hline $\begin{array}{l}\text { CVS Secondary Dilution } \\
\text { and Filter Flow Rates }\end{array}$ & $\begin{array}{l}\text { Mass Flow } \\
\text { Controllers }\end{array}$ & $\begin{array}{l} \pm 1 \% \text { of full scale } \\
\text { Full Scale }=2.5 \text { SCFM }\end{array}$ & {$[12]$} \\
\hline PFS Dilution Flow Rate & $\begin{array}{l}\text { Laminar Flow } \\
\text { Element }\end{array}$ & $\pm 1.5 \%$ of reading & {$[21]$} \\
\hline PFS Filter Flow Rate & $\begin{array}{l}\text { Positive } \\
\text { Displacement }\end{array}$ & $\pm 1.5 \%$ of reading & {$[21]$} \\
\hline Filter Mass & \multicolumn{2}{|l|}{$\begin{array}{l}\text { Repeatability } \pm 0.25 \mu \mathrm{g} \\
\text { Linearity } \pm 0.9 \mu \mathrm{g}\end{array}$} & {$[22]$} \\
\hline
\end{tabular}




\subsection{The Class 1000 Clean Room}

All PM filters are weighed in the clean room. At West Virginia University, the clean room is a class 1000 environment, meaning there are less than 1000 particles of impurities per cubic meter of air inside the room (Figure 3-4). Before engine tests, the filters are pre-weighed, and after the test, the filters are post-weighed and the difference in weight from pre to post gives the total mass collected during the test. Reference filters are left in the clean room at all times and weighed each time a test filter is weighed. These reference filters show the effects of the clean room's atmospheric conditions on the weighing of filters. The clean room atmospheric conditions all abide within the regulations found in 40 CFR 1065.

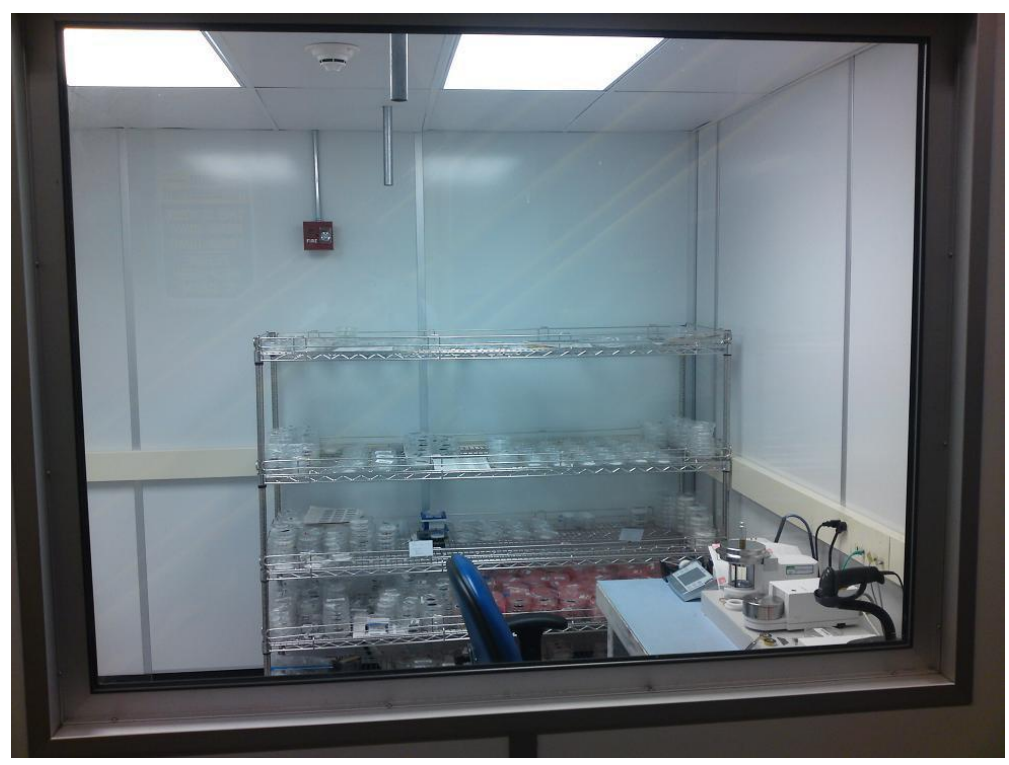

Figure 3-4: WVU Clean Room [23]

The filters are weighed by a Sartorius SE2-F microbalance (Figure 3-5). The microbalance is placed on a special table to isolate it from vibration. The balance also has a lid to ensure the filters are weighed in an environment without air pressure changes which could cause variation in the mass measurement. The specifications of the microbalance are given in Table 3-1. 


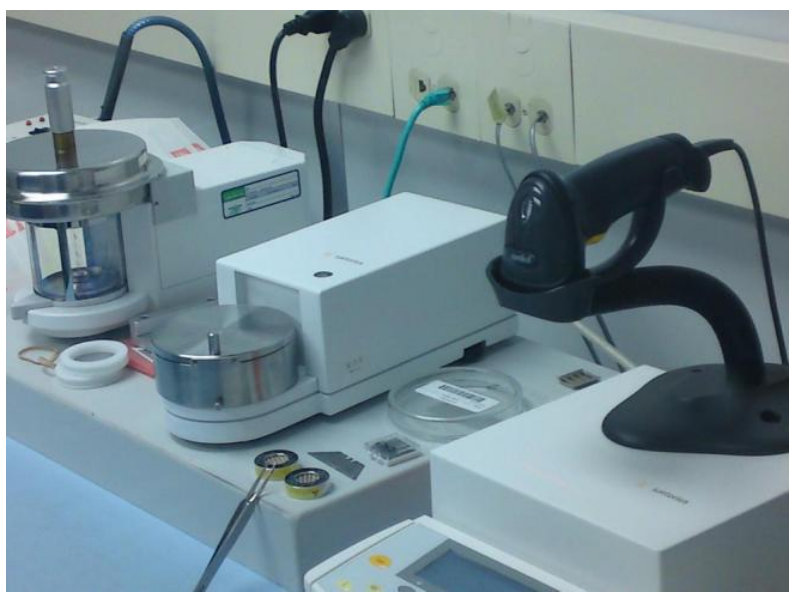

Figure 3-5: Sartorius SE2-F Microbalance [23]

\subsection{The Sierra BG-3}

The PFS PM measurement system used in this research was the Sierra Instruments BG-3 (Figure 3-6). It is the newest iteration of their BG series. The Sierra BG-3 manual states that it meets or exceeds all ISO 16183 correlation standards to full dilution, and that it meets 40 CFR 1065 engine certification criteria. The technical specifications of the BG-3 are given below in Table 3-1. In Figure 3-7, the probe and dilution tunnel are shown coming from the exhaust pipe. In this study, all of the PFS system data was measured using the BG-3 [21]. 


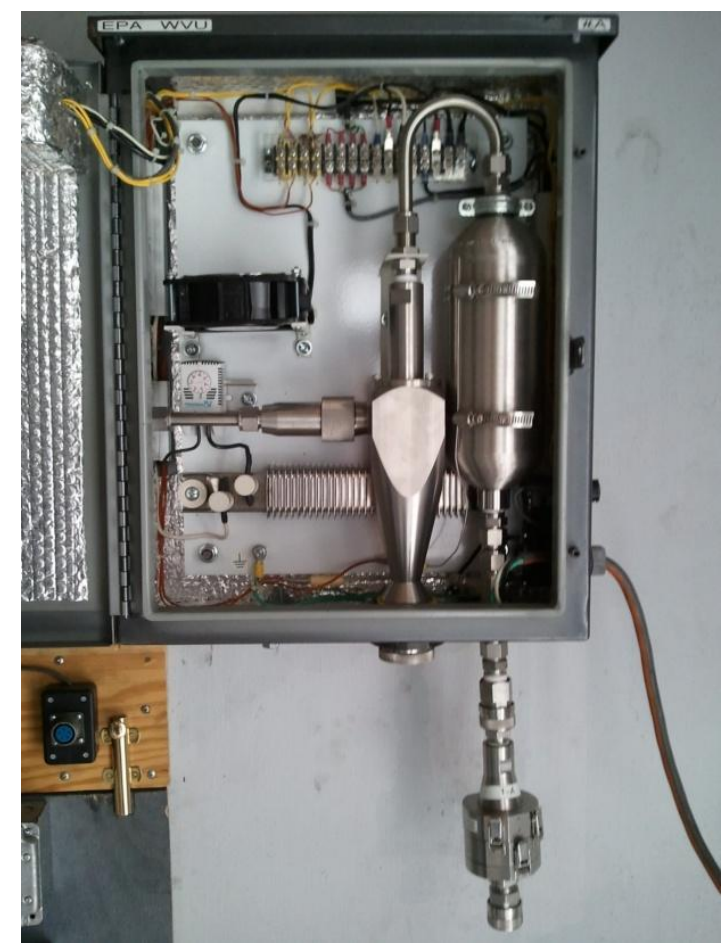

Figure 3-6: Sierra Instruments BG-3

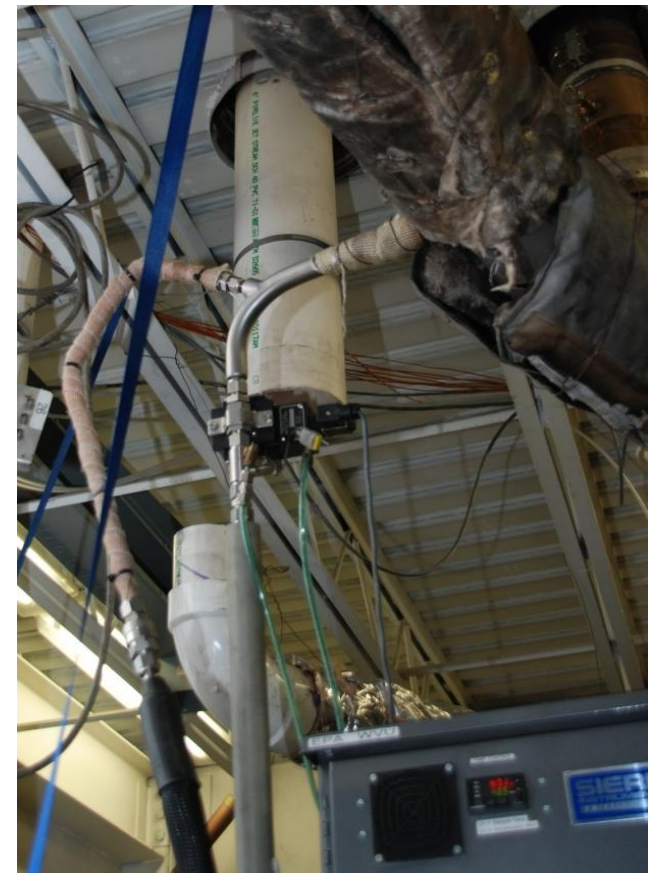

Figure 3-7: BG-3 Dilution Tunnel [18] 


\subsection{Engine Exhaust Particle Sizer Spectrometer}

The Engine Exhaust Particle Sizer (EEPS) Spectrometer made by TSI Incorporated was used to collect the particle distribution data that was used in the PM loss model. EEPS data was not available from the 2004 Cummins ISX, so data from another engine, 2004 Volvo MD11, with the same technologies that meets 2004 EPA standards was used. Since the EEPS collects data as a concentration, the difference in flow rate between the two engines can be scaled to the larger engine. The particle distribution data was used as part of the continuous error analysis and loss model. It was noted that if the modeling were to be run based on particle spectrometer data, CVS system data, and PFS system data from the same engine, the result would be different and most likely more accurate.

\subsection{Chemical Balance}

The chemical balance is used to discover the fraction of dilution air flow in the CVS primary dilution tunnel. The chemical balance uses the test and background concentrations of all the regulated gaseous emissions, conditions of the engine intake air, humidity measurements in multiple locations in the sampling system, and fuel properties. It takes these inputs and puts them through a system of equations found in 40 CFR 1065.655. An error analysis was run for the chemical balance. The result was that the error propagated from the chemical balance led to a $2 \%$ error in the fraction of dilution air flow in the CVS primary dilution tunnel.

\subsection{Error Propagation Analysis}

An analysis of the errors in the instrumentation was conducted. Using the equations from CFR 1065 a new equation was derived using error analysis techniques. This process was done for a PFS system as well as a CVS system. Since the flow rates in the PFS system were constantly changing to account for the transients in the exhaust flow, the error was analyzed on a continuous basis. Then the error was integrated to get total error. In addition, the CVS error analysis was conducted on a continuous basis even though the flow rates were not very transient. 
Error propagation analysis was a technique to see how error in an instrument's reading would propagate through the equation and affect the final result. The method was defined in the equation below for a function $\mathrm{y}$ that depended on $\mathrm{x}$ and $\mathrm{z}$.

$\Delta y=\sqrt{\left(\frac{\partial}{\partial x}(y) * \Delta x\right)^{2}+\left(\frac{\partial}{\partial z}(y) * \Delta z\right)^{2}}$

$\Delta y$ was the error in the result, $\mathrm{y}$ was a function of $\mathrm{x}$ and $\mathrm{z}, \Delta x$ was the error in the $\mathrm{x}$ measurement, and $\Delta z$ was the error in the $\mathrm{z}$ measurement. For each term in the equation, the partial derivative was found and then multiplied by the error in that term. Each of those new terms were squared, added to each other, and the square root was taken to get the total propagated error in $\mathrm{y}$. The following equation was the equation for PM mass from a PFS system from CFR 1065.

$M_{P M}=\frac{M_{\text {sample }}}{V_{\text {s,filter }}-V_{\text {s,dilution }}} * V_{s, \text { exh }}$

In this equation $M_{P M}$ was the total mass of PM emitted by the engine during the test, $M_{\text {sample }}$ was the mass of PM collected on the sample filter, $V_{s, \text { filter }}$ was the standard volumetric flow through the sample filter, $V_{s, \text { dilution }}$ was the standard volumetric flow of dilution air in the PFS system, and $V_{s, \text { exh }}$ was the standard volumetric flow of exhaust out of the engine. Now applying the error propagation formula yielded,

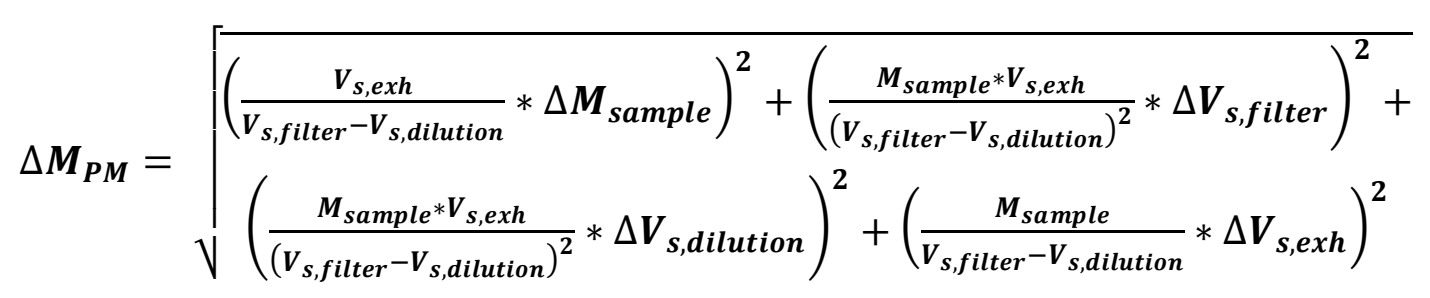


The CVS system PM mass equation from CFR 1065 is shown below. It was also made into an error propagation equation according to the process in Equation 2. The error propagation equation is not shown in this section, but can be found in the code in Appendix 7.1.

$M_{P M}=\left(\frac{\mathbf{M}_{\text {sample }} * \mathrm{~V}_{\mathrm{s}, \text { tunnel }}}{\mathbf{V}_{\mathbf{s}, \text { filter }}-\mathrm{V}_{\mathrm{s}, \text { dilution }}}\right)-\left(\frac{\mathrm{X}_{\mathrm{dilute}} * \mathrm{~V}_{\mathrm{s}, \text { tunnel }} * \mathbf{M}_{\text {background }}}{\mathbf{V}_{\mathrm{s}, \text { filterback }}-\mathrm{V}_{\mathrm{s}, \text { dilutionback }}}\right)$

This error analysis was conducted continuously over the engine test. In order to do this analysis, MATLAB was used. A program was created for both the PFS error analysis and CVS analysis. The codes can be found in Appendix 7.1 and 7.2.

\subsection{Particle Loss Model}

To predict the possible losses in CVS and PFS PM measurement systems, a model was developed. The model was a computer model in the language of MATLAB. The model took several key inputs including a particle distribution and output a new particle distribution after the losses had occurred. Many of the types of losses were considered in the model including diffusion, thermophoretic, isokinetic, and bend losses. Other loss types, such as settling and electrostatic losses, were neglected [3]. Settling was neglected because of the assumption that the particles are very small and the flow is sufficiently fast to keep the small particles suspended. The electrostatic losses were neglected because of the assumption that stainless steel pipe walls would not accumulate static electricity.

To determine diffusion losses, equations from Baron and Willeke [24] were used. They were as follows.

Diffusion Penetration $=$

$$
\begin{cases}1-2.56 \xi^{\frac{2}{3}}+1.2 \xi+0.77 \xi^{\frac{3}{4}} & \text { when } \xi \leq 0.02 \\ 0.819 e^{-3.657 \xi}+0.097 e^{-22.3 \xi}+0.032 e^{-57 \xi} & \text { when } \xi>0.02\end{cases}
$$


$\xi=\frac{\pi * D * L}{V}$

$D=\left(\frac{K * T}{3 * \pi * \mu * D p}\right) *\left(1+\left(\frac{15.39}{P * D p}\right)+\left(7.518 * e^{(-0.0741 * P * D p)}\right)\right)$

$\boldsymbol{\mu}=1.827 * 10^{-5} *\left(\frac{291.15+120}{T+120}\right) *\left(\left(\frac{T}{291.15}\right)^{\frac{3}{2}}\right)$

Where, D was the particle diffusion coefficient, L was the tube length in units of meters, V was the volumetric flow rate in units of $\mathrm{m}^{3} / \mathrm{s}$, $\mathrm{T}$ was the temperature in units of Kelvin, $\mathrm{K}$ was the Boltzmann constant, $\mu$ was the viscosity in units of $\mathrm{kg} / \mathrm{s} * \mathrm{~m}, \mathrm{P}$ was the absolute pressure in units of $\mathrm{Pa}$, and $\mathrm{Dp}$ was the particle diameter in meters.

The thermophoretic particle loss was determined by an equation from Wei and Kittelson [11]. The equation was based on the difference in temperature from the inlet to the outlet. When the temperature drop was increased, the thermophoretic loss was increased. Both temperatures were in units of Kelvin.

Thermophoretic loss $=1-\left(\left(\frac{T_{\text {out }}}{T_{\text {in }}}\right)^{0.38}\right)$

Losses due to anisokinetic probe flow were also significant. The following formulae from Hinds [25] were used to model the isokinetic effect.

Iso Pen $=1+\left(1-\left(\frac{v_{s}}{v_{p}}\right)\right) *\left(\sum_{\mid\left(1+\left(\operatorname{stk} *\left(2+\left(0.617 *\left(\frac{v_{p}}{v_{s}}\right)\right)\right)\right)\right.}|-1|\right) \mid$ 
$S t k=\left(\frac{\tau * v_{s}}{d_{\text {probe }}}\right)$

$\tau=\left(\frac{\rho_{p} * D p^{2}}{18 * \mu}\right) * C_{c}$

$C_{c}=1+\left(\left(\frac{1}{P * D p}\right) *\left(15.6+\left(7 * e^{-0.059 * P * D p}\right)\right)\right)$

$v=\frac{4 * V}{\pi * \mathbf{d}^{2}}$

Where, $\mathrm{v}_{\mathrm{s}}$ was the source flow velocity in units of $\mathrm{m} / \mathrm{s}, \mathrm{v}_{\mathrm{p}}$ was the probe flow velocity in units of $\mathrm{m} / \mathrm{s}$, Stk was the Stokes number, $\tau$ was the relaxation time in units of seconds, $d_{\text {probe }}$ was the probe diameter in units of meters, $\rho_{p}$ was the particle density in units of $\mathrm{kg} / \mathrm{m}^{3}, \mathrm{C}_{\mathrm{c}}$ was the Cunningham slip correction, $\mathrm{v}$ was the velocity in a pipe in units of $\mathrm{m} / \mathrm{s}, \mathrm{d}$ was the pipe diameter in units of meters.

IsoPen was the penetration of the particles due to the anisokinetic condition. It was a function of the difference of flow velocity in the exhaust pipe and the probe and also of the Stokes number. Equations 16-19 showed how to get the parameters needed in the penetration formula.

The density of the PM particles was not a constant. According to Virtanen et al. [26], the density of small particles was high, and then the density decreased linearly with particle size. The density of the small particles was $1.1 \mathrm{~g} / \mathrm{cm}^{3}$, and the largest particles had a density of $0.2 \mathrm{~g} / \mathrm{cm}^{3}$. The following formula was used.

$\rho_{p}= \begin{cases}1.1 & \text { when psize } \leq 50 \mathrm{~nm} \\ 1.1-\left(\left(\frac{9}{9500}\right) *(D p-50)\right) & \text { when psize }>50 \mathrm{~nm}\end{cases}$ 
There were also significant losses in PM systems due to bends in the sampling tube. These bend losses were calculated by the following formula proposed by Pui et al in Hinds' book [25].

Bend Loss $=1-e^{-2.88 * S t k * \theta}$

The loss due to bends depended on the Stokes number in the sampling system and the bend angle, $\theta$ in units of radians.

These losses were calculated on a continuous basis over the entire FTP test cycle using particle size data from the engine exhaust particle sizer. The particle size data were used as an input to the model. The model would take the particle size data and run it through a PM measurement system and yield a new particle size distribution. The distributions were then integrated to find the mass difference which is the particle mass lost in the system. 


\section{Simulation Results and Discussion}

In this section the results of both the error analysis and the loss model were reported. These results gave insight into the unique challenges of measuring PM.

\subsection{Batch Error Propagation Analysis}

Using the accuracy criteria from Table 3-1 and the PM equations from the CFR, the error analysis model was run for the CVS and PFS systems. The results for the CVS are given in Table 4-1 and Table 4-2, and the results for the PFS are given in Table 4-3 and Table 4-4.

Table 4-1: CVS Error Propagation Analysis Results

\begin{tabular}{|c|c|c|}
\hline PM & 0.103 & $\mathrm{~g} / \mathrm{bhp}-\mathrm{hr}$ \\
\hline Error & 0.0106 & $\mathrm{~g} / \mathrm{bhp}-\mathrm{hr}$ \\
\hline Percent Error & 10.3 & $\%$ \\
\hline
\end{tabular}

Table 4-2: CVS Error Propagation Analysis Breakdown

\begin{tabular}{|c|c|c|c|c|}
\hline Component & Accuracy & $\begin{array}{c}\text { Error } \\
(\mathrm{g} / \text { test })\end{array}$ & $\begin{array}{c}\text { Error } \\
(\mathrm{g} / \mathrm{bhp}-\mathrm{hr})\end{array}$ & $\begin{array}{c}\text { Percent of } \\
\text { total error }\end{array}$ \\
\hline Microbalance & $\pm 0.9 \mu \mathrm{g}$ & 0.00378 & 0.000100 & 0.9 \\
\hline $\begin{array}{c}\text { Mass Flow } \\
\text { Controllers }\end{array}$ & $\pm 1 \%$ of full scale & $2.86 \mathrm{E}-04$ & $7.56 \mathrm{E}-06$ & 0.1 \\
\hline Subsonic Venturi & $\pm 2 \%$ of reading & 0.400 & 0.0106 & 98.5 \\
\hline Chemical balance & $2 \%$ & 0.00199 & 0.0000526 & 0.5 \\
\hline
\end{tabular}

Table 4-3: PFS Error Propagation Analysis Results

\begin{tabular}{|c|c|c|}
\hline PM & 0.107 & $\mathrm{~g} / \mathrm{bhp}-\mathrm{hr}$ \\
\hline Error & 0.0389 & $\mathrm{~g} / \mathrm{bhp}-\mathrm{hr}$ \\
\hline Percent Error & 36.4 & $\%$ \\
\hline
\end{tabular}


Table 4-4: PFS Error Propagation Analysis Breakdown

\begin{tabular}{|c|c|c|c|c|}
\hline Component & Accuracy & $\begin{array}{c}\text { Error } \\
\text { (g/test) }\end{array}$ & $\begin{array}{c}\text { Error } \\
\text { (g/bhp-hr) }\end{array}$ & $\begin{array}{c}\text { Percent of total } \\
\text { error }\end{array}$ \\
\hline $\begin{array}{c}\text { Intake LFE (used as } \\
\text { exhaust flow surrogate) }\end{array}$ & $\begin{array}{c} \pm 0.86 \% \text { of } \\
\text { reading }\end{array}$ & 0.0349 & 0.000923 & 1.6 \\
\hline Dilution LFE & $\begin{array}{c} \pm 1.5 \% \text { of } \\
\text { reading }\end{array}$ & 1.01 & 0.0267 & 47.6 \\
\hline Filter Flow PDP & $\begin{array}{c} \pm 1.5 \% \text { of } \\
\text { reading }\end{array}$ & 1.07 & 0.0283 & 50.5 \\
\hline Microbalance & $\pm 0.9 \mu \mathrm{g}$ & 0.00404 & 0.000107 & 0.2 \\
\hline
\end{tabular}

Both the CVS and PFS systems had calculated the PM result to be close to $0.1 \mathrm{~g} / \mathrm{bhp}-\mathrm{hr}$, which was where the PM result should be for a 2004 engine. The error in the two systems was very different. The CVS relative error was approximately $10 \%$ whereas the PFS relative error was around $36 \%$.

With the CVS system, $98.5 \%$ of the error originated from the error in the tunnel flow measurement by the subsonic venturi. The remaining $1.5 \%$ of the total error propagated from inaccuracies in the mass flow controllers of dilution and total PM filter flow, the microbalance, and the chemical balance method of finding the primary dilution ratio. This $1.5 \%$ of total error only led to approximately $0.2 \%$ relative error. The breakdown of errors in the CVS system is given in Figure 4-1. 


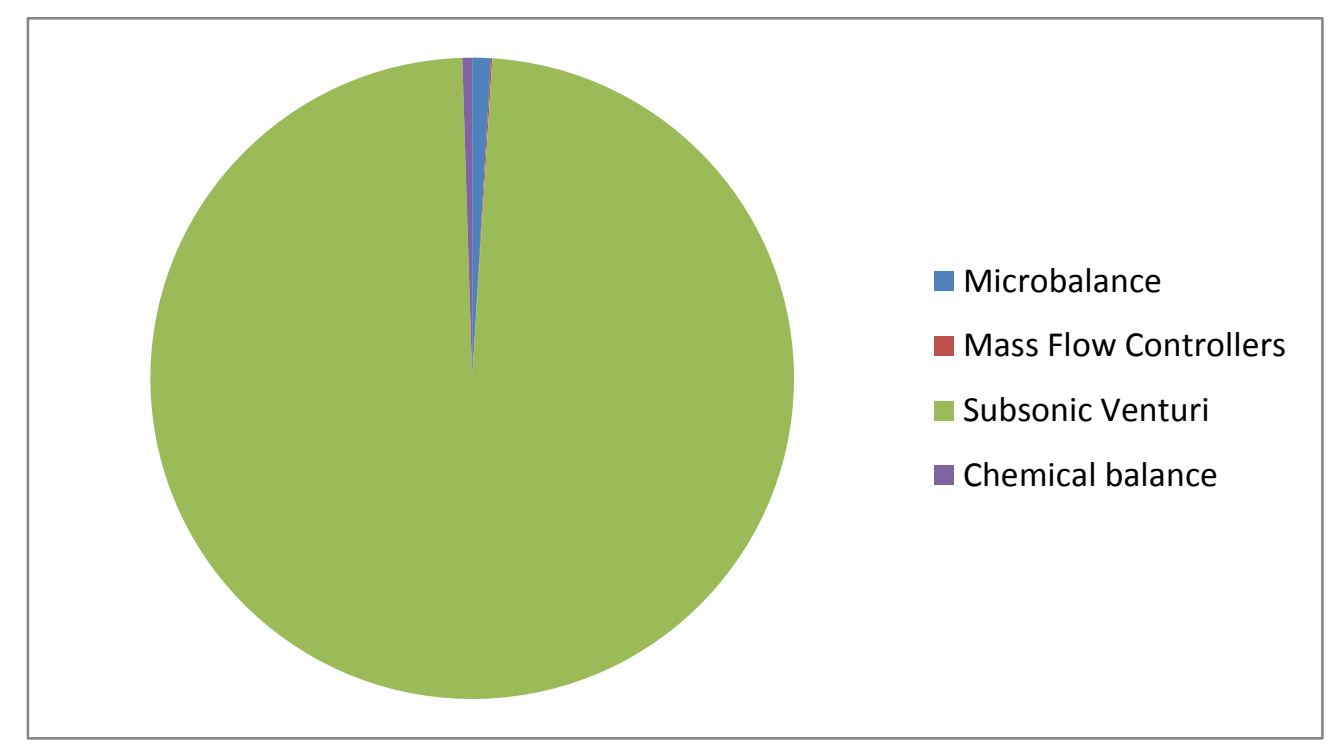

Figure 4-1: CVS Error Breakdown

The PFS system error propagated from four sources. The intake air LFE was what the PFS system used as a surrogate for exhaust flow. It attributed $1.6 \%$ of the total error which translated to approximately $0.5 \%$ relative error. The microbalance error contributed $0.2 \%$ of the total error and produced only $0.07 \%$ relative error. Inaccuracies in measurement of dilution air flow and filter flow accounted for the other $98.2 \%$ of total error. The dilution air LFE error propagated to $47.6 \%$ of the total error which was approximately $17 \%$ relative error. The filter flow PDP error propagated to $50.5 \%$ of the total error which was approximately $18 \%$ relative error. The breakdown of errors in the PFS system is given in Figure 4-2. 


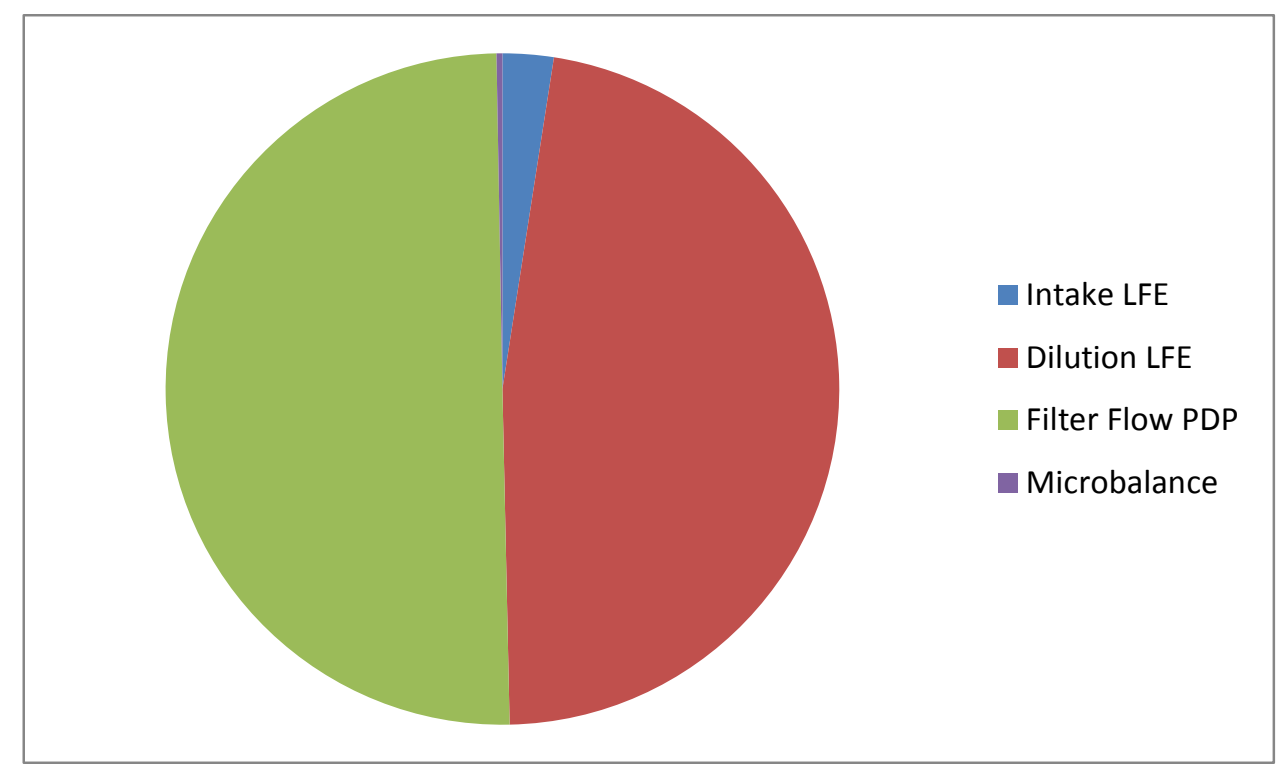

Figure 4-2: PFS Error Breakdown

The literature about the BG-3 specified that both the dilution air LFE and filter flow PDP had inaccuracies of $1.5 \%$ of reading [21]. The error analysis model was run again with the LFE and PDP error at $1 \%$ of reading to show how a small increase in accuracy would change the propagated error result. The results of this additional PFS error analysis are given in Table 4-5 and Table 4-6. Changing the inaccuracy of the dilution LFE and filter flow PDP each from 1.5\% to $1 \%$ of reading propagated to a relative error of around $24 \%$ from around $36 \%$. For a PFS system the dilution air flow meter and filter flow meter were components that needed to be quite accurate to get satisfactory results.

Table 4-5: Adjusted PFS Error Propagation Analysis Results

\begin{tabular}{|c|c|c|}
\hline PM & 0.107 & $\mathrm{~g} / \mathrm{bhp}-\mathrm{hr}$ \\
\hline Error & 0.0260 & $\mathrm{~g} / \mathrm{bhp}-\mathrm{hr}$ \\
\hline Percent Error & 24.3 & $\%$ \\
\hline
\end{tabular}


Table 4-6: Adjusted PFS Error Propagation Analysis Breakdown

\begin{tabular}{|c|c|c|c|c|}
\hline Component & Accuracy & $\begin{array}{c}\text { Error } \\
(\mathrm{g})\end{array}$ & $\begin{array}{c}\text { Error } \\
(\mathrm{g} / \mathrm{bhp}-\mathrm{hr})\end{array}$ & $\begin{array}{c}\text { Percent of total } \\
\text { error }\end{array}$ \\
\hline Intake LFE & $\pm 0.86 \%$ of reading & 0.0349 & 0.000923 & 2.4 \\
\hline Dilution LFE & $\pm 1 \%$ of reading & 0.674 & 0.0178 & 47.2 \\
\hline Roots meter & $\pm 1 \%$ of reading & 0.714 & 0.0189 & 50.1 \\
\hline Microbalance & $\pm 0.9 \mu \mathrm{g}$ & 0.00404 & 0.000107 & 0.3 \\
\hline
\end{tabular}

\subsection{Continuous Error Propagation Analysis}

Continuous error propagation analysis gave information as to when in the test cycle the errors were occurring. This was not possible in the batch analysis. One problem in getting continuous results was that the PM was collected as a batch sample. For this continuous error propagation analysis, a continuous mass emission was calculated using continuous particle spectrometer data. The simulated continuous mass emission was used as an approximation to show how the errors in the measurement devices propagate continuously. This method was better than the assumption of constant mass emission over time because the test cycle was transient. Again, if particle spectrometer data, CVS system data, and PFS system data from the same engine were used the result may have been different. The simulated PM mass rate is shown in Figure 4-3.

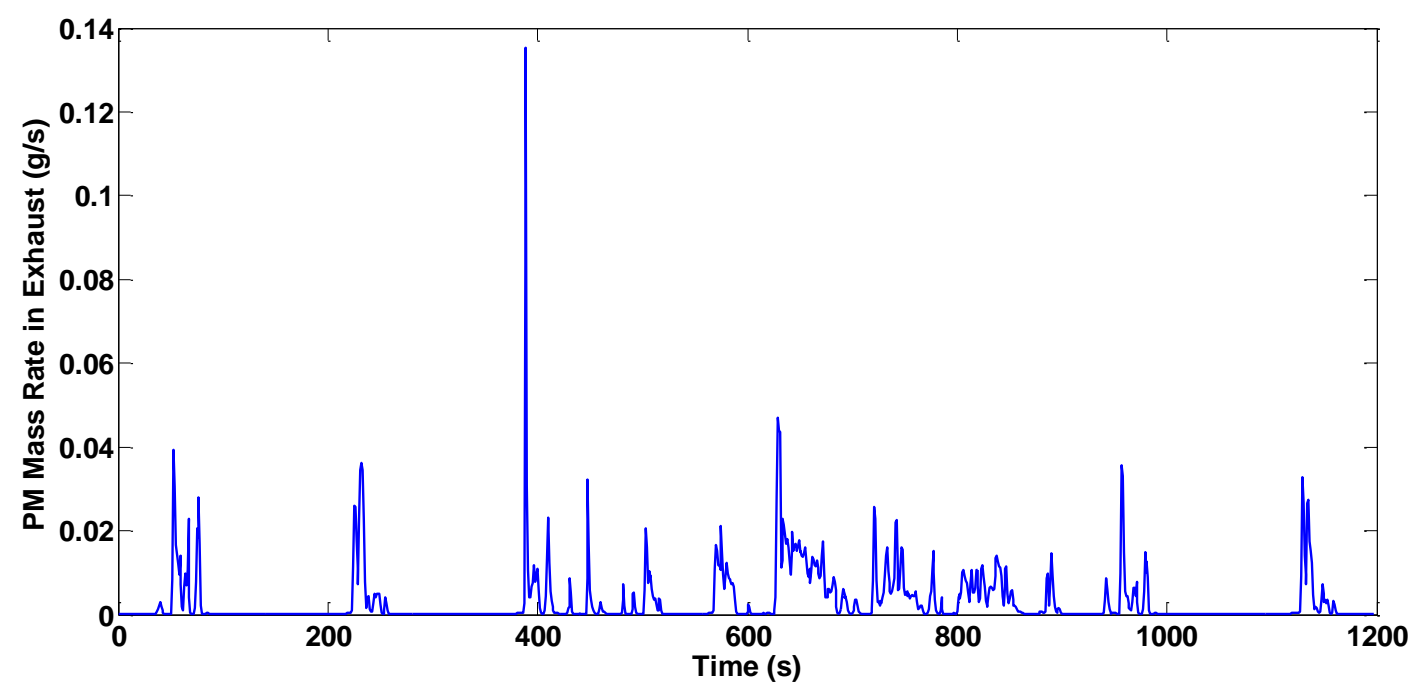

Figure 4-3: Calculated PM Mass Rate 
The CVS PM system flow rates varied little with changes in exhaust flow, but due to the transient nature of the PM mass emitted, the error propagated transiently from the constant flow rates and equipment accuracies. For the continuous error analysis of the CVS system, the batch values were eliminated. The part of the PM equation that corrects for background PM was removed in this analysis due to the fact that it was a batch correction. Without the background correction the total result could be skewed, but the continuous analysis was to only show insight as to where in the test cycle the most error occurred. Figure 4-4 shows the continuous error analysis of the CVS system. The highest errors occurred when the high levels of mass was being emitted. The CVS tunnel flow measurement propagated the most error just as was shown in the batch analysis. The MFCs contributed an extremely low amount to the total propagated error also just as was shown in the batch analysis.

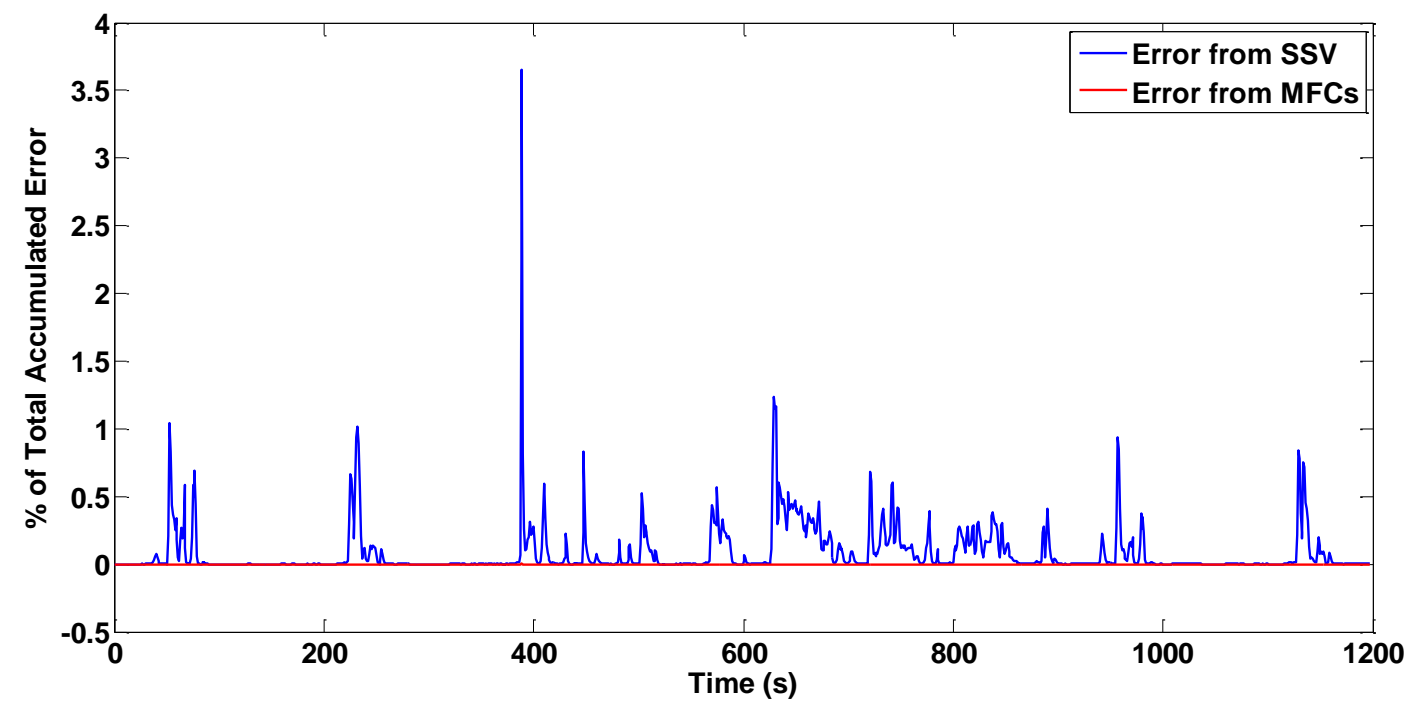

Figure 4-4: Continuous Error Analysis of the CVS System

The PFS PM system flow rates changed markedly with changes in exhaust flow. The error that was propagated at one exhaust flow rate would be different from that of another flow rate. A continuous error propagation analysis showed when in the test cycle the most error came from and when the least error was propagated. Figure 4-5 shows the results of the continuous error analysis of the PFS system. 


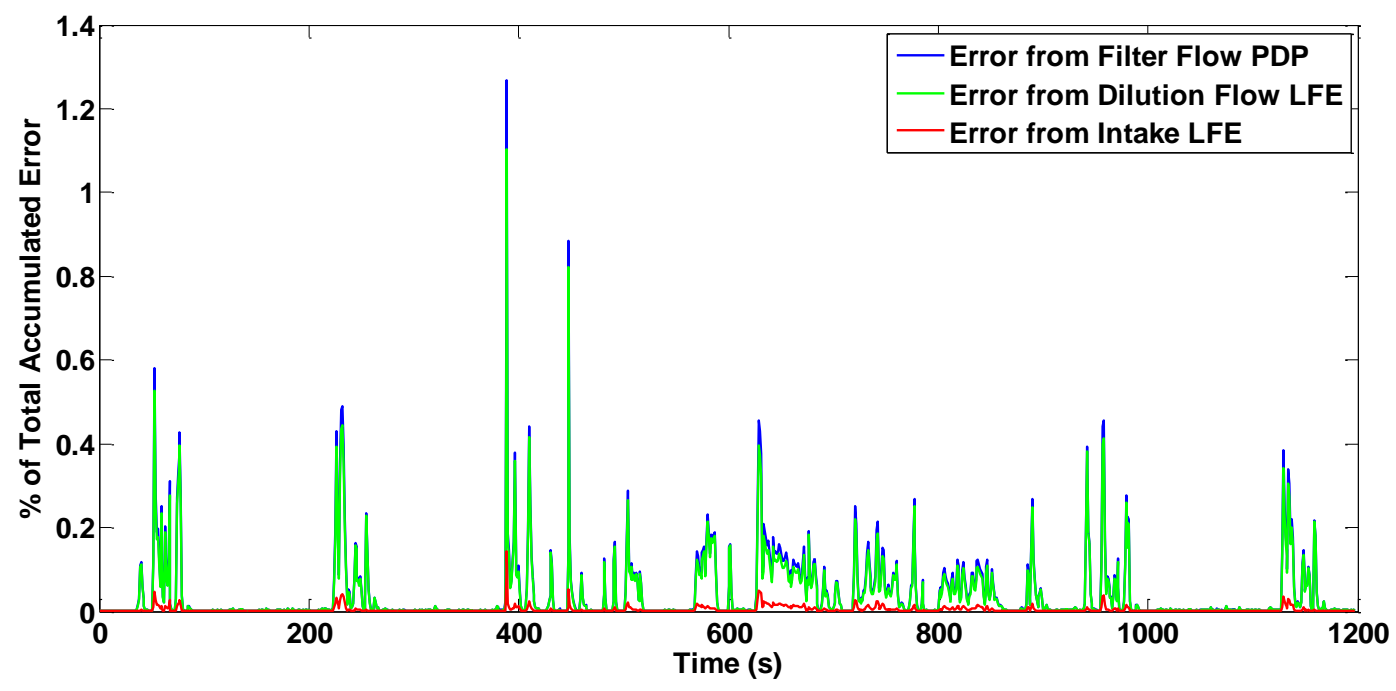

Figure 4-5: Continuous Error Analysis of the PFS System

Figure 4-5 shows the error propagated from inaccuracies in measurement of filter flow, dilution flow, and exhaust flow. It was very clear that the error from the dilution and filter flow was low when the exhaust flow was low, and the opposite was also true. When the exhaust flow was high the dilution and filter flow error was high. The error propagated from the exhaust flow measurement was nearly insignificant which was congruent with the batch analysis.

All three constituents of the propagated error were higher when the engine load was higher. This was due to the fact that more PM was emitted in the high load events. The propagated errors tended to follow the PM mass rate proportionately. However, the propagated errors were disproportionately high in the areas of non-idle low flow. This phenomenon could be explained by the way the PM error propagation error equation was constructed. The error propagation equation for filter flow is listed below.

$$
\text { PFS filter flow error }=\left(\frac{\mathrm{M}_{\mathrm{PM}} * \mathrm{~V}_{\mathrm{s} \text { exh }}}{\left(\mathrm{V}_{\mathrm{S}, \text { filter }}-\mathrm{V}_{\mathrm{s}, \mathrm{dilution}}\right)^{2}}\right) * \Delta \mathbf{V}_{\mathrm{s}, \text { filter }}
$$

The difference between filter and dilution flow were in the denominator of the equation. When this difference became smaller during a low flow situation, the error would tend to become 
exponentially larger due to the squared term. On the other hand, when exhaust flow and PM mass in the numerator became smaller, the error would tend to become linearly smaller. Furthermore, the exhaust flow and the difference between filter and dilution flow were directly proportional. The squared term in the denominator was what made the error large when exhaust flow and the difference between filter and dilution flow were small. The square of a small number in the denominator increased the result more than the proportional small number in the numerator decreased the result. The result was that when the exhaust flow was decreased, the error from filter and dilution flow was increased. But at idle the PM mass was so near to zero that it dominated the equation. That was why the non-idle low flow events had error that was not proportional to the PM mass rate.

\subsection{Validation of Loss Model}

As another part of the analysis of CVS and PFS systems a PM loss model was used. In order for the loss model to have any validity the calculated result from the model should be somewhere close to that of the experimental. The model uses a particle distribution that comes from a particle spectrometer and integrated the distribution over the test to yield a mass result. The result from experimentation from the CVS system was $0.105 \mathrm{~g} / \mathrm{bhp}-\mathrm{hr}$, and the result from the model was $0.204 \mathrm{~g} / \mathrm{bhp}-\mathrm{hr}$, which was a difference of $0.099 \mathrm{~g} / \mathrm{bhp}-\mathrm{hr}$. This would seem to be a huge difference, but the model was not meant to accurately find the mass of PM. It was however meant to find where and why PM was lost in the sampling systems. A scaling factor of 0.5 was used to bring the model results closer to the experimental results. Since the model PM result was in the same order of magnitude as the experimental PM result and the loss results were given as percentages, the model yielded applicable results. If particle spectrometer data, CVS system data, and PFS system from the same engine were to be used the results may have been different.

\subsection{Integrated Loss Model Results}

Particulate loss analysis was conducted for both the CVS and PFS systems. Using data from experiments along with physical dimensions of the sampling systems, the particle distribution in the exhaust was cut down by equations that explain loss of particles by different methods. After 
the equations cut down the distribution, the new distribution was integrated over the test to find a new brake specific mass result. The total loss was then split up into the respective loss method to show how particulate was lost in a sampling system.

\subsubsection{CVS Integrated Loss Results}

The CVS system was analyzed first. The physical dimensions of the system were found and compiled in Table 4-7.

Table 4-7: CVS Physical Dimensions

\begin{tabular}{|l|r|l|}
\hline CVS Main Dilution Tunnel Length & 200 & inch \\
\hline CVS Main Dilution Tunnel Diameter & 20 & inch \\
\hline CVS PM Probe Diameter & 1 & inch \\
\hline CVS PM Tube Length & 105 & inch \\
\hline CVS PM Tube Diameter & 1 & inch \\
\hline CVS Total Bend Angle & 480 & degrees \\
\hline
\end{tabular}

In the CVS system several modes of PM loss were considered. Diffusion and thermophoretic losses were considered in the primary dilution tunnel. Isokinetic loss was considered in the PM probe. In the CVS PM system, diffusion, thermophoretic, and bend losses were also considered. The integrated results are listed in Table 4-8 and the breakdown of the losses is shown in Table 4-9.

Table 4-8: CVS Integrated Loss Results

\begin{tabular}{|l|r|l|}
\hline Exhaust PM & 0.102 & $\mathrm{~g} / \mathrm{bhp}-\mathrm{hr}$ \\
\hline CVS PM & 0.091 & $\mathrm{~g} / \mathrm{bhp}-\mathrm{hr}$ \\
\hline Loss & 0.0112 & $\mathrm{~g} / \mathrm{bhp}-\mathrm{hr}$ \\
\hline $\begin{array}{l}\text { Percent Loss from } \\
\text { Exhaust PM }\end{array}$ & 11.0 & $\mathrm{\%}$ \\
\hline
\end{tabular}


Table 4-9: CVS Integrated Loss Breakdown

\begin{tabular}{|l|r|r|}
\hline Mode of loss & $\mathrm{g} / \mathrm{bhp}-\mathrm{hr}$ & $\begin{array}{r}\text { Percent of } \\
\text { total loss }\end{array}$ \\
\hline Diffusion in Primary Tunnel & 0.0000663 & 0.6 \\
\hline $\begin{array}{l}\text { Thermophoretic in Primary } \\
\text { Tunnel }\end{array}$ & 0.00581 & 51.7 \\
\hline Isokinetic & -0.0000527 & -0.5 \\
\hline $\begin{array}{l}\text { Diffusion in Secondary } \\
\text { Dilution Tunnel }\end{array}$ & 0.00474 & 42.2 \\
\hline $\begin{array}{l}\text { Thermophoretic in } \\
\text { Secondary Dilution Tunnel }\end{array}$ & 0.000658 & \\
\hline Bend & $1.79 \mathrm{E}-05$ & 5.8 \\
\hline
\end{tabular}

The percent of mass lost in the CVS system was $11.0 \%$. In the primary dilution tunnel, diffusion loss accounts for $0.6 \%$ of the total mass lost in the system, whereas thermophoretic losses account for $51.7 \%$ of the total mass lost. Diffusion losses were low because the flow velocity was fast and tube diameter was large. In the primary dilution tunnel the flow velocity was fairly high, varying in the range of 6-11 m/s. This high velocity explains why the diffusion loss was so low. Thermophoretic losses occurred when there was a temperature gradient due to heat transfer out of the pipe. The primary dilution tunnel lost heat and that heat loss caused particle loss to the walls of the pipe. Thermophoretic loss in the primary dilution tunnel was a major mode of loss in the CVS system.

Isokinetic effects were considered in the model and accounted for $-0.5 \%$ of total mass lost. This indicated that the isokinetic effects actually caused the system to have a higher reading. The reason that the isokinetic effect caused particle gain was that the probe flow velocity was lower than the tunnel flow velocity. The heavier particles with more momentum could not stay in their streamlines and were thrown into the probe (See Figure 2-3). At only $-0.5 \%$ of the total mass lost, the isokinetic effect was considered to be a fairly insignificant contribution to the total.

Diffusion, thermophoretic, and bend losses in the secondary dilution PM system accounted for the rest of the total mass lost in the system. The diffusion loss contributed $42.2 \%$ to the total 
mass lost. This was due to the flow velocity being approximately $1.8 \mathrm{~m} / \mathrm{s}$. Particles have less momentum in slower flows, so the small particles are more likely to diffuse toward areas of low particle concentration at the wall. Thermophoretic losses in the secondary dilution system accounted for only $5.8 \%$ of the total mass lost. By the time the flow reached the secondary system the initial temperature was closer to the final temperature in the PM system. Since there was not a great difference in temperature from the inlet to the outlet, the heat transfer out of the system was relatively small. This fact showed why the thermophoretic loss in the secondary dilution system was small. Bend loss in the secondary dilution system accounted for $0.2 \%$ of the total mass lost. The bend loss only affected the heavier particles, and there were very few particles in the range that was affected by bend losses. This mode of loss was insignificant compared to the other modes. A breakdown of the losses was given in Figure 4-6. Again, the isokinetic portion of the total was a gain instead of a loss, but it was shown in the figure to give a sense of the size of the contribution in comparison to the other methods.

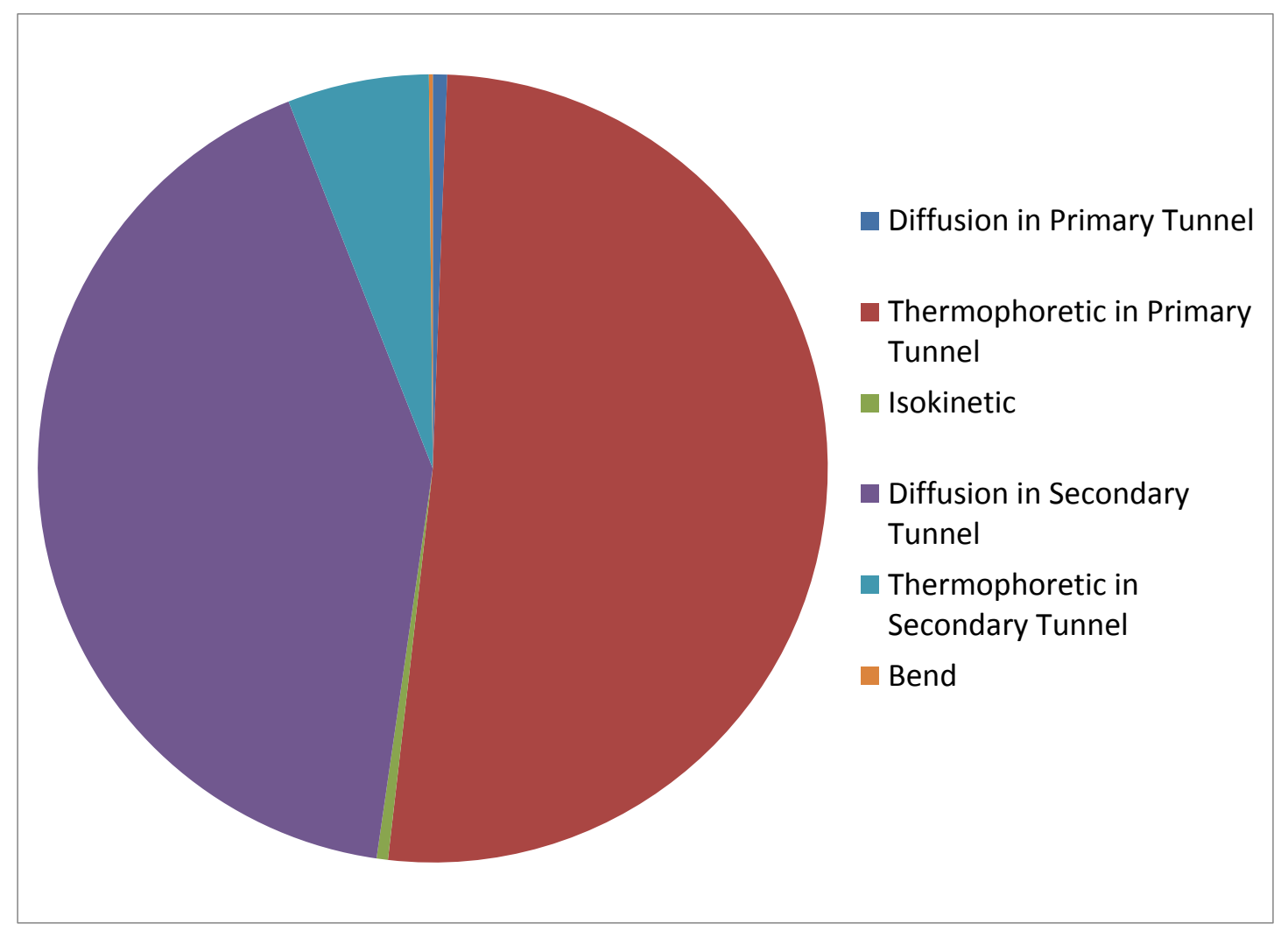

Figure 4-6: Loss Breakdown in the CVS System 
Thermophoretic loss in the primary tunnel and diffusion loss in the secondary tunnel account for $94 \%$ of the total mass lost. A solution to reduce the thermophoretic loss would be to heat the primary tunnel, which is required for cold start tests according to CFR 1065. To reduce the thermophoretic losses in the secondary dilution system the final temperature (filter face temperature) would have to be raised. Yet another way to reduce thermophoretic particle loss would be to reduce dilution air temperature. The latter two changes would transgress $40 \mathrm{CFR}$ 1065 which has set the filter face temperature and dilution air temperature, and also it would likely change the mass collected on the filter due to the volatility of the SOF content.

A solution to reduce the diffusion losses would be to increase the flow velocity in the system and increase the transfer tube diameter. This solution would also be a transgression of 40 CFR 1065 which has set the filter face velocity, and would change the SOF content. These examples showed that measurement of PM was a difficult and somewhat arbitrary process. When the PM measurement method was changed, the PM itself was changed.

\subsubsection{PFS Integrated Loss Results}

The PFS system had only one dilution, so the loss model had to only show the losses in that one area. Diffusion, thermophoretic, isokinetic, and bend losses were the modes of loss considered in the PFS system. The physical dimensions of the PFS system used in the model are listed in Table 4-10.

\section{Table 4-10: PFS Physical Dimensions}

\begin{tabular}{|l|r|l|}
\hline Exhaust Pipe Diameter & 6 & inch \\
\hline PFS Probe Diameter & 0.5 & inch \\
\hline PFS Tube Length & 89 & inch \\
\hline PFS Tube Diameter & 0.5 & inch \\
\hline PFS Total Bend Angle & 450 & degrees \\
\hline
\end{tabular}

The probe of the PFS was directly installed in the exhaust pipe, so the isokinetic effect came from differences between exhaust flow velocity and probe flow velocity. Inside the PFS dilution 
tunnel the other three loss types occurred. The integrated results from the loss model for the PFS system are shown in Table 4-11, and the breakdown of the particle losses is given in Table 4-12.

Table 4-11: PFS Integrated Loss Results

\begin{tabular}{|l|r|l|}
\hline Exhaust PM & 0.102 & $\mathrm{~g} / \mathrm{bhp}-\mathrm{hr}$ \\
\hline PFS PM & 0.097 & $\mathrm{~g} / \mathrm{bhp}-\mathrm{hr}$ \\
\hline Loss & 0.0049 & $\mathrm{~g} / \mathrm{bhp}-\mathrm{hr}$ \\
\hline $\begin{array}{l}\text { Percent Loss from } \\
\text { Exhaust PM }\end{array}$ & 4.8 & $\%$ \\
\hline
\end{tabular}

\section{Table 4-12: PFS Integrated Loss Breakdown}

\begin{tabular}{|l|r|r|}
\hline Mode of loss & g/bhp-hr & $\begin{array}{r}\text { Percent of } \\
\text { total loss }\end{array}$ \\
\hline Diffusion & 0.00429 & 87.3 \\
\hline Isokinetic & -0.00146 & -29.6 \\
\hline Thermophoretic & 0.00195 & 39.7 \\
\hline Bend & 0.000131 & 2.7 \\
\hline
\end{tabular}

The loss in the PFS system was $4.8 \%$ of the exhaust PM. Of that mass lost, $87.3 \%$ of it was lost due to diffusion losses. More particles were lost due to diffusion when the flow velocity was slow, when the tube length was long, and when the tube diameter was small. Although the diffusion loss was the largest contributor in the PFS system, the amount lost to diffusion was less than in the CVS secondary tunnel. This difference comes from the flow velocity being faster in the PFS system than the CVS secondary due to the smaller tube diameter and the tube length being shorter in the PFS than the CVS. The amounts of PM mass lost in the PFS system and the CVS secondary tunnel were very similar at only a $9 \%$ difference between the two.

The isokinetic effect accounted for a gain of $29.6 \%$ of the total mass lost in the PFS system. While the other types of loss could only cause particle loss, isokinetic effects could be gains or losses. The gain was due to the exhaust flow velocity being greater than the probe flow velocity and causing the heavier particles to be thrown out of their streamlines and into the probe (See Figure 2-3). This effect was the same as the effect observed in the CVS PM probe but to a 
greater extent due to a larger difference between the velocities of engine raw exhaust gas and that of the PM sampling probe.

Thermophoretic loss in the PFS system accounted for $39.7 \%$ of the total PM mass lost. To achieve a dilution factor in the PFS that was similar to the CVS, the sample was diluted to the correct factor with a single dilution, whereas the CVS had a two-step dilution. Diluting the sample greatly with a single dilution brings the initial temperature in the system down considerably without any heat transfer to the walls. When the initial and final (filter face) temperature were closer together the thermophoretic loss was reduced. This explains why the PFS thermophoretic loss was much less than the total CVS thermophoretic loss.

The bend loss in the PFS system accounted for only $2.7 \%$ of the total mass lost. Bend loss occurred due to the larger particles not making the turn, due to their momentum, and impacting the wall. This type of loss affected the total mass minimally because most of the mass came from smaller particles that were not affected by bends. The bend loss was higher in the PFS than the CVS because the flow velocity through the bends was much higher in the PFS. With higher velocities the particles had more momentum. Figure 4-7 showed a breakdown of the loss in the PFS system. The isokinetic portion of the chart was a gain, so the isokinetic portion was also part of both the diffusion and thermophoretic losses.

A way to reduce mass lost in a system would be to design a probe that would give just enough gain to compensate for the other losses. This could work strictly for mass emission, but would change the particle distribution result considerably. The particle losses would be many of the small particles and the particle gains would be a few of the large particles. The mass would balance out but the particle distribution would be severely biased toward the large particles. 


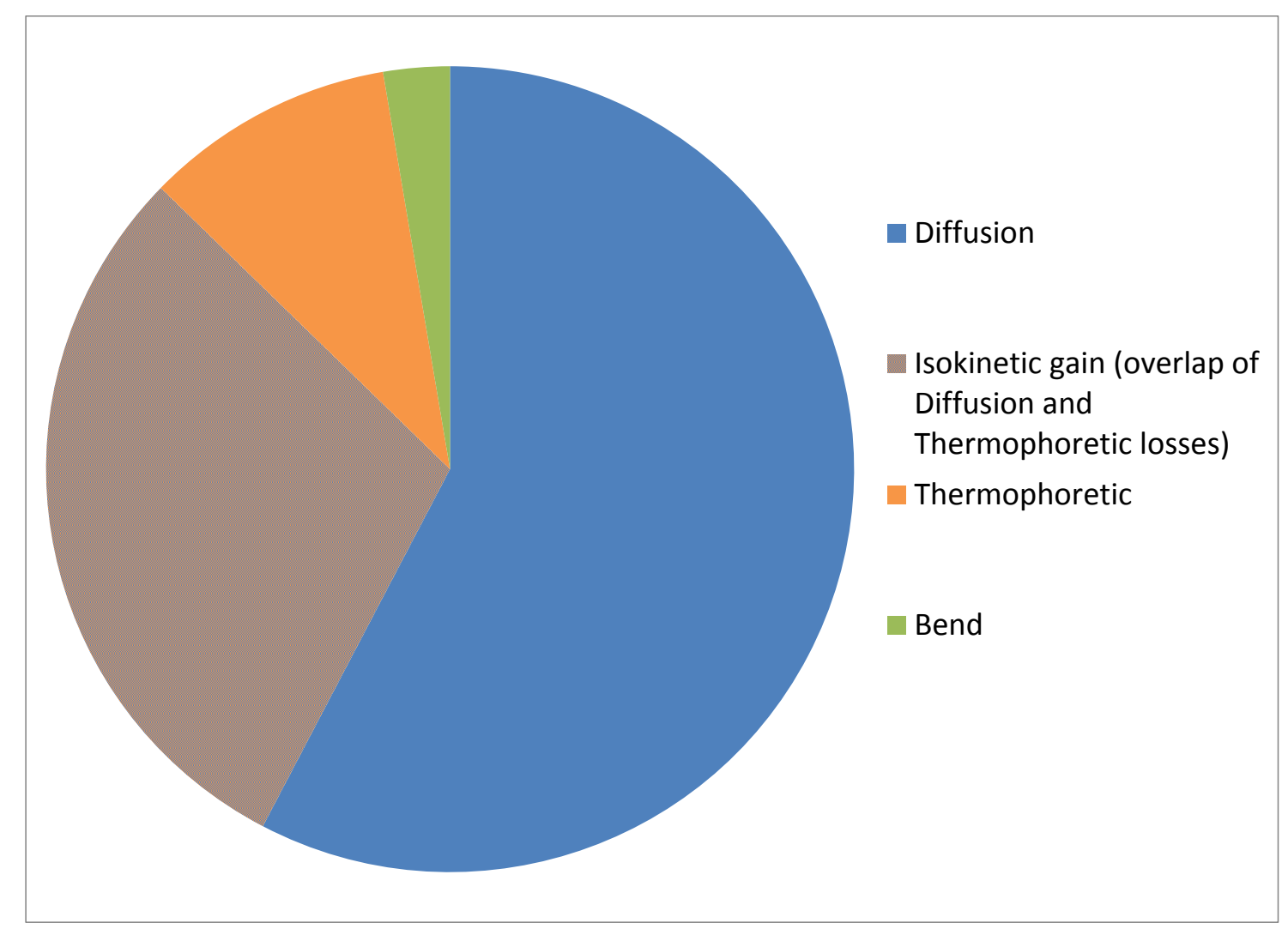

Figure 4-7: Loss Breakdown in the PFS System

\subsection{Continuous Loss Model Results}

Integrated results gave very good insight into the losses in PM sampling systems, but to see the transient effects on the different types of particle losses, a continuous analysis was done. The test cycle used was the transient FTP cycle. During the test many things such as flow rates, temperatures, and the particle distribution continuously changed. These changes caused continuous changes in where particles were lost and how many of them were lost. The continuous particle distribution from the EEPS is shown in Figure 4-8. It shows the amount of particles in the exhaust flow vs. time and particle size. 


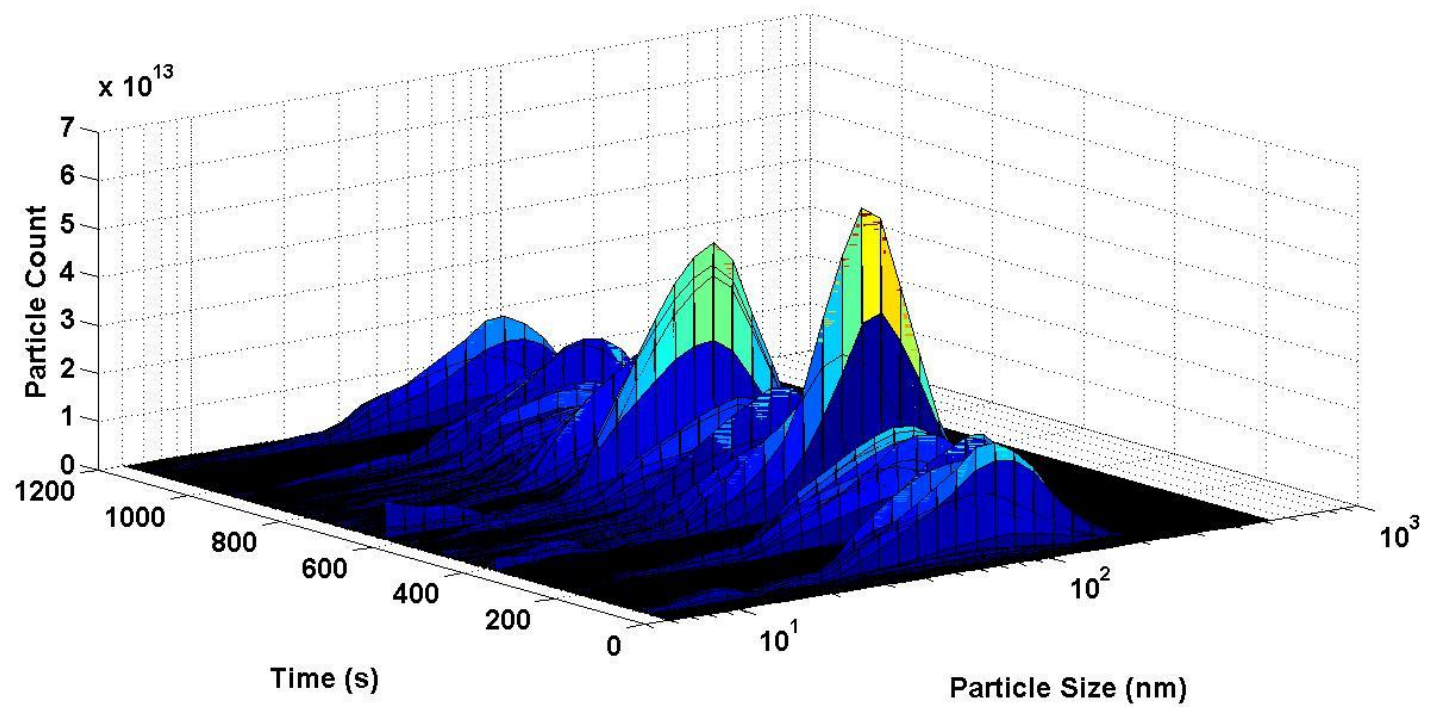

Figure 4-8: Continuous Particle Distribution

The particles distribution showed that nearly all of the particles were in the $0-200 \mathrm{~nm}$ range over the entire test. There were more particles emitted in the high load sections of the cycle, and very few particles emitted in the idle times. The highest peak in the data was 6.2E13 particles in the $93 \mathrm{~nm}$ bin at 388 seconds into the test.

\subsubsection{CVS Continuous Loss Results}

The CVS was modeled for continuous loss to show transient effects on the different types of loss. The primary dilution tunnel was modeled with diffusion and thermophoretic losses. The continuous losses were shown as a penetration. In a penetration graph a value of one denotes that all particles were getting through and a value of zero denotes that none of the particles were getting through. The loss fraction was the opposite of penetration. Figure 4-9 shows the penetration graph for diffusion in the CVS primary tunnel. 


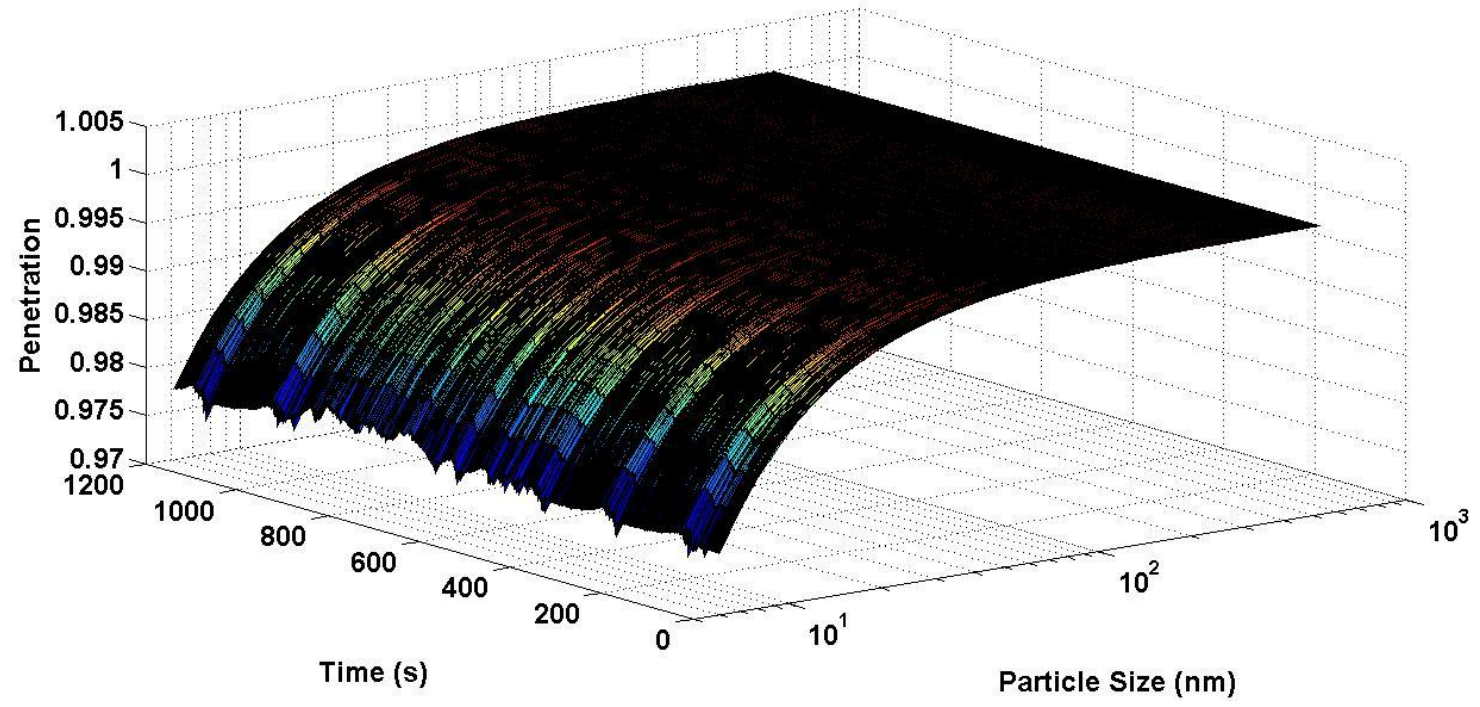

Figure 4-9: CVS Primary Diffusion Penetration

The diffusion in the CVS primary tunnel varied little with time, and did not affect the largest particles. The smallest particles were the most affected at only $98 \%$ penetration. As mentioned in the integrated results, diffusion in the CVS primary tunnel had minimal effect on particle loss because of the factors of high flow velocity and large tube diameter.

Thermophoretic loss in the CVS primary dilution tunnel accounted for the largest portion of the mass lost in the CVS system in the integrated results. To achieve greater insight into why this loss occurred, the continuous particle penetration is shown in Figure 4-10. 


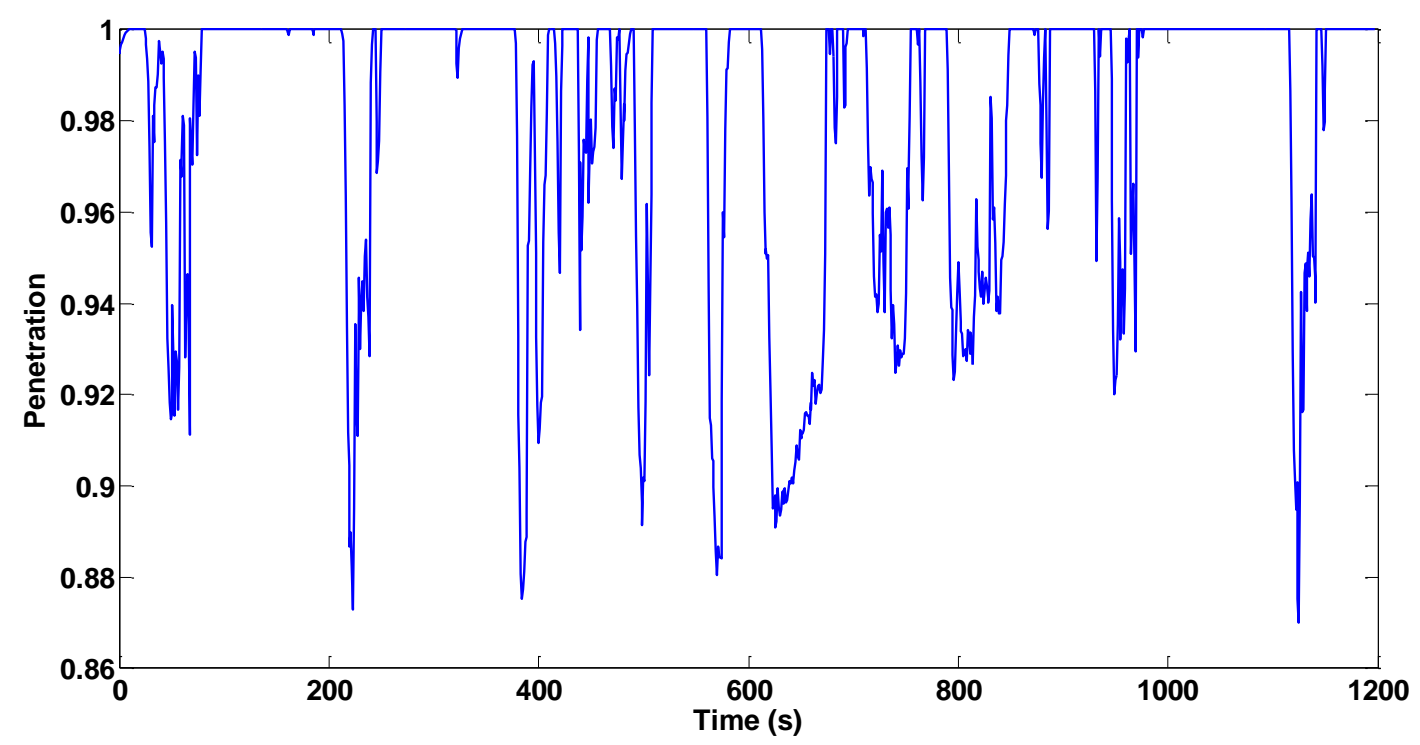

Figure 4-10: CVS Primary Dilution Tunnel Thermophoretic Penetration

The thermophoretic losses affected all sizes of particles, and thermophoretic losses were greatest when there was a greater temperature difference between the inlet and the outlet temperature. The inlet temperature of the tunnel was the highest when the engine was providing more exhaust. Higher exhaust flows generally meant that the engine has a higher load applied. Higher load normally meant more particle emission. So the thermophoretic loss percent was highest when the most particles were being emitted, and the thermophoretic loss percent was zero when the fewest particles were being emitted at idle. It can be clearly seen that the thermophoretic penetration was lower at every high load segment in the test cycle (See Figure 3-2 for engine load). This was why the integrated loss was high even though the particle penetration never dipped below $86 \%$. 


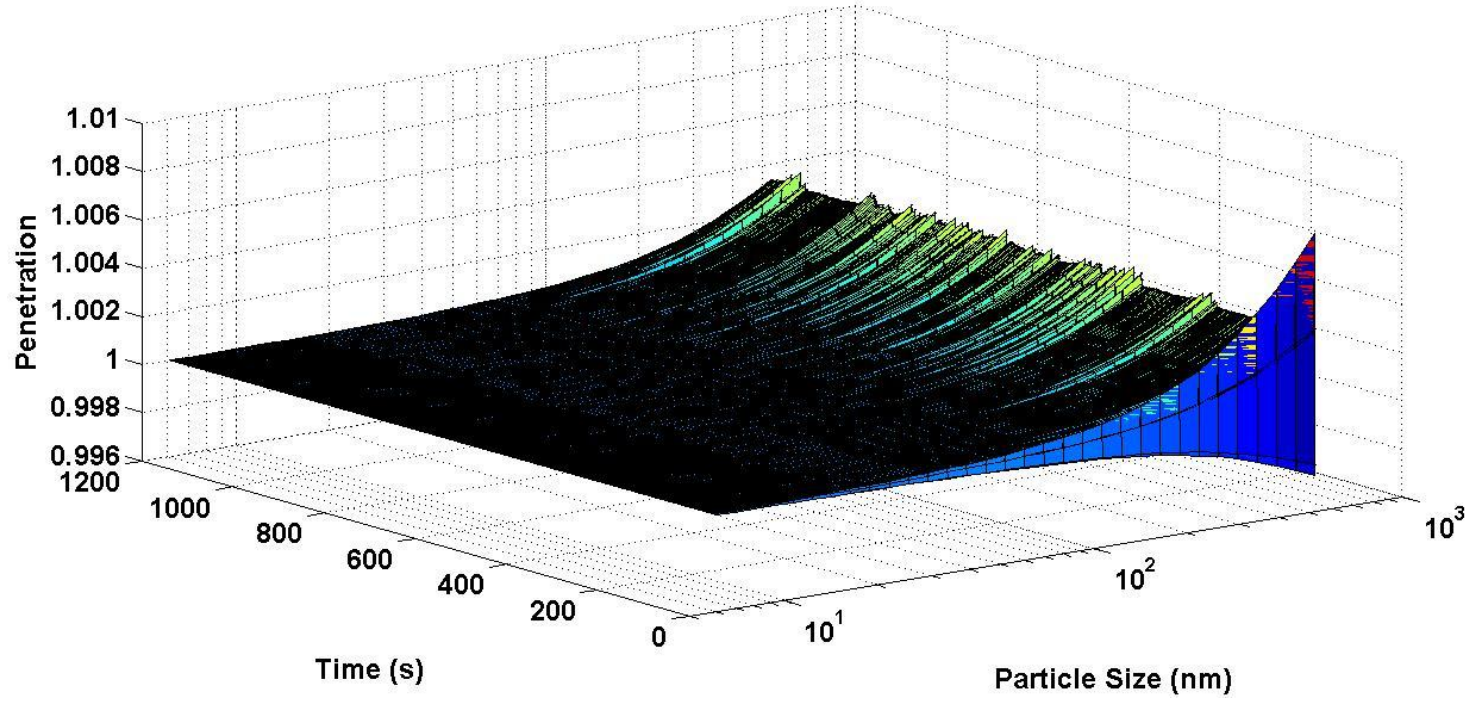

Figure 4-11: CVS PM Probe Isokinetic Penetration

The isokinetic effect of the CVS PM probe is shown in Figure 4-11. As shown, the effect was the greatest on the largest particles. The largest particles carried the most momentum and were therefore more subject to this effect. There was variation in the isokinetic effect with time mainly due to flow control errors. The two flow rates, tunnel flow and probe flow, were controlled to constant standard flow rates. Isokinetic effects were primarily dependent on the difference in the two relatively constant flow velocities. With the penetration between $99 \%$ and $101 \%$, the isokinetic effect from the CVS PM probe was minimal.

Figure 4-12 showed the diffusion particle penetration in the CVS secondary system. The diffusion penetration varied little with time. Diffusion loss targeted the smallest particles with only $2 \%$ particle penetration at the smallest bin size of $6 \mathrm{~nm}$ but around $90 \%$ particle penetration at $50 \mathrm{~nm}$. The smallest particles had the best ability to slip between the other flowing particles toward areas of lower concentration near the walls, and many of those actually impacted the wall and were lost from the stream. Larger particles had a more difficult time slipping between other particles obviously due to their size and also to their momentum tending to keep them flowing in the direction of the stream. 


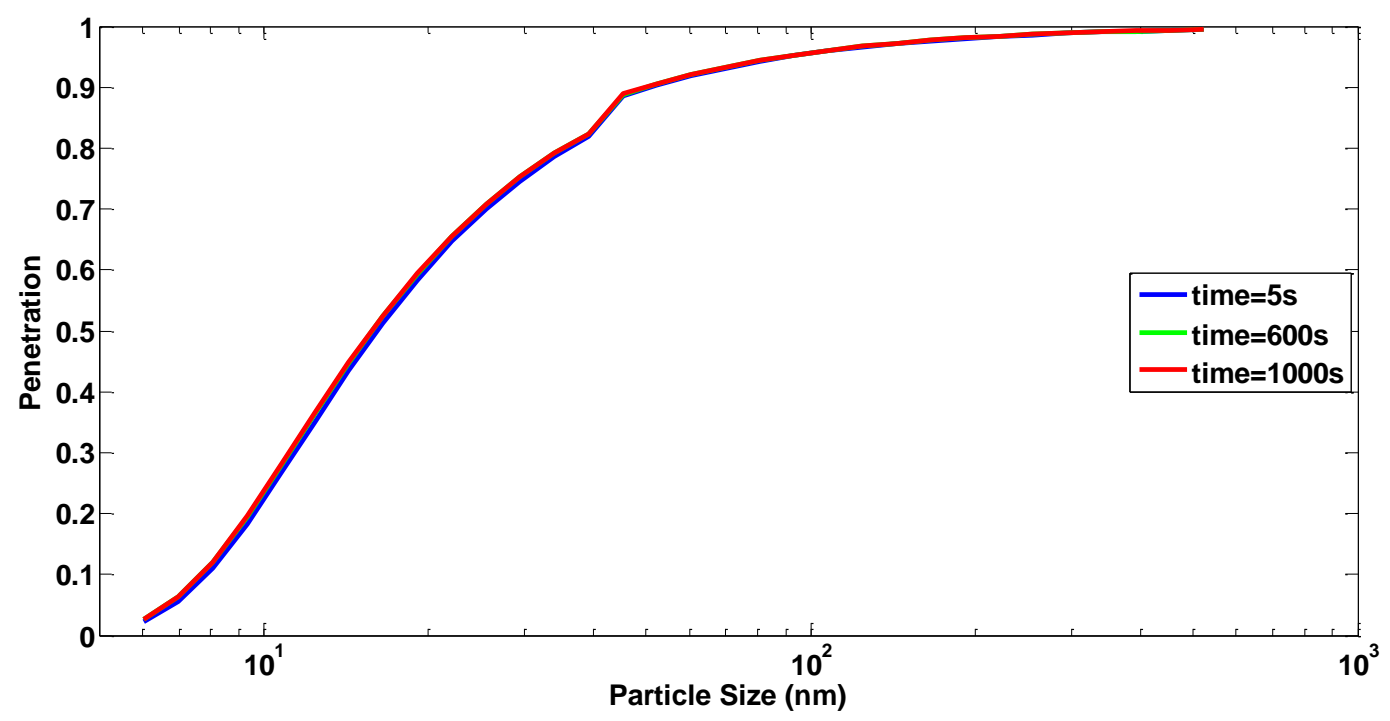

Figure 4-12: CVS Secondary Dilution Tunnel Diffusion Penetration

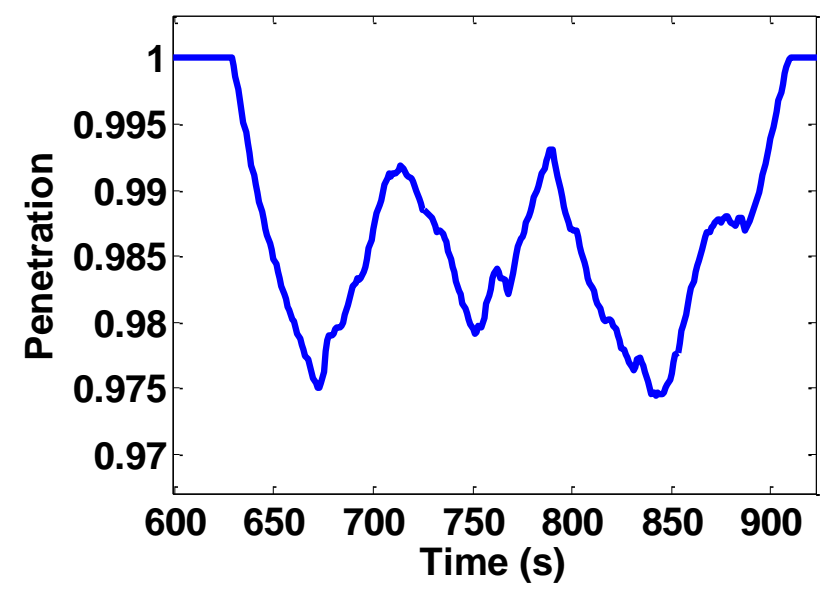

Figure 4-13: CVS Secondary Dilution Tunnel Thermophoretic Penetration

Figure 4-13 shows the particle penetration for thermophoretic loss in the secondary dilution system of the CVS. Thermophoretic loss did not change with particle size. The CVS secondary dilution system was in a heated enclosure to reduce temperature effects and to help keep the filter face temperature in the specified range. In almost all points in the test cycle the filter face 
temperature was higher than the secondary dilution tunnel temperature with one exception. During the Los Angeles Freeway part of the FTP the secondary dilution tunnel temperature was higher than the filter face temperature. This section in the test cycle was the only time when thermophoretic loss occurred in the CVS PM system, and the particle penetration never went below 97\%. This section was also a section of high particle emission, again showing that thermophoretic losses were the highest when particle emission was the highest.

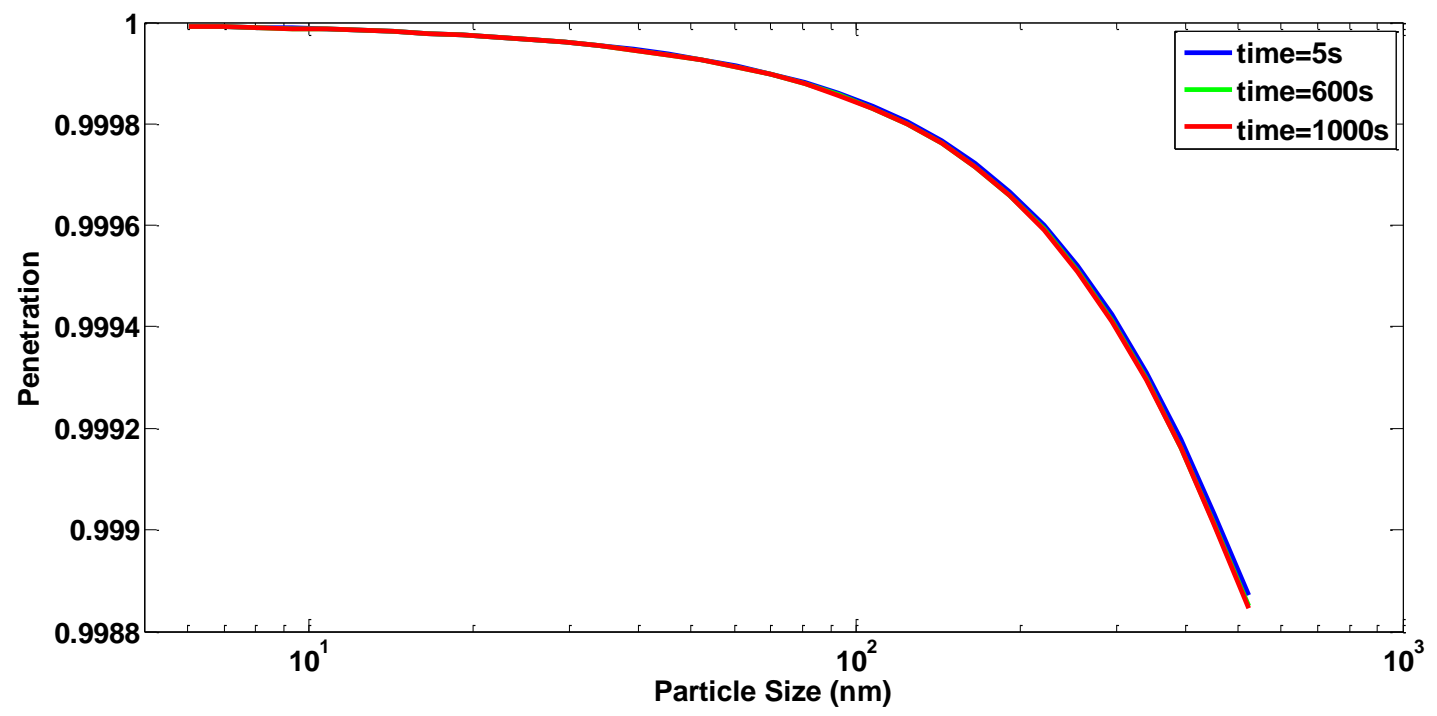

Figure 4-14: CVS Bend Penetration

Figure 4-14 shows the particle penetration due to bends in the CVS system. Since the flow rates were so constant in the CVS PM system the bend loss did not change with time during the test. It should be noted that bend loss affected the larger particles more, but the penetration for any particle size never went below 99.8\%. As with the integrated results, bend losses were an insignificant source of particle loss. 


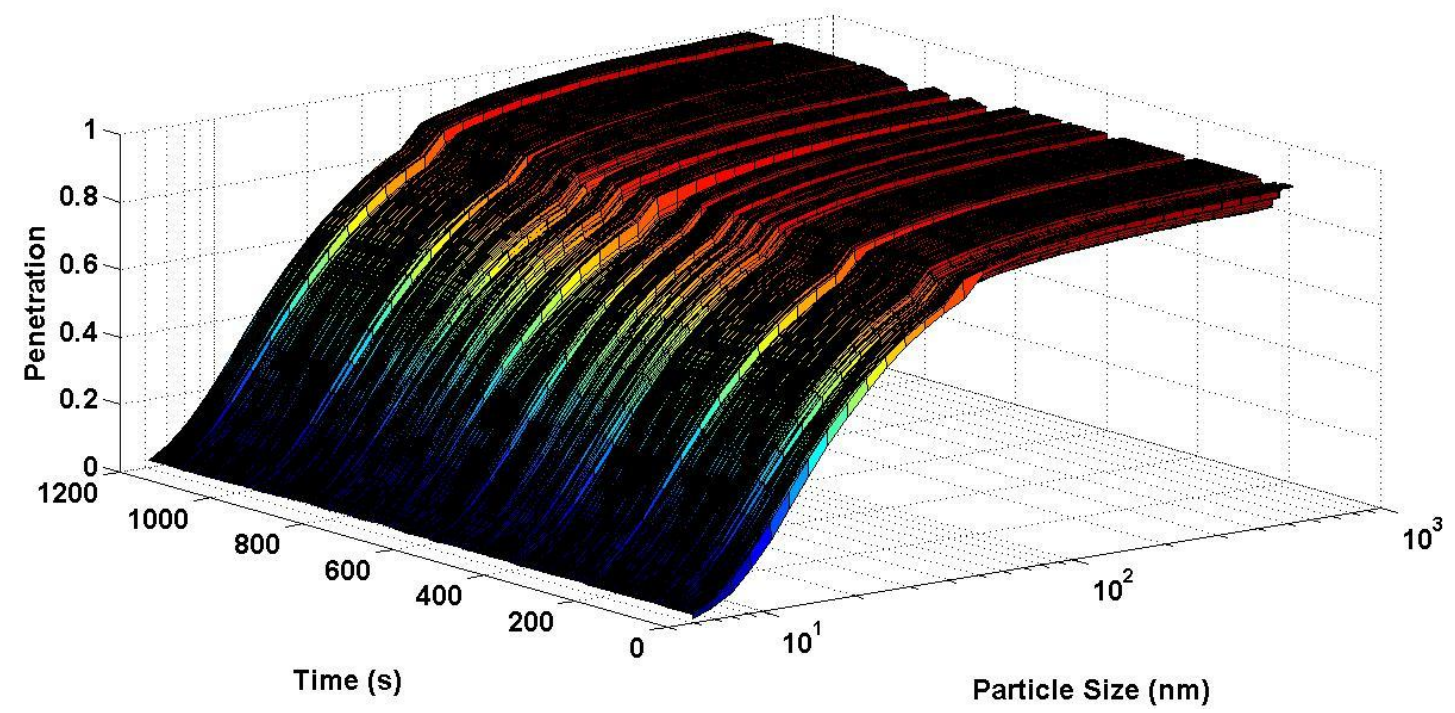

Figure 4-15: CVS Combined Particle Penetration

Figure 4-15 shows the combined particle penetration from all loss sources. This penetration indicated how the CVS system lost particles. The penetration was the fraction of particles that made it through the system to be measured. Most of the particles in the distribution were in the smaller size range, and more particles were emitted when system temperature was high. The losses in the CVS targeted these areas based on the nature of the two main loss types, diffusion and thermophoretic. Figure 4-16 shows the distribution in the CVS system after the losses had occurred. In this new distribution the highest peak was 5.3E13 particles in the $93 \mathrm{~nm}$ bin at 388 seconds into the test. This peak was in the same bin size and at the same time as the original distribution, but the number of particles was $14.5 \%$ less than the original distribution. 


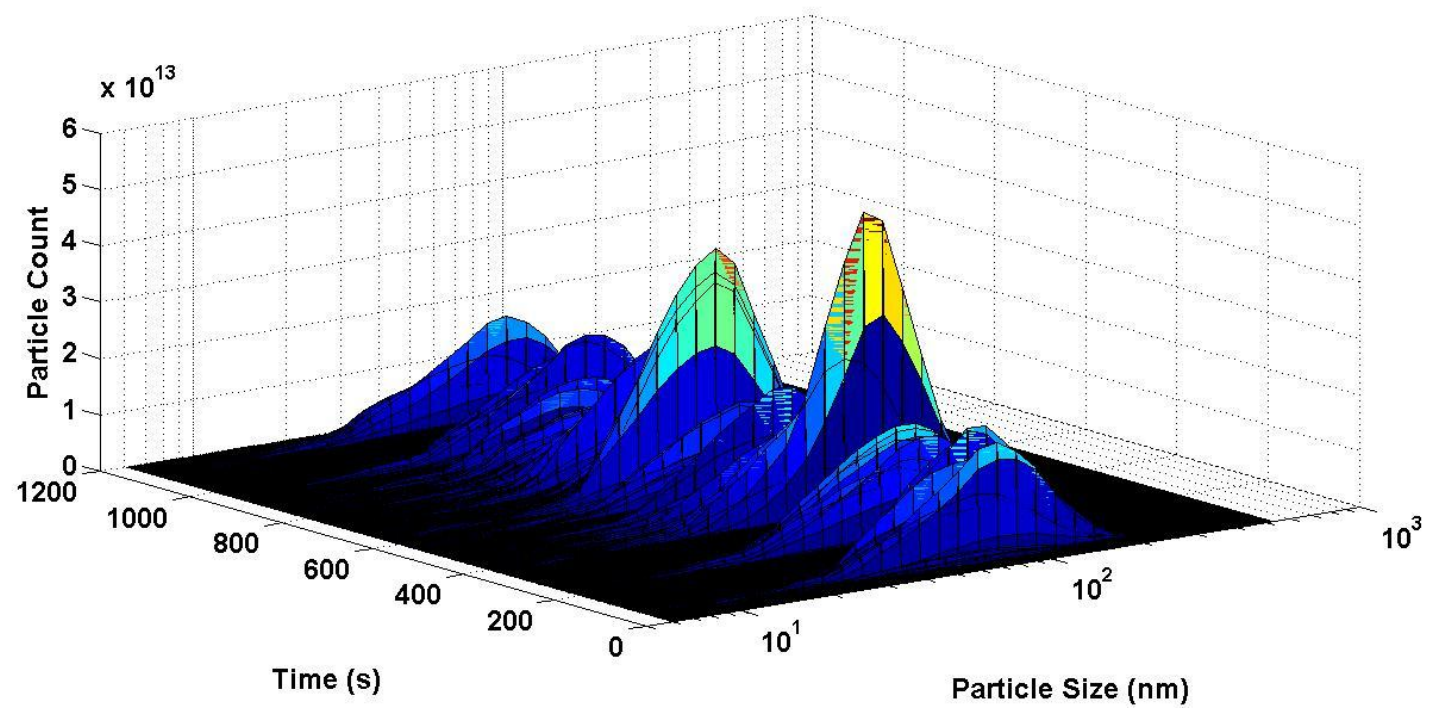

Figure 4-16: CVS Particle Distribution

\subsubsection{PFS Continuous Loss Results}

The PFS system was also modeled for particle losses. The types of loss that were modeled were diffusion, thermophoretic, isokinetic, and bend. As indicated in the integrated loss analysis, the total mass loss in the PFS system was less than that of the CVS. This continuous analysis gave insight as to when and how particles were lost in the system.

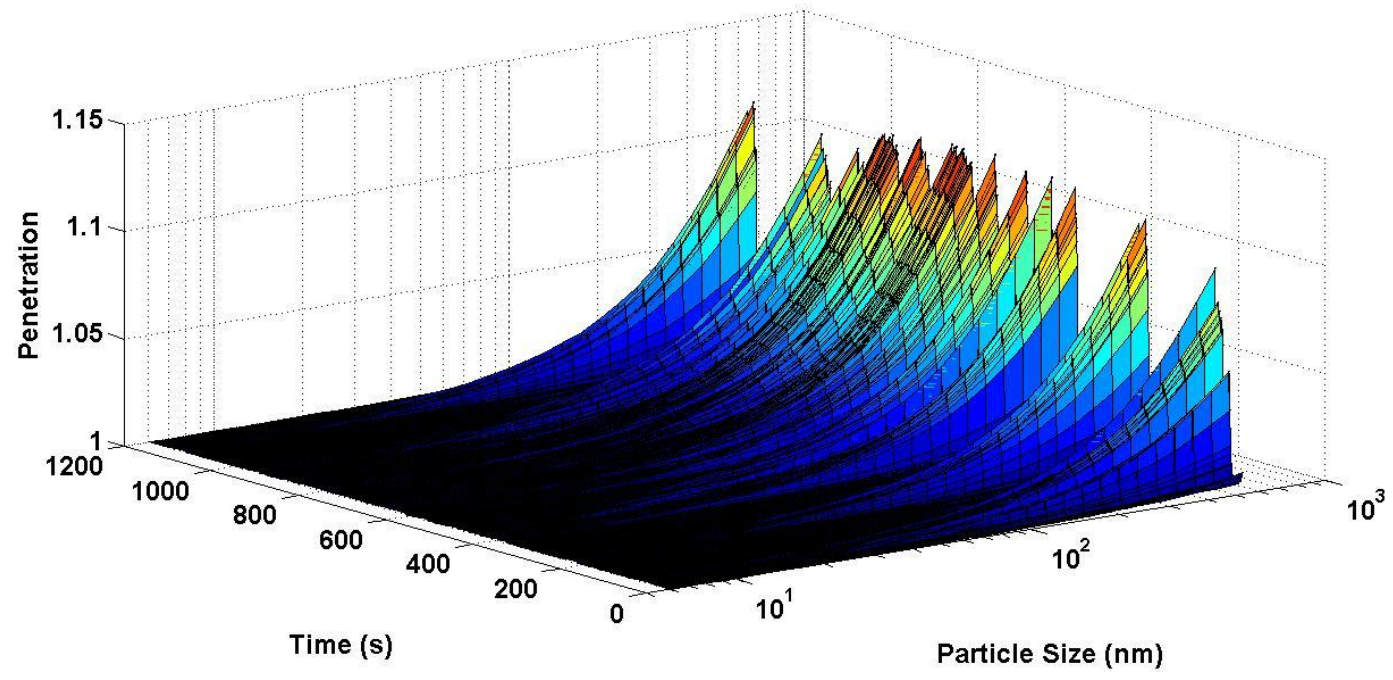

Figure 4-17: PFS Probe Isokinetic Effect 
Figure 4-17 shows the isokinetic effect on particle penetration. There was around 112\% penetration of the largest particles. The PFS probe was directly in the exhaust stream, and the standard probe flow was controlled to a constant proportion of the standard exhaust flow.

Temperature became a great cause of the isokinetic effect because when the exhaust temperature was higher the actual flow velocity was higher at the same standard flow rate. When the velocity was higher in the exhaust, the particles had a higher tendency to over-penetrate the sample probe. This was seen where there was higher penetration in the parts of the cycle where the exhaust temperature was higher.

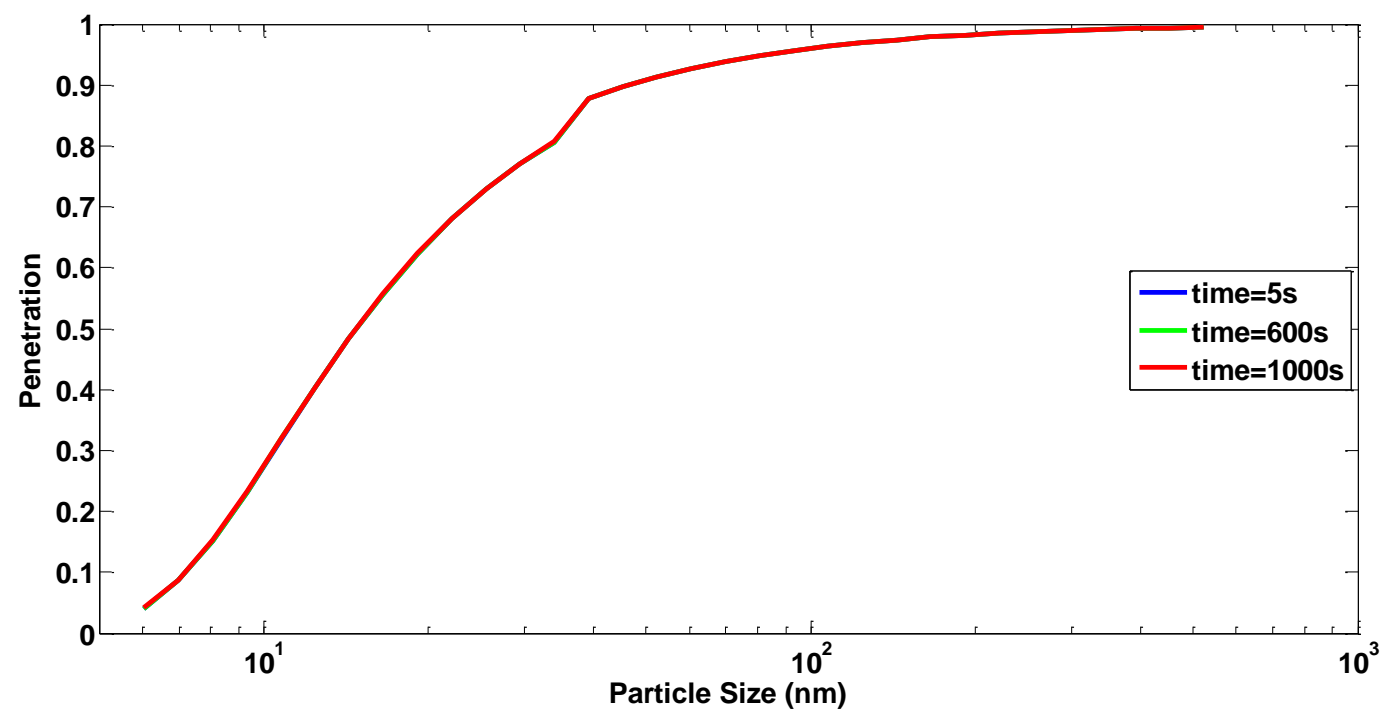

Figure 4-18: PFS Diffusion Particle Penetration

Figure 4-18 shows the particle penetration due to diffusion in the PFS system. The diffusion loss was more effective on the smallest particles as was mentioned earlier. The bump in the graph was due to the piece-wise nature of the diffusion equation. The PFS penetration was nearly identical to the CVS secondary tunnel because there was little difference in geometry and flow rates between the two. Figure 4-19 shows an overlay of the two diffusion penetrations of the CVS secondary tunnel and the PFS system. As expected the PFS system diffusion penetration was slightly higher than the CVS secondary system diffusion penetration. This shows good agreement with the integrated loss result of the PFS system having $10 \%$ less mass lost to diffusion than the CVS secondary system. 


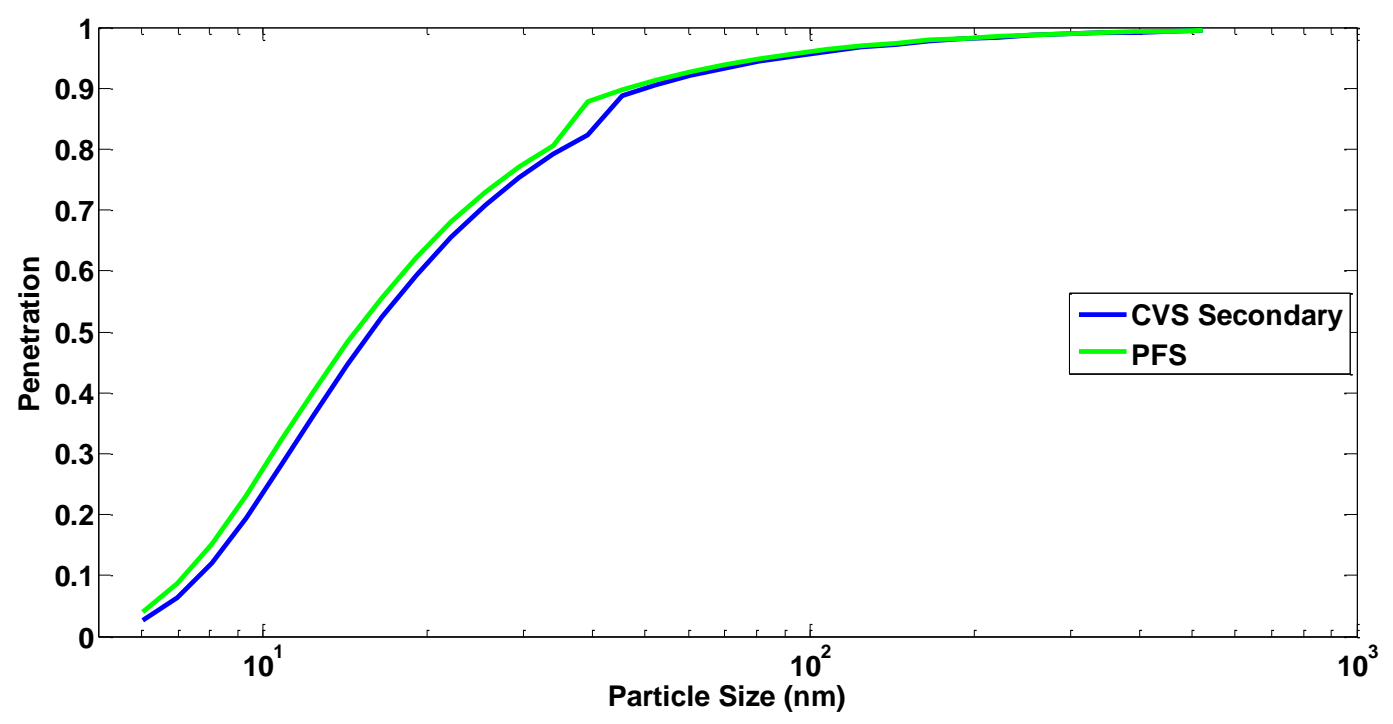

Figure 4-19: Diffusion Penetration Comparison

Thermophoretic losses affected the PFS system when the inlet temperature was higher than the outlet. Figure 4-20 shows the particle penetration due to thermophoretic loss. When the engine load was higher the exhaust temperature was generally higher. This higher exhaust temperature caused the dilution tunnel inlet temperature to be higher. At the times when the tunnel inlet temperature was higher than the filter face temperature thermophoretic loss occurred at a proportion of the difference in temperature. Since there was no change in thermophoretic loss with particle size, the figure showed the penetration of all particle sizes against time. It can be seen that the thermophoretic penetration looks similar to an upside down torque trace of the FTP test cycle because the areas of higher torque normally produce higher engine temperature. The thermophoretic particle penetration never went below $87 \%$, but thermophoretic loss affected all particle sizes including the heaviest ones, so the contribution to the mass loss was significant. 


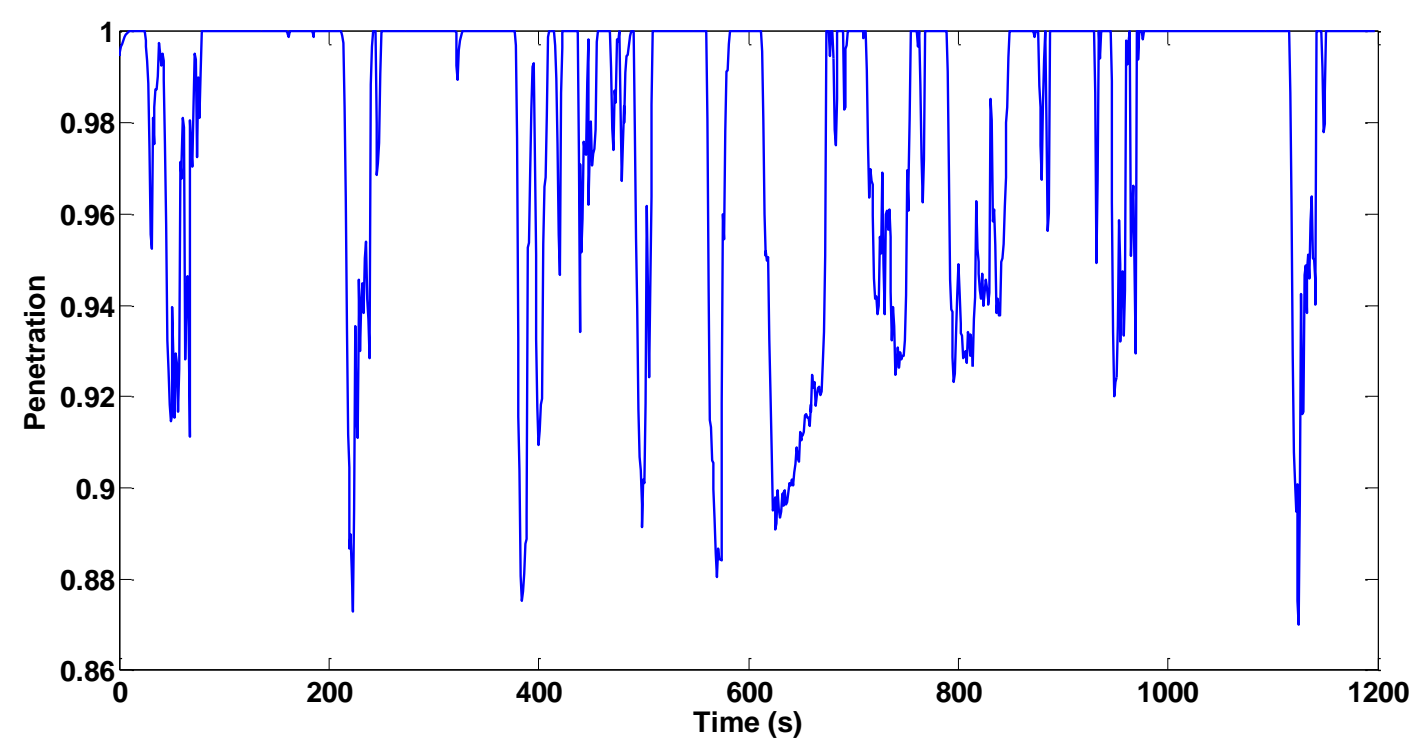

Figure 4-20: PFS Thermophoretic Particle Penetration

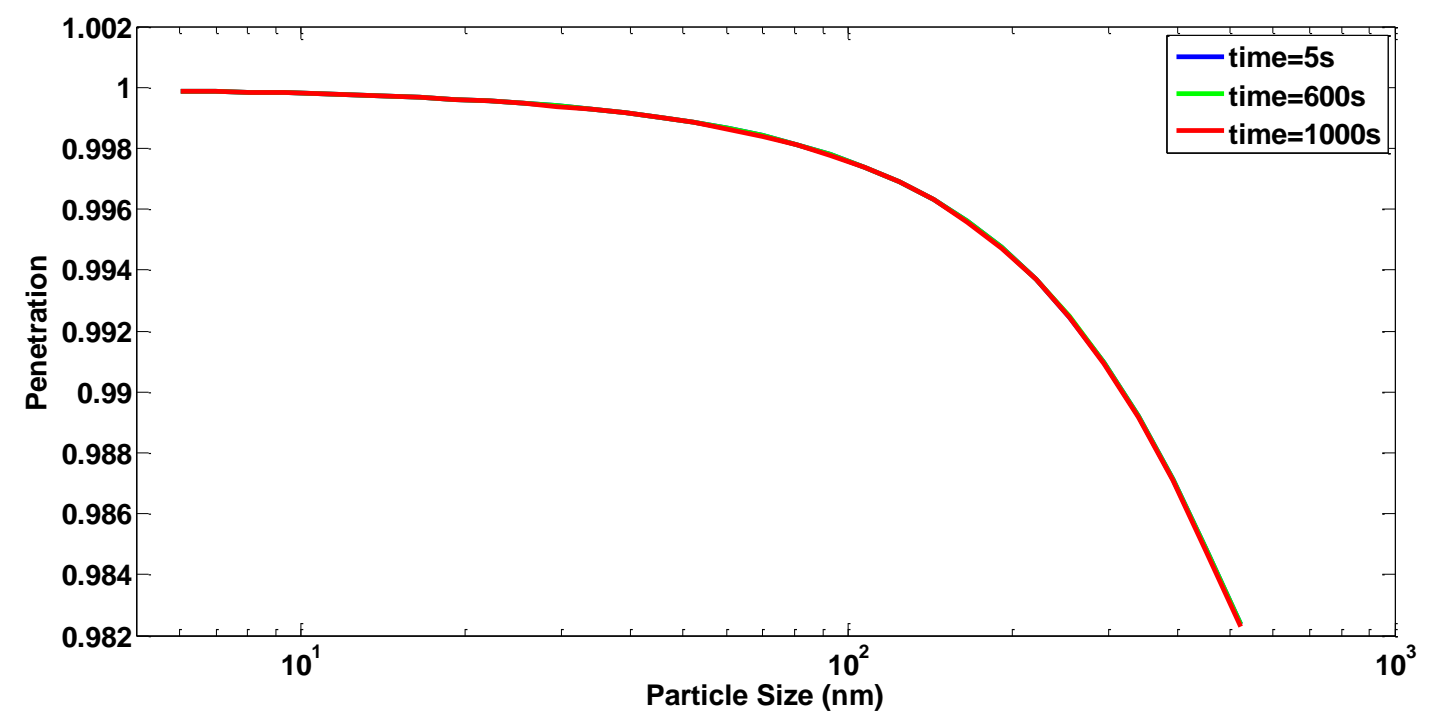

Figure 4-21: PFS Bend Particle Penetration

Figure 4-21 shows the particle penetration due to bends in the PFS system. Since the flow rate was fairly constant the bend loss varied little with time. Bend loss in the PFS was similar to that of the CVS secondary system because the flow rates and geometry were very similar. The bend losses affected the largest particles more because of their higher momentum, and the bend losses 
were higher in the PFS system than the CVS secondary system because the flow velocity was higher due to the smaller diameter tube.

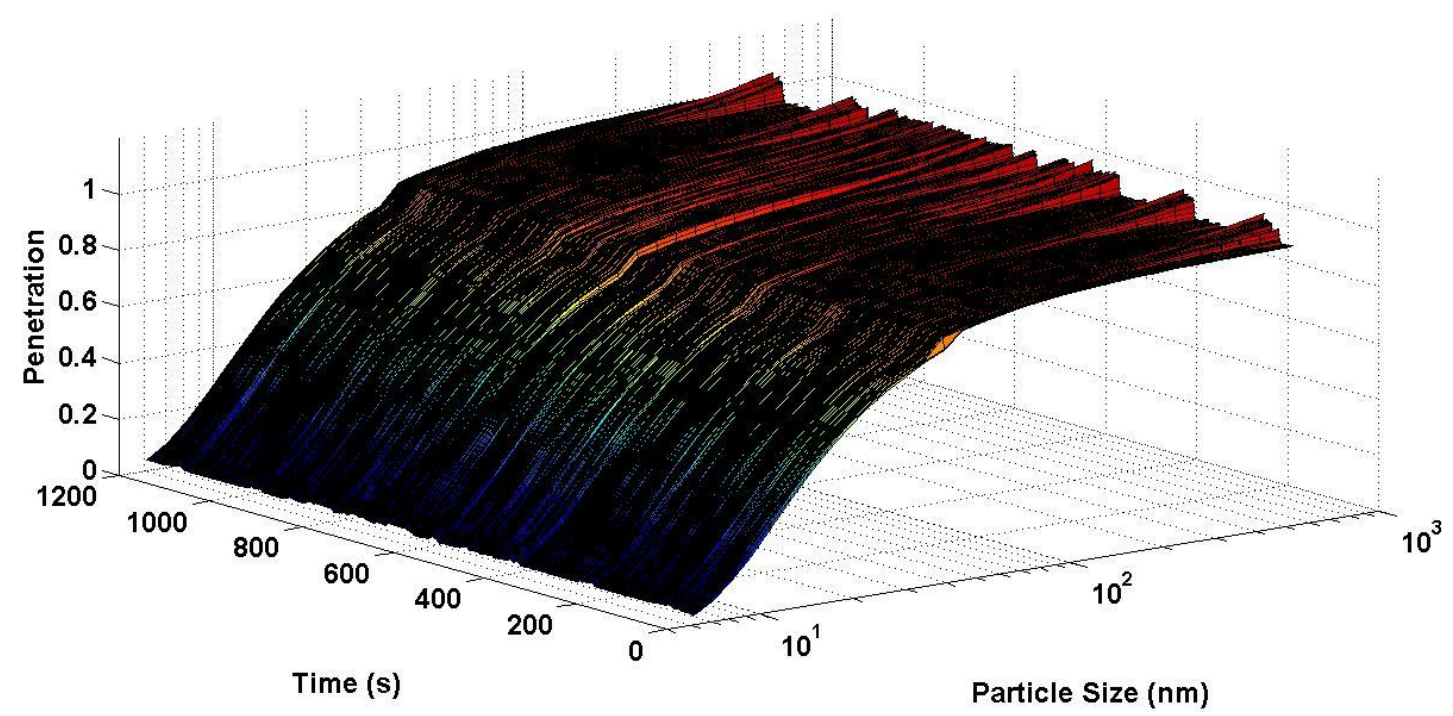

Figure 4-22: PFS Combined Particle Penetration

Figure 4-22 shows the particle penetration associated with all of the losses in the PFS system combined. In the very low particle size range the diffusion loss dominated. In the low to medium range of particle size the thermophoretic loss was the main loss contributor. In the high particle size range the isokinetic effect dominated particle gain. The bend loss had a small effect to cancel out some of the isokinetic gain. Figure 4-23 shows the resulting particle distribution after the losses had occurred. The distribution was similar to the original distribution. The peak in this PFS system distribution was in the $93 \mathrm{~nm}$ bin size at 388 seconds and has a value of 5.9E13 particles. This means that there was a $5 \%$ loss at the peak value. 


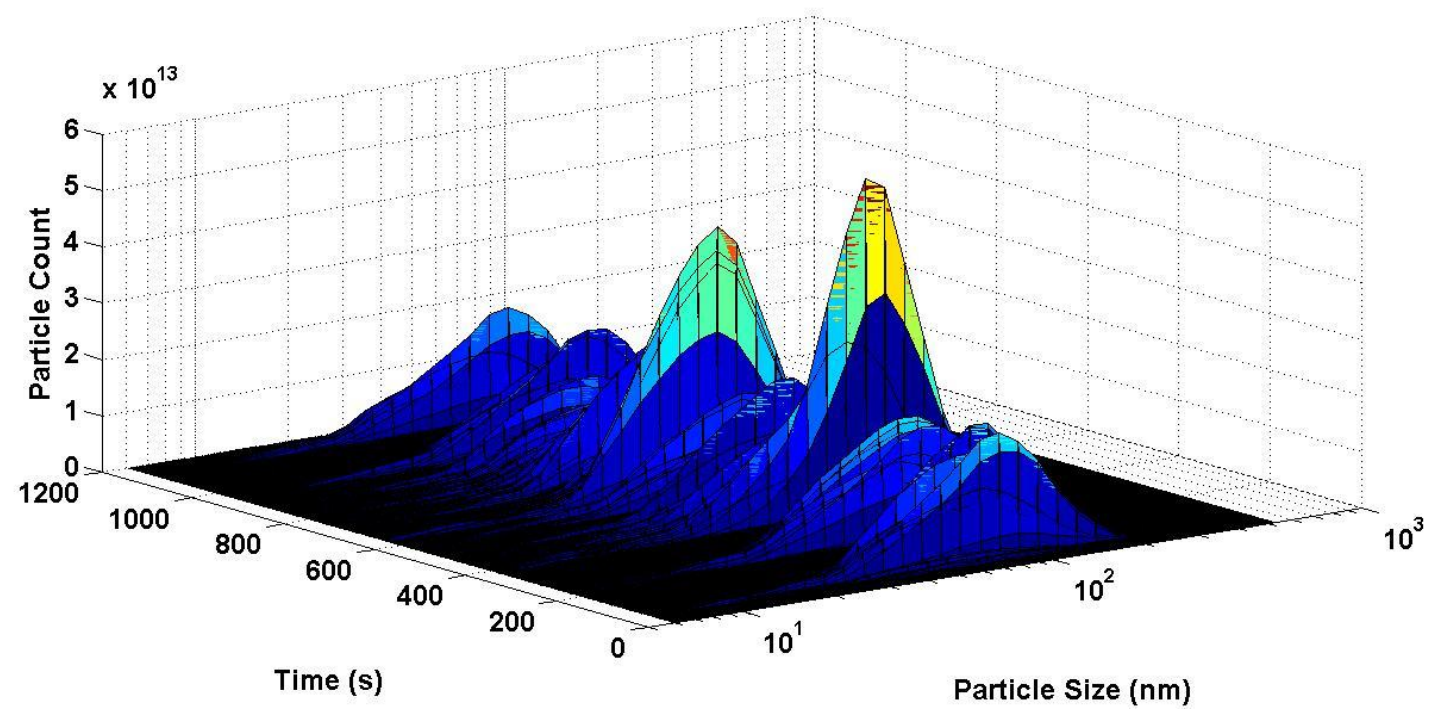

Figure 4-23: PFS Particle Distribution

As an additional view of the differences between the two systems, the CVS particle penetration was subtracted from the PFS particle penetration. Figure 4-24 shows this difference. At low particle size and at times of idle the difference between the two penetrations was the smallest. In the times of higher exhaust temperature the difference was larger. The peaks that were in the figure were where the diffusion equation changed from one to the other part of the piece-wise function. At the largest particle size, the difference became negative because the PFS system penetration was higher than the CVS due to the isokinetic effect. The difference between the penetrations never exceeded $20 \%$. 


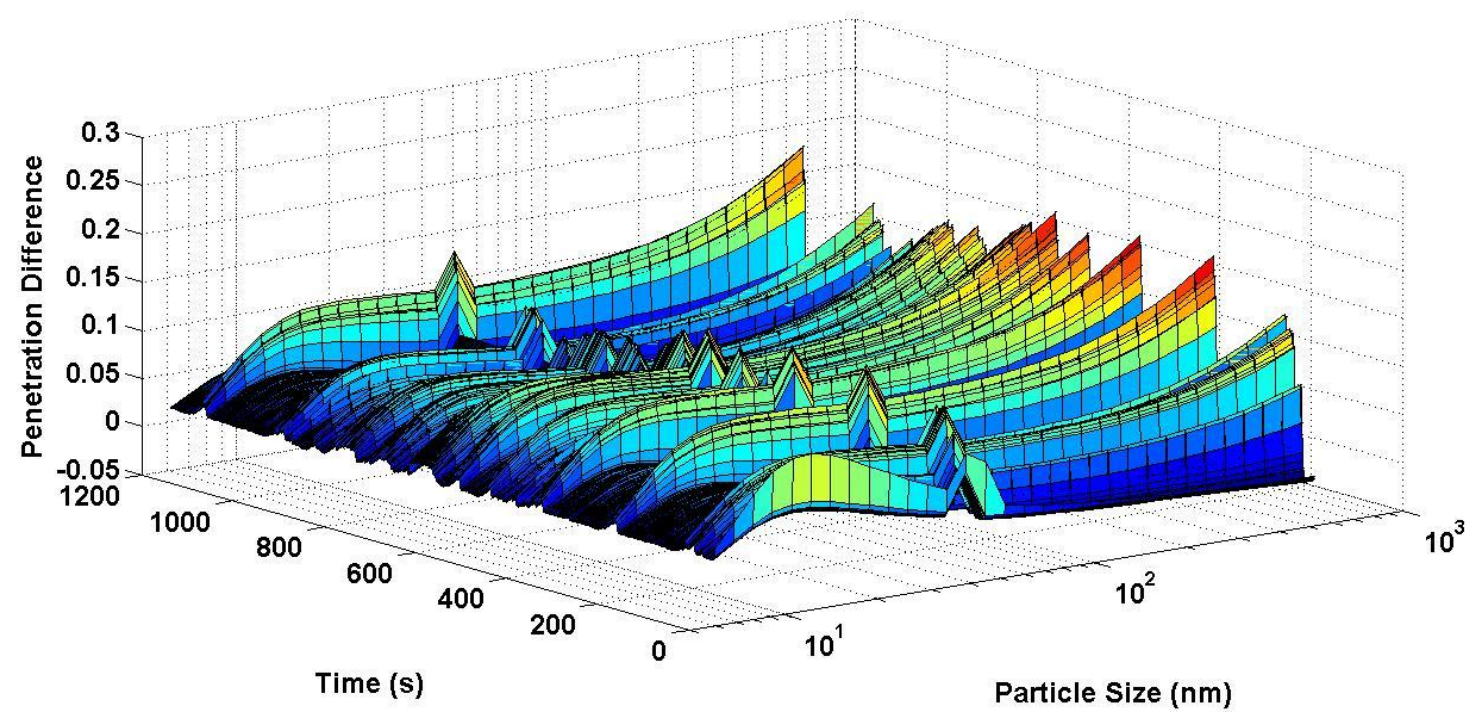

Figure 4-24: Difference between PFS and CVS Particle Penetration 


\section{Conclusions and Recommendations}

PM is a harmful regulated emission that needs to be accurately measured. This study showed some of the differences between the CVS and PFS PM measurement systems. The CVS system is the standard method of PM measurement, and the PFS system is a relative newcomer (accepted in 2011) to PM measurement. The systems were modeled to see how errors in their components propagated to error in their PM result. The systems were also modeled to see how the types of losses - thermophoretic, diffusion, isokinetic, and bend-affected the PM result.

\subsection{Conclusions}

The CVS system had a relative error in the PM result of 10.3\%. The largest source of error for the CVS system was the subsonic venturi for measuring tunnel flow rate. The other sources of error contributed very little to the total error.

The PFS system had a relative error in the PM result of 36.3\%. The two main sources of error in the PFS system were the LFE that measured dilution air flow and the PDP that measured total filter flow. The errors were more pronounced when the difference between the flows was small, and when the difference in flow was larger during high exhaust flow events the error shrank immensely. The errors caused by other sources were small.

The CVS system lost $11 \%$ of the mass of particles that entered into it according to the loss model. Thermophoretic loss in the primary dilution tunnel contributed $51.7 \%$ of the total lost mass, and according to the continuous analysis most of the particles were lost in high load portions of the test cycle. Diffusion loss in the secondary tunnel contributed $42.2 \%$ of the total mass lost, mostly the smallest particles. Another $5.8 \%$ was lost due to thermophoretic losses in the secondary tunnel. The other losses contribute very little to the total mass lost.

The PFS system lost $4.8 \%$ of the mass of particles that entered into it according to the loss model. Diffusion losses caused $87.3 \%$ of the total mass lost, mainly due the heavy loss of the smallest particles. Thermophoretic loss contributed $39.7 \%$ of the total mass lost, where more 
particles were lost during the high load portions of the test. The isokinetic effect gained $29.6 \%$ of the total mass lost because the largest particles were caused to over-penetrate. Also affecting the largest particles, the bend loss contributed $2.7 \%$ of the total mass lost.

\subsection{Recommendations}

PM is an interesting challenge to measure. There are so many factors that can affect the measured result. SOF content can be different based on filter face temperature and filter face velocity. Different dilution ratios and residence times can cause particles to form differently. Particle loss and re-entrainment can occur. And PM in the infinite dilution ratio of the environment can and probably does act completely different than in the pipes and tubes of a sampling system. With all the effort to try to achieve repeatable measurements in the laboratory, parameters of residence time, dilution ratio, and filter face temperature and velocity are set into place that are convenient for the testers but completely untrue to what would be happening in real life scenarios. Although on the regulation side, if less PM is emitted according to the sampling systems, then it stands to reason that less PM would be emitted into the environment in real life, which is the ultimate goal. More research should be done in the area of real life PM emission measurement.

Several things could be done in these models to minimize the error and particle loss. However, in order to be compliant with the CFR, many things cannot be changed. One easy thing to change, to reduce the isokinetic effect, is to select a probe that is the appropriate size to achieve an isokinetic condition. Another idea that would reduce loss would be to heat the primary tunnel in the CVS. According to the model, over half of the PM losses occurred here; however heating the large primary tunnel would require large heating elements and much energy. There is not much that can be done to reduce diffusion loss that does not also transgress the CFR. 


\section{References}

1. U.S. EPA. "Particulate Matter-Health and Environment." http://www.epa.gov/pm/health.html, Accessed 7/7/2011.

2. U.S. EPA. "Particulate Matter-Basic Information." http://www.epa.gov/pm/basic.html, Accessed 7/7/2011.

3. Burtscher, H. "Physical characterization of particulate emissions from diesel engines: a review.” Journal of Aerosol Science. Vol. 36, No. 7, pp. 896-932, 2005.

4. Khalek, I. "2007 Diesel Particulate Measurement Research.” Alpharetta, GA: Coordinating Research Council, Inc., 2008.

5. “Emissions Standards, European Union,” DieselNet, Brampton, ON, Canada, 2006. http://www.dieselnet.com/standards/eu/hd.php, Accessed 7/7/2011.

6. AVL. "AVL Smart Sampler." https://www.avl.com/smart-sampler, Accessed 7/7/2011.

7. Theil, W., Hornreich, C., Morsch, O., and Seifert, G. "Problems of partial Sample Systems for Raw Exhaust Mass Emission Measurement." 2003 SAE World Congress. Detroit, MI: SAE International, SAE Technical Paper No. 2003-01-0779, 2003.

8. Wei, Q., Porter, S., Harvey, N., Kihara, N., Khalek, I., and Bougher, T. "Diesel Exhaust Particulate Sampler for On-board PM Measurement.” 2008 World Congress. Detroit, MI: SAE International, SAE Technical Paper No. 2008-01-1180, 2008.

9. Silvis, W., Mareelsk, G., Kreft N., and Schindler, W. "Diesel Particulate Measurement with Partial Flow Sampling Systems: A New Probe and Tunnel Design that Correlates with Full FlowTunnels." SAE 2002 World Congress. Detroit, MI: SAE International, SAE Technical Paper No. 2002-01-0054, 2002.

10. Swanson, J. and Kittelson, D. "Factors Influencing Mass Collected During 2007 Diesel PM Filter Sampling.” SAE Int. J. Fuels Lubr. Vol. 2, No. 1, pp.718-729, 2009.

11. Wei, Q., Kittelson, D., and Watts, W. "Single-Stage Dilution Tunnel Performance." SAE 2001 World Congress. Detroit, MI: SAE International, SAE Technical Paper No. 2001-010201, 2001.

12. Sierra Instruments Inc. "Smart Trak ${ }^{\circledR} 2$ Series 100 Instruction Manual." Sierrainstruments.com. Accessed 7/7/2011. 
13. TSI Incorporated. "Model 3090 Engine Exhaust Particle Sizer ${ }^{\mathrm{TM}}$ Spectrometer, Operation and Service Manual." P/N 1980494, Revision F. March 2009.

14. Bielaczyc, P. and Szczotka, A. "Analysis of Uncertainty of the Emission Measurement of Gaseous Pollutants on Chassis Dynamometer." SAE 2007 World Congress. Detroit, MI: SAE International, SAE Technical Paper No. 2007-01-1324, 2007

15. Velosa, J. "Error Analysis of the Vehicle Exhaust Emission Measurement System." SAE 1993 World Congress. Detroit MI: SAE International, SAE Technical Paper No. 930393, 1993.

16. Khalek, I., Ullman, T., Silvis, W., Kreft, N., Shimpi, S., Harvey, R., Munday, D., Yamagishi, Y., Jackson, C., Graze, R., Dharmawardhana, B., Smitherman, J., and Adkins, J. "Performance of Partial Flow Sampling Systems Relative to Full Flow CVS for Determination of Particulate Emissions under Steady-State and Transient Diesel Engine Operation." International Spring Fuels \& Lubricants Meeting \& Exhibition. Reno, NV: SAE International, SAE Technical Paper No. 2002-01-1718, 2002.

17. Cummins Southern Plains, Ltd. "Cummins ISX." http://www.cumminssp.com/engines/automotive/isx_engine.htm, Accessed 7/7/2011.

18. Shade, B. Pictures taken during testing. 2008.

19. "Heavy-Duty FTP Transient Cycle," DieselNet, Brampton, ON, Canada, 2006. http://www.dieselnet.com/standards/cycles/ftp_trans.html, Accessed 7/7/2011.

20. Meriam Process Technologies. "Laminar Flow Elements." http://www.meriam.com/pdf/Brochures/catalog/Sct8_LaminarFlowElements.pdf. Accessed 7/7/2011.

21. Sierra Instruments Inc. "BG-3 Particulate Partial Flow Sampling System," http://www.sierrainstruments.com/emissions/bg3.html, Accessed 7/7/2011.

22. Precision Weighing Balances. "Sartorius Ultra-Micro \& Micro Analytical Balances." http://sartorius.balances.com/sartorius/sartorius-micro-balances.html. Accessed 7/7/2011.

23. Shewalla, U. "Verification of a level-3 diesel emissions control strategy for transport refrigeration units," Master's Thesis, Dept. of Mechanical and Aerospace Engineering, West Virginia University, 2010.

24. Ayala, A., Olson, B., Cantrell, B., Drayton, M., and Barsic, N. "Estimation of Diffusion Losses when Sampling Diesel Aerosol: A Quality Assurance Measure.” 2003 JSAE/SAE 
Intl. Spring Fuels \& Lubricants Meeting. Yokohama, Japan: SAE International, SAE Technical Paper No. 2003-01-1896, 2003.

25. Hinds, W. “Aerosol Technology,” John Wiley \& Sons, Inc., New York, 1999.

26. Virtanen, A., Ristimaki, J., Marjamaki, M., Vaaraslahti, K., Keskinen, J., and Lappi, M. "Effective Density of Diesel Exhaust Particles as a Function of Size," Warrendale, PA, SAE Technical Paper No. 2002-01-0056, 2002. 


\section{Appendices}

\subsection{Code for CVS Error Propagation Analysis Model}

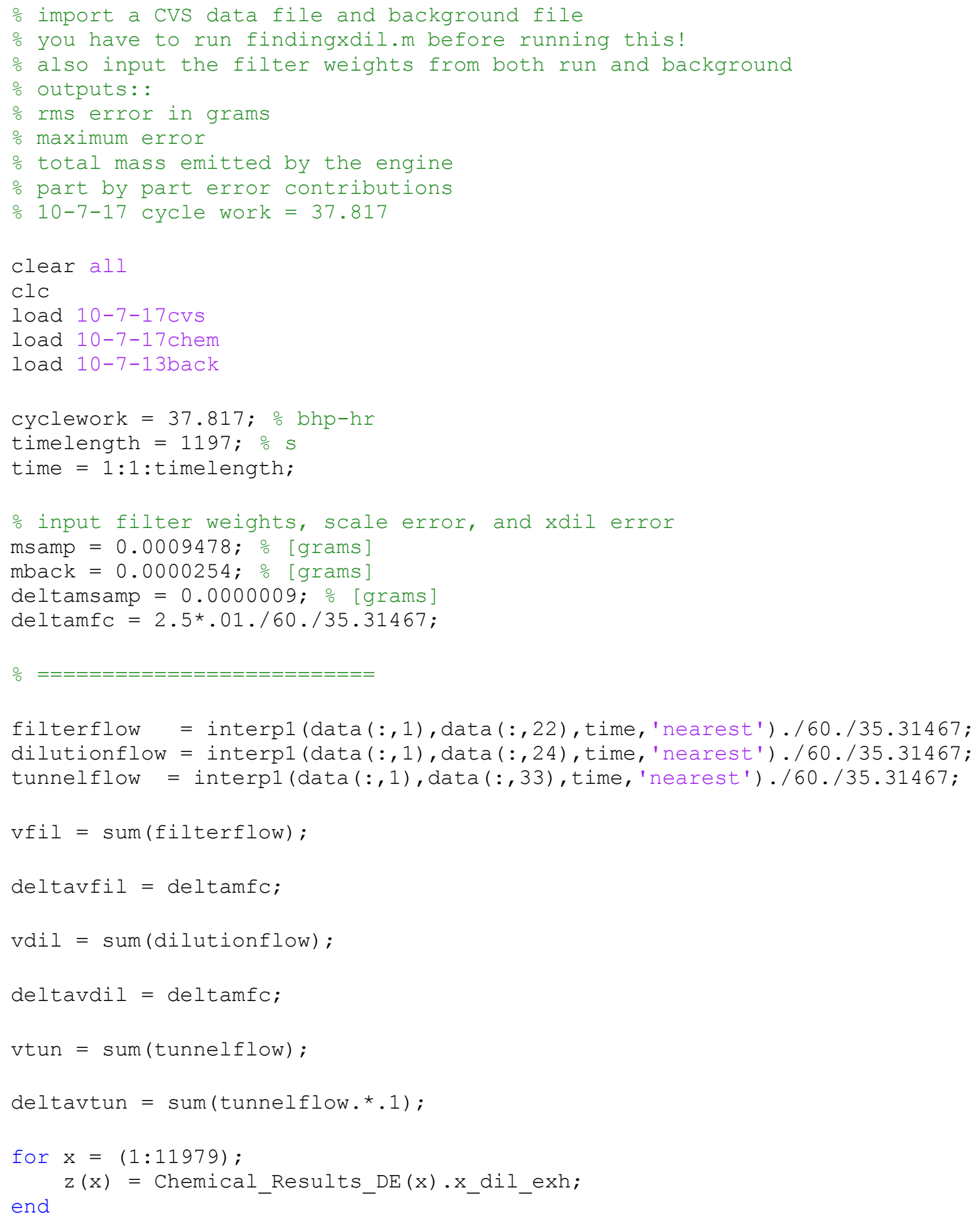




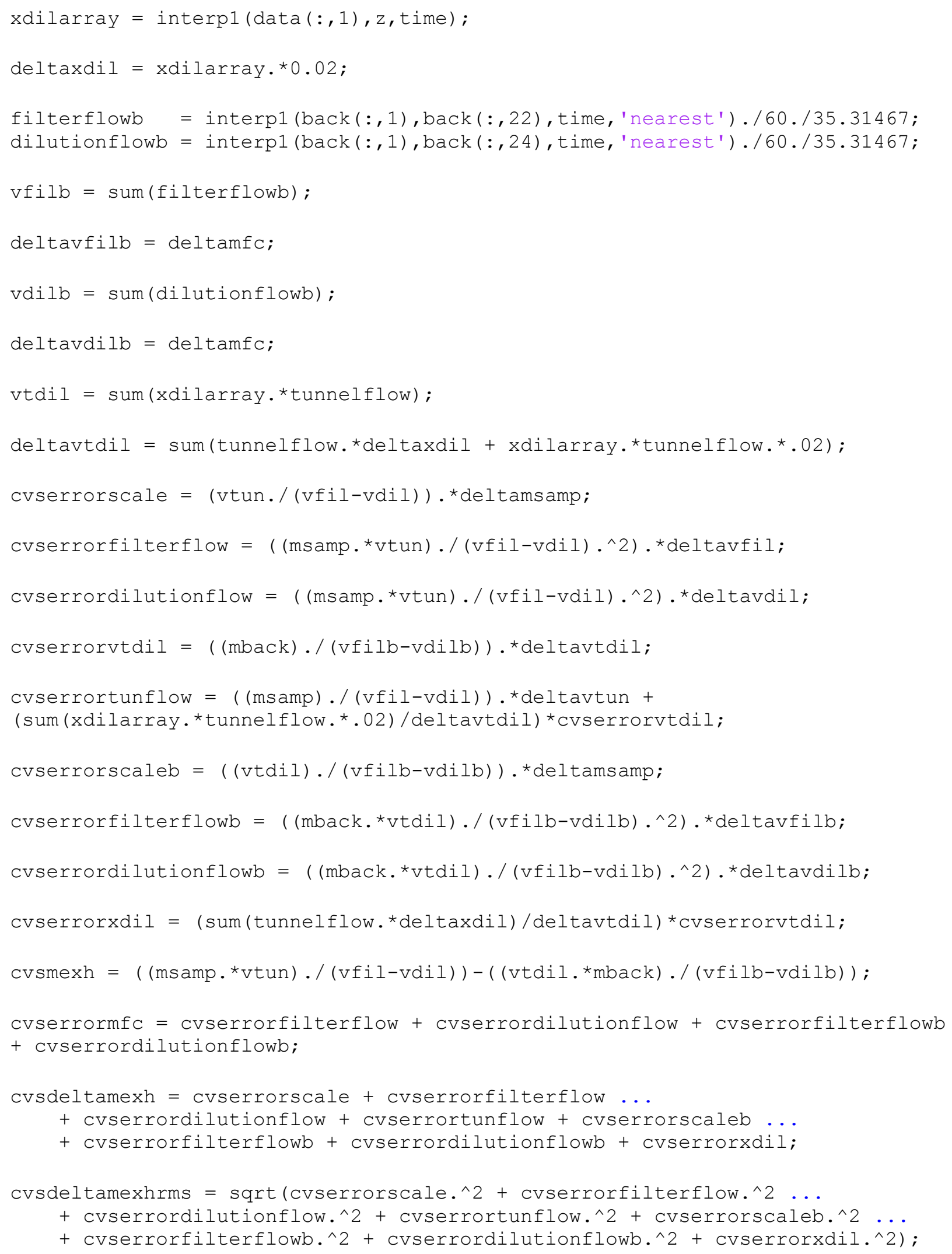




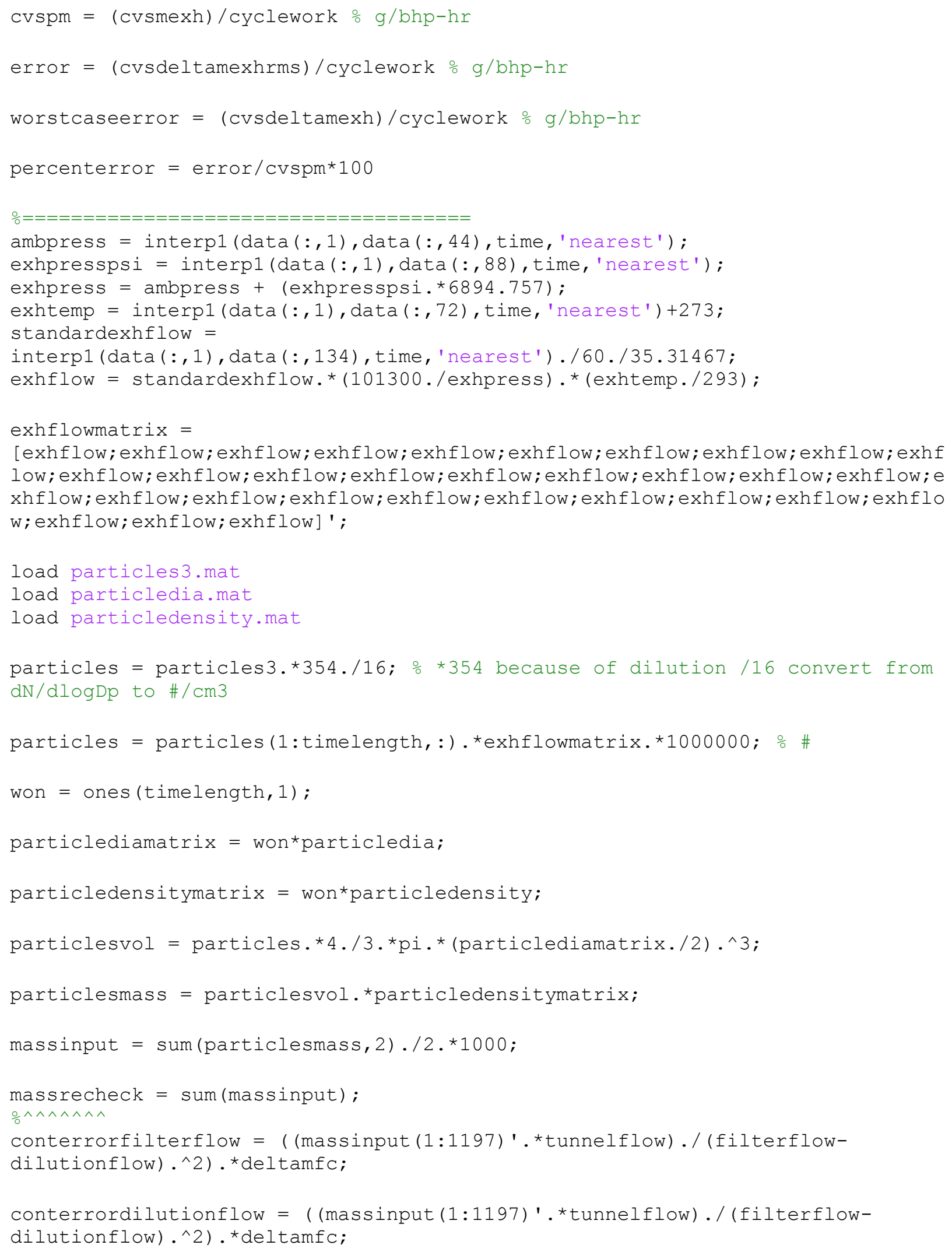




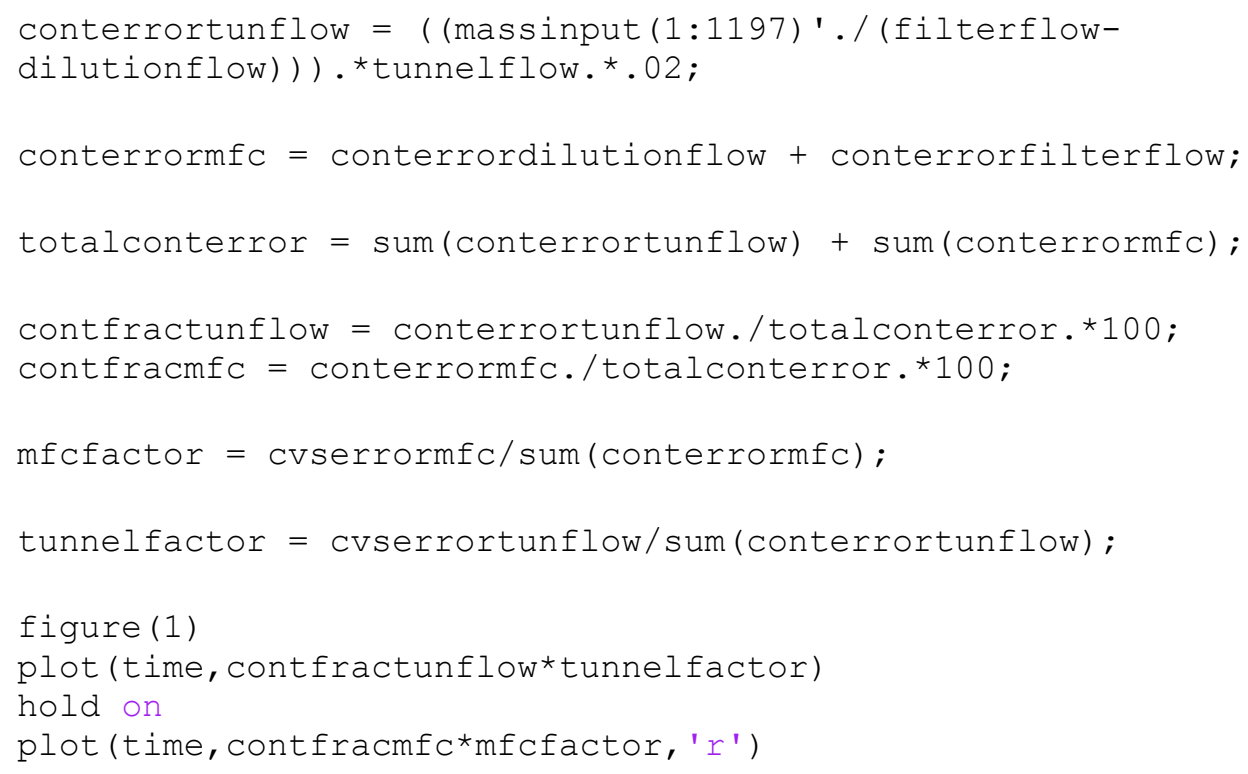

\subsection{Code for PFS Error Propagation Analysis Model}

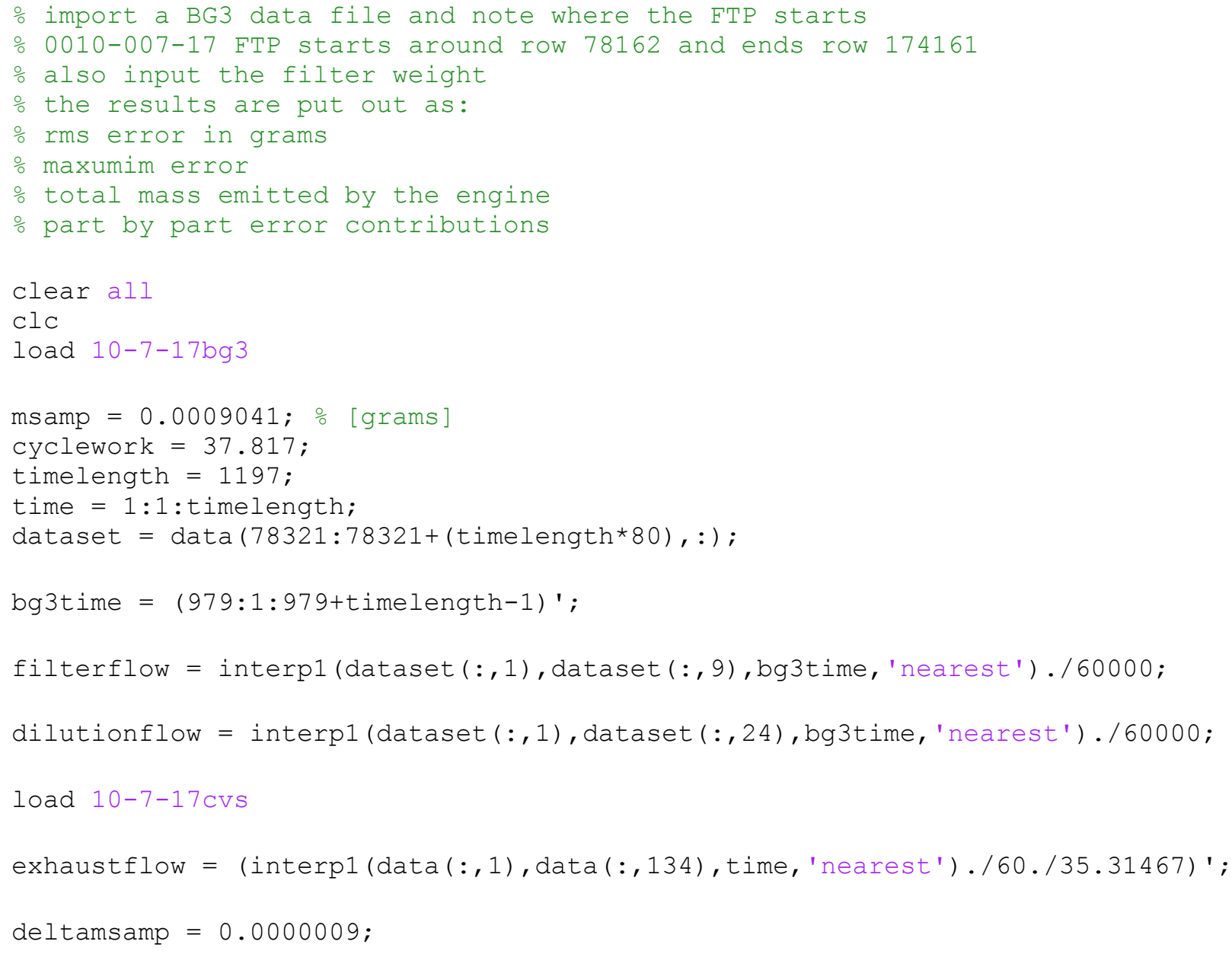




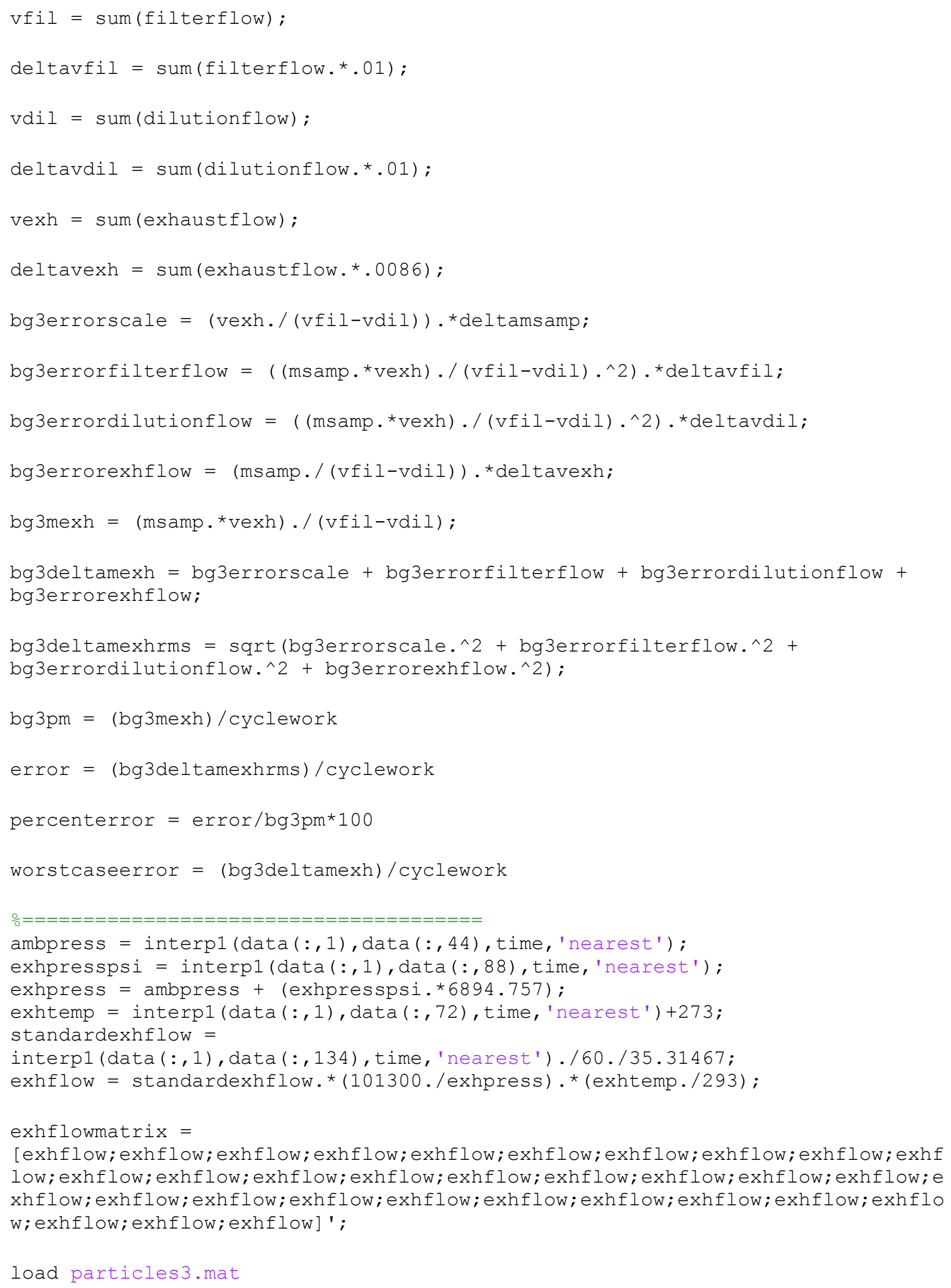




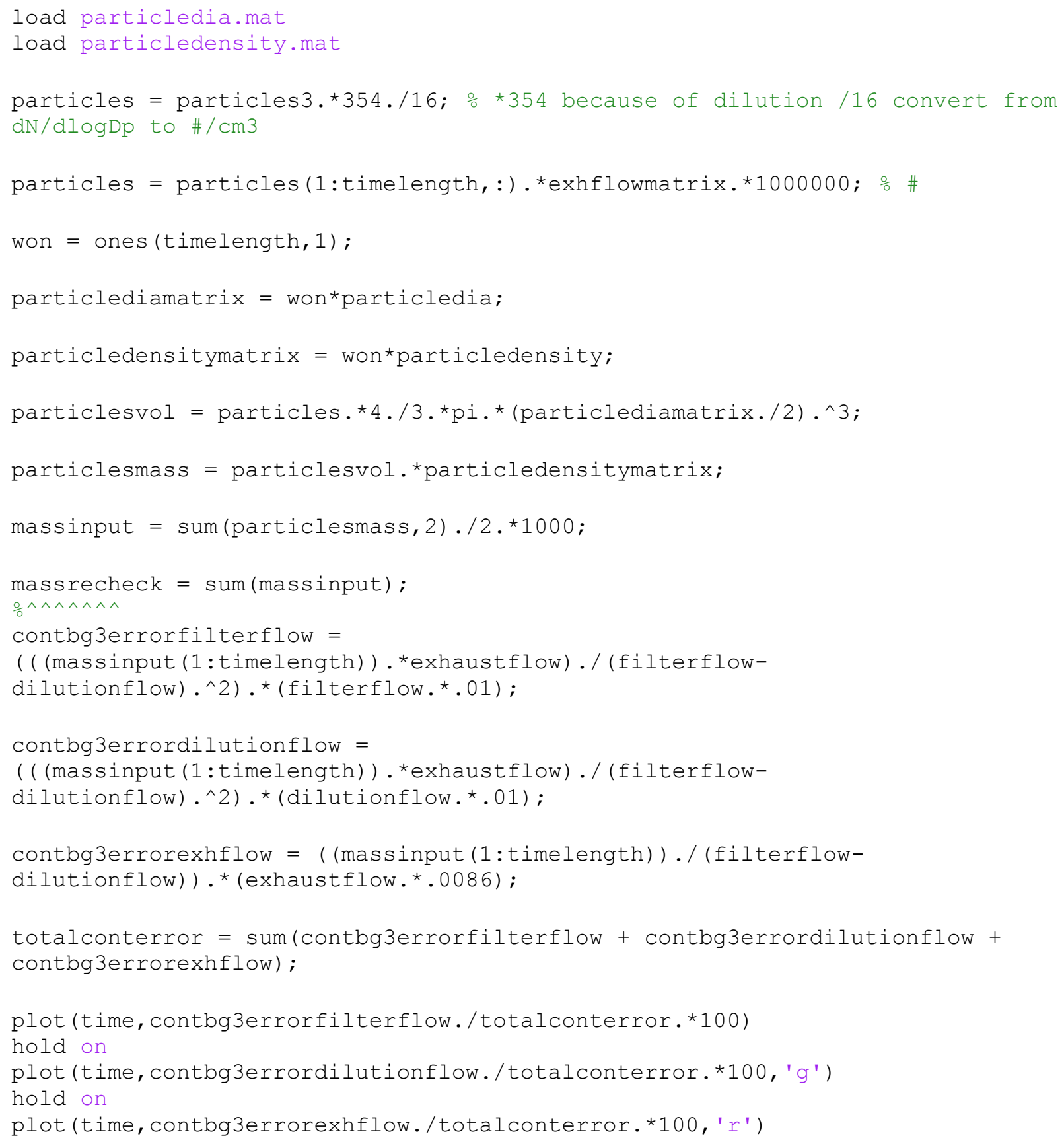




\subsection{Code for Loss Model}

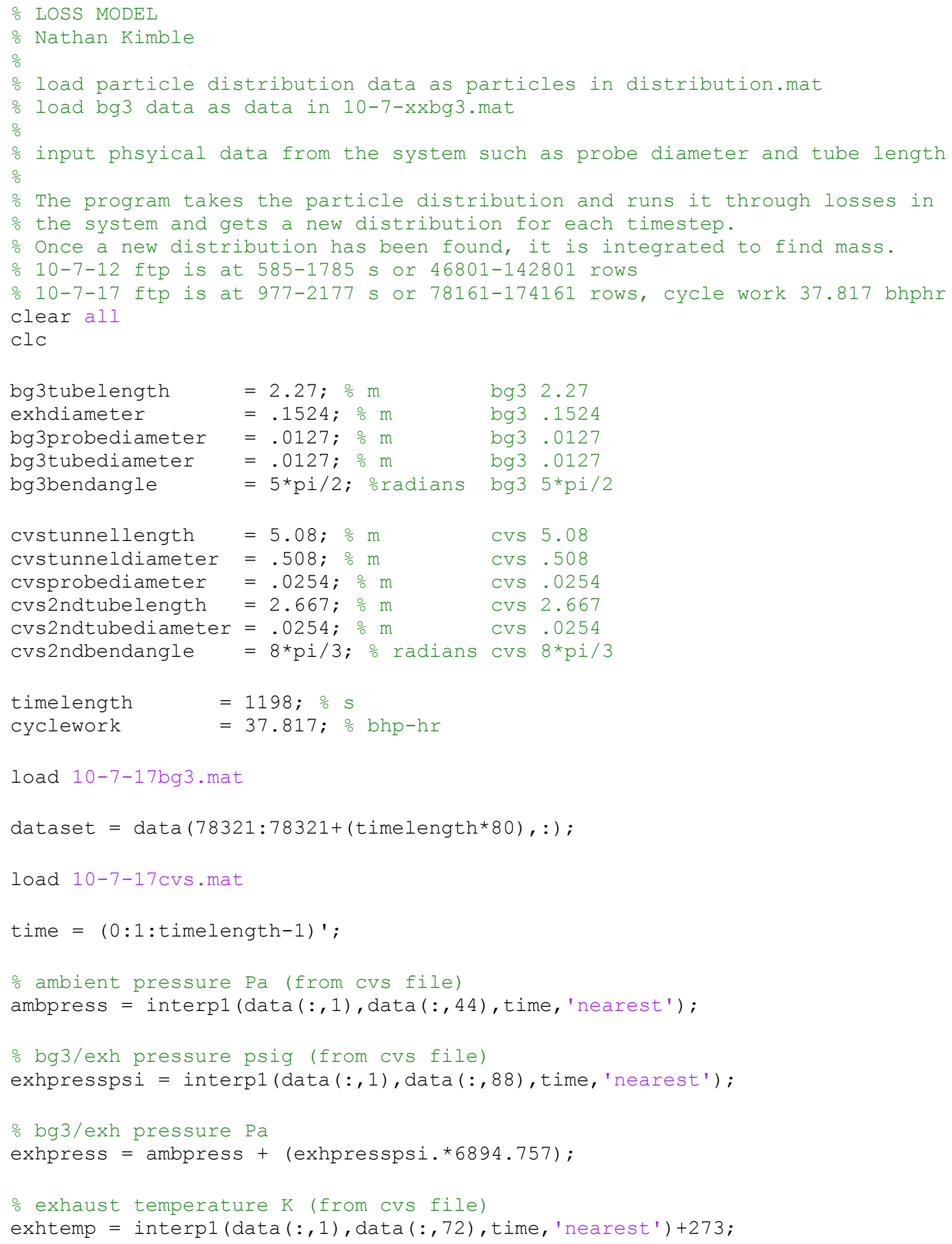




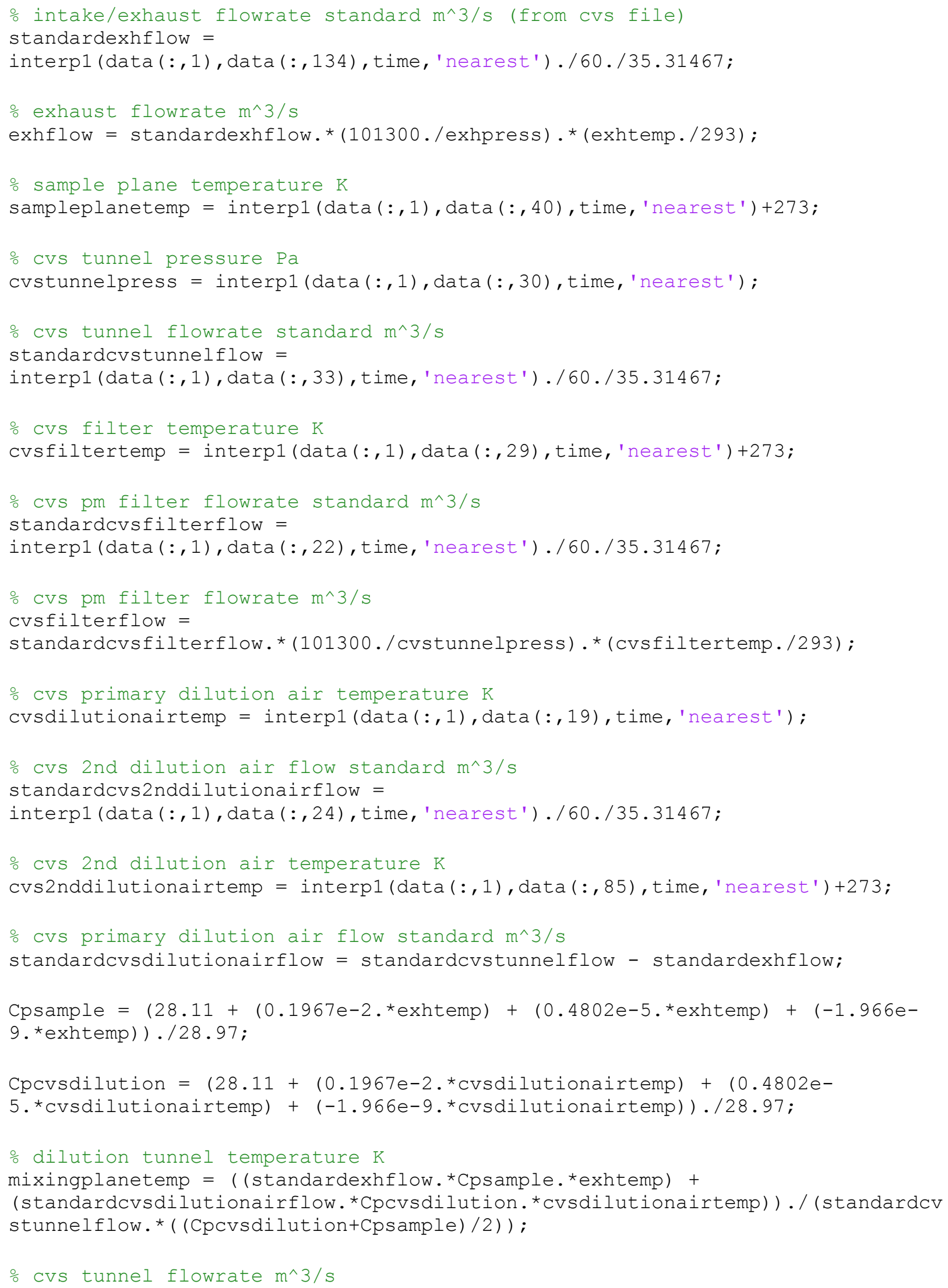




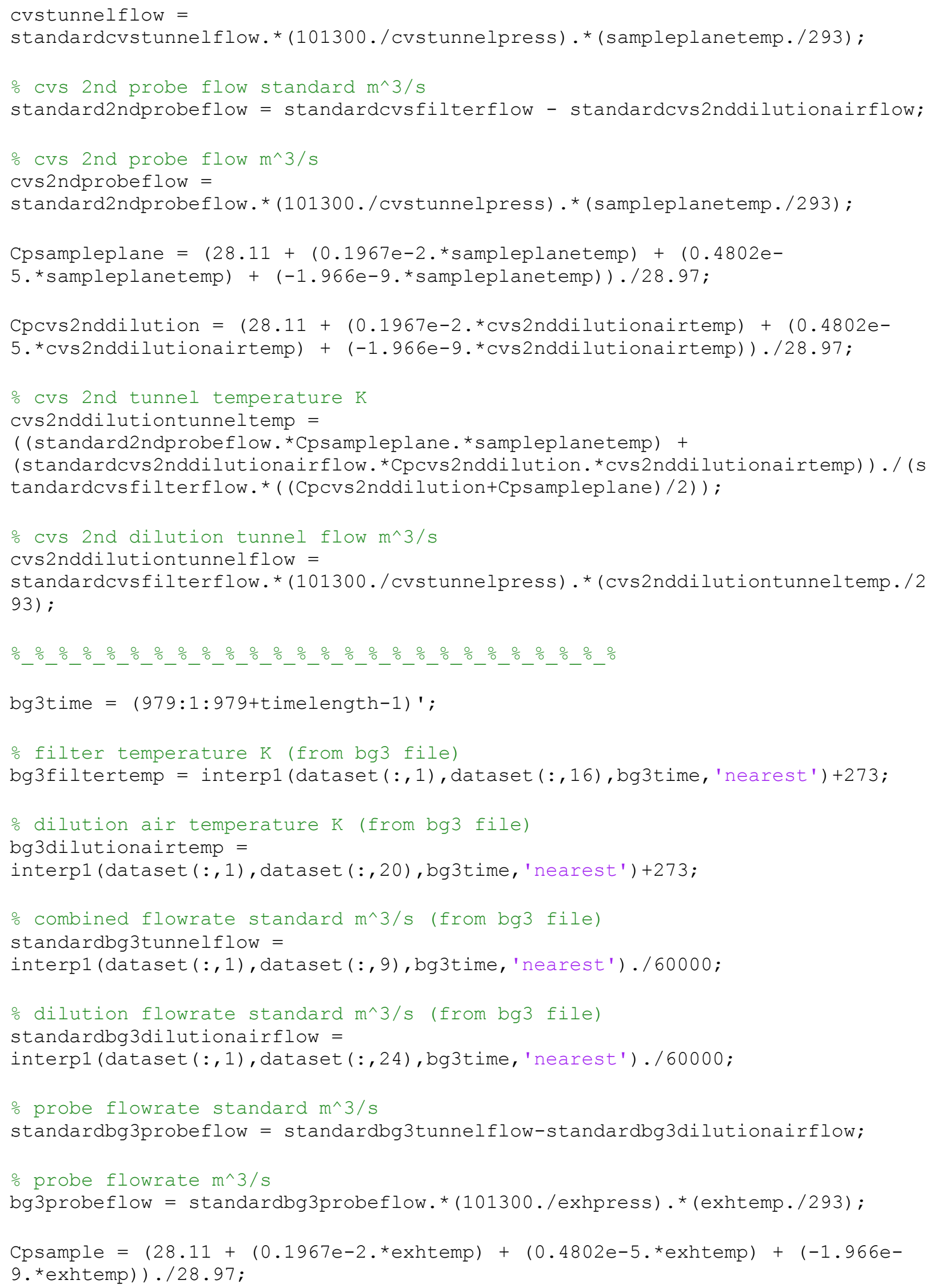




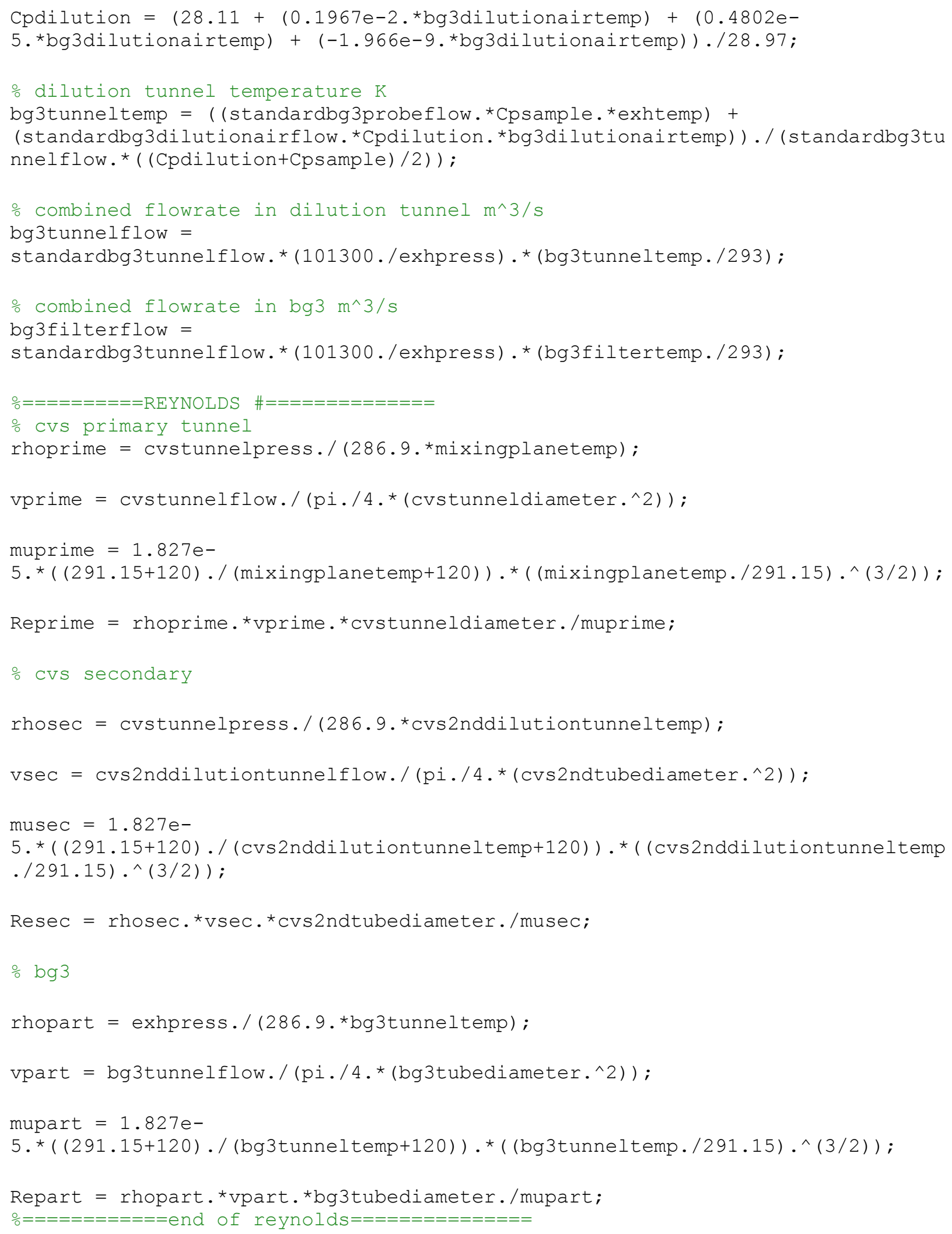




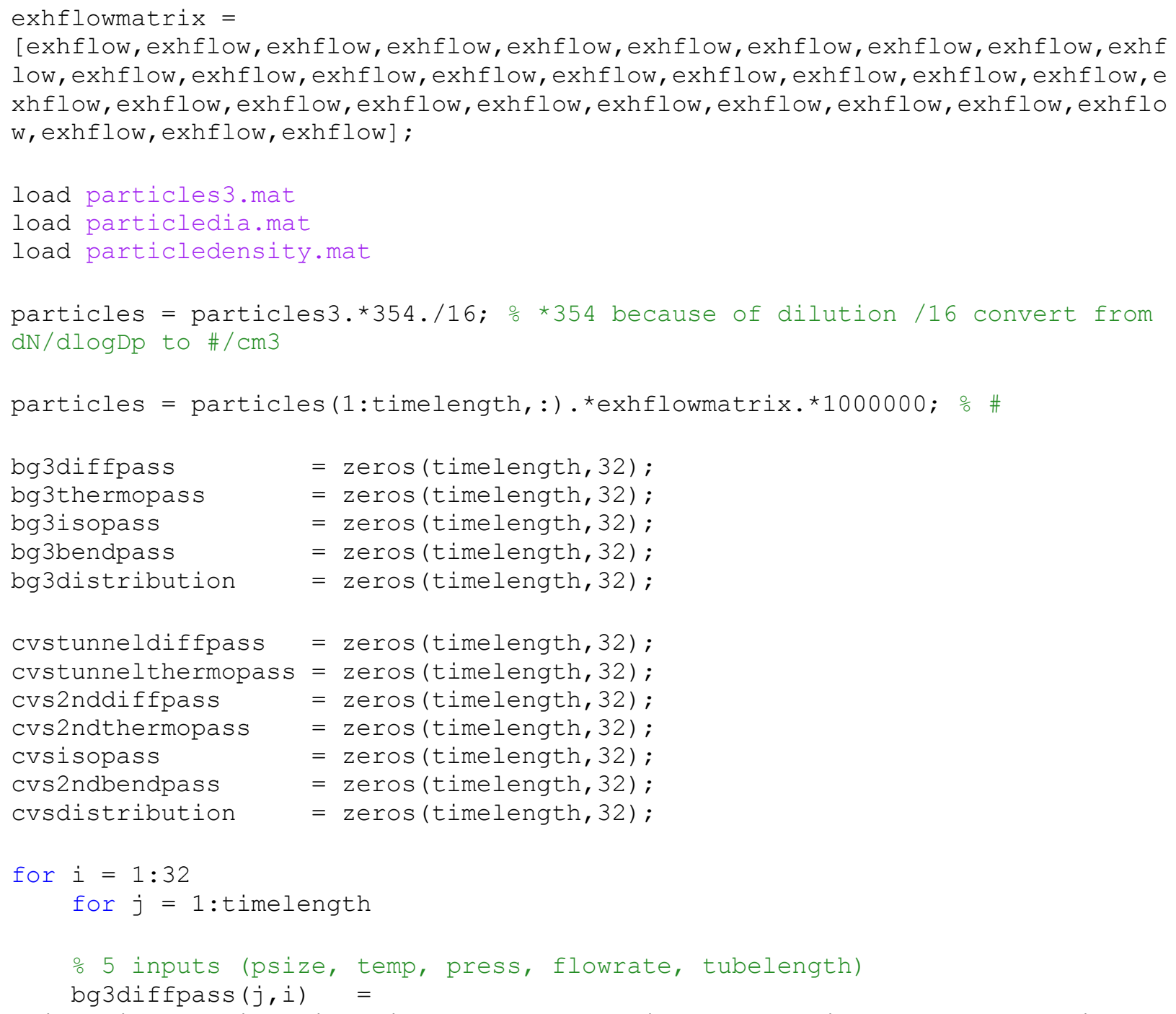




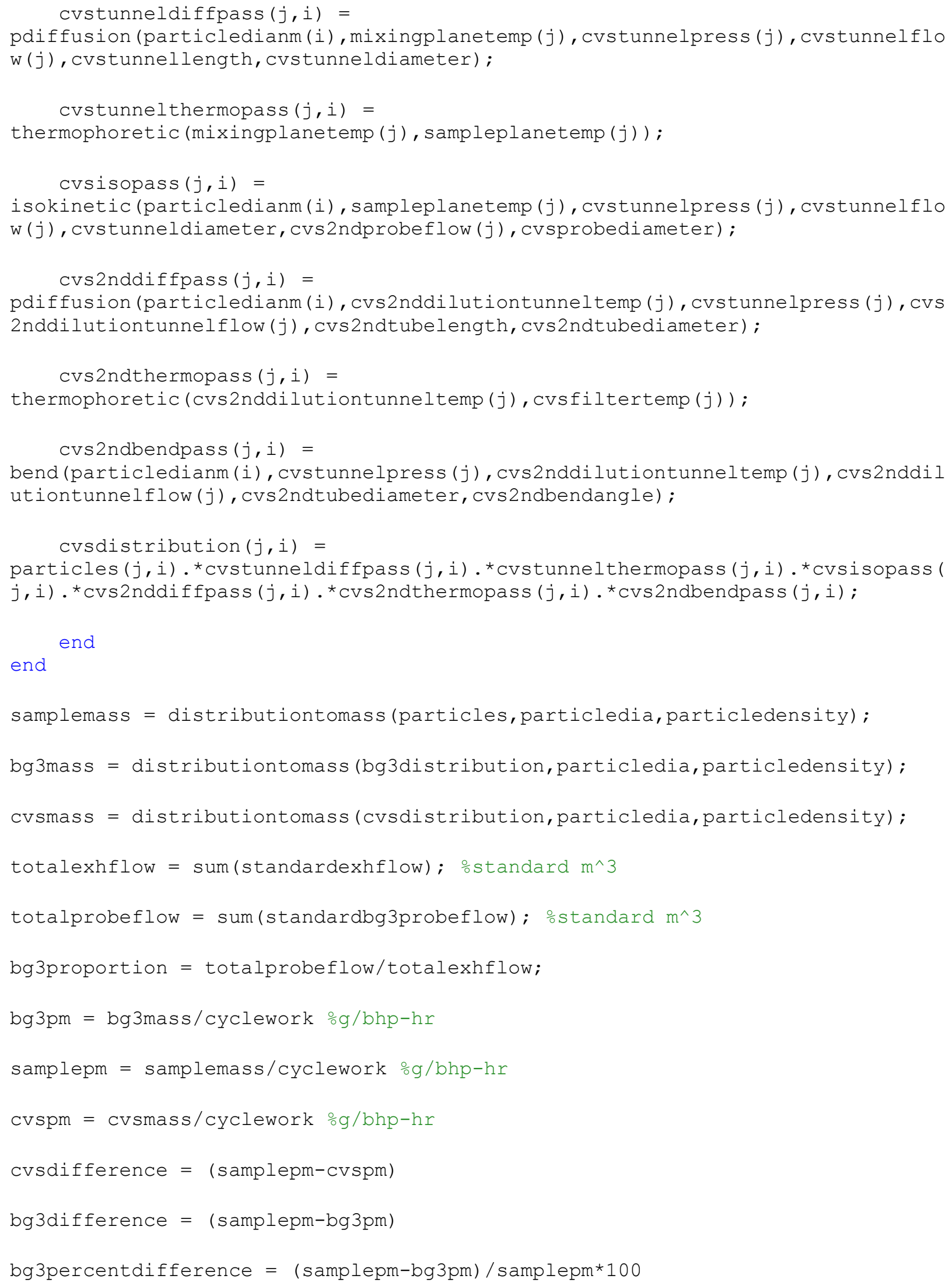




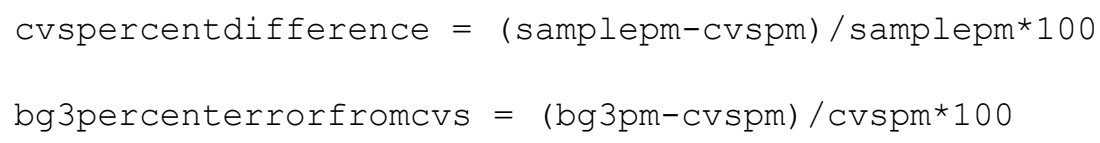




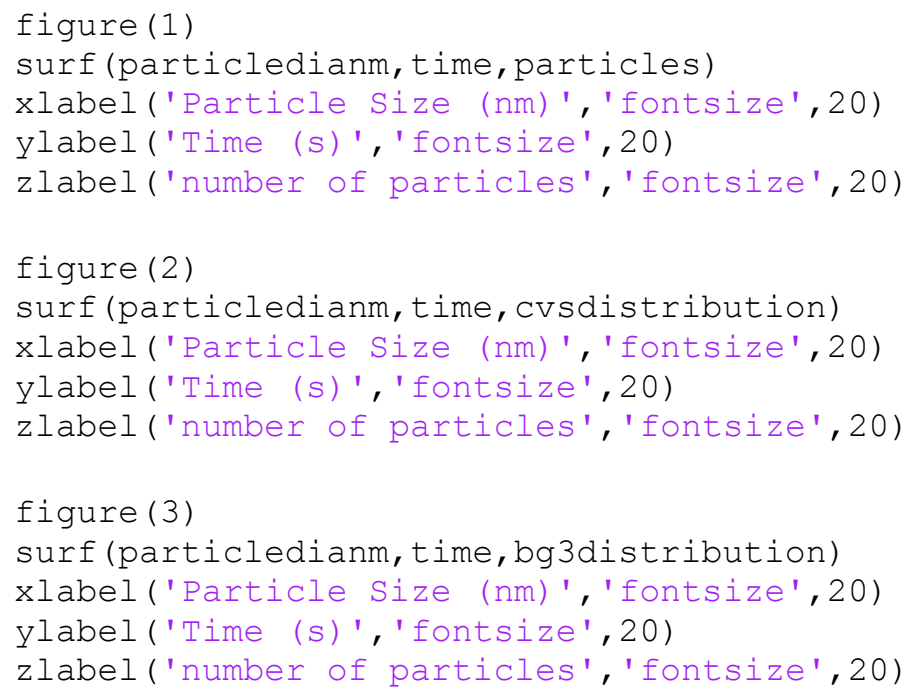




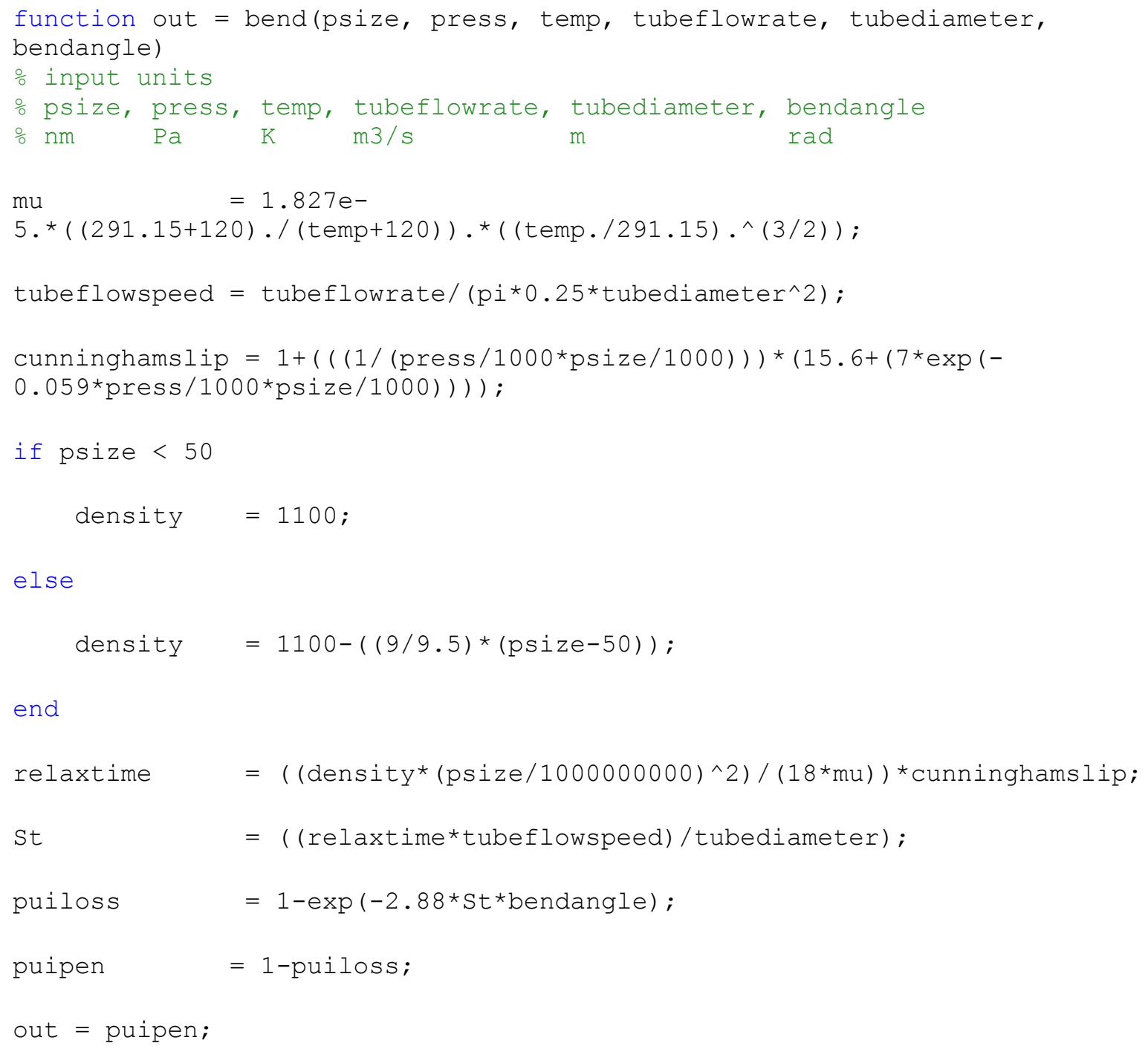




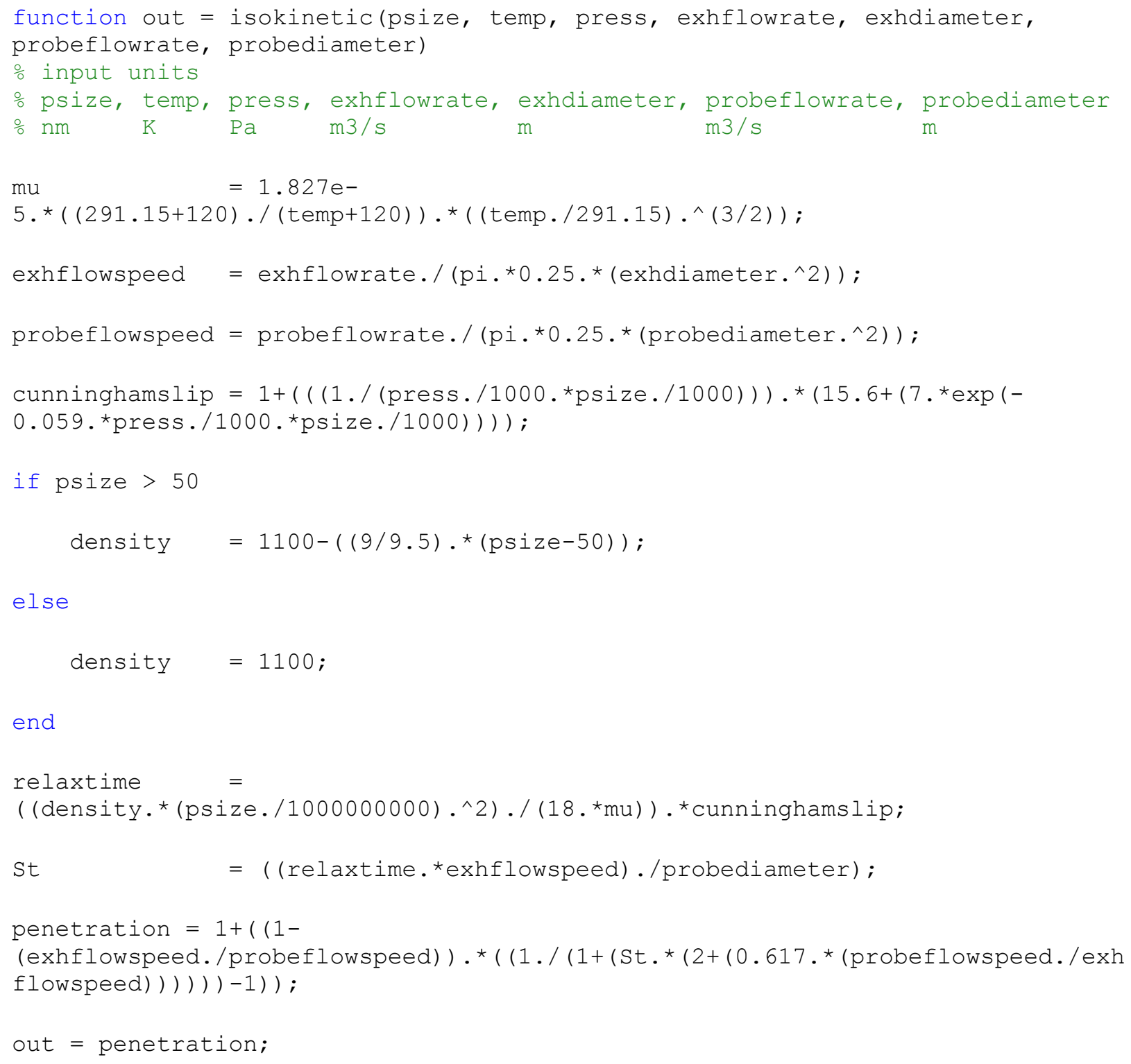




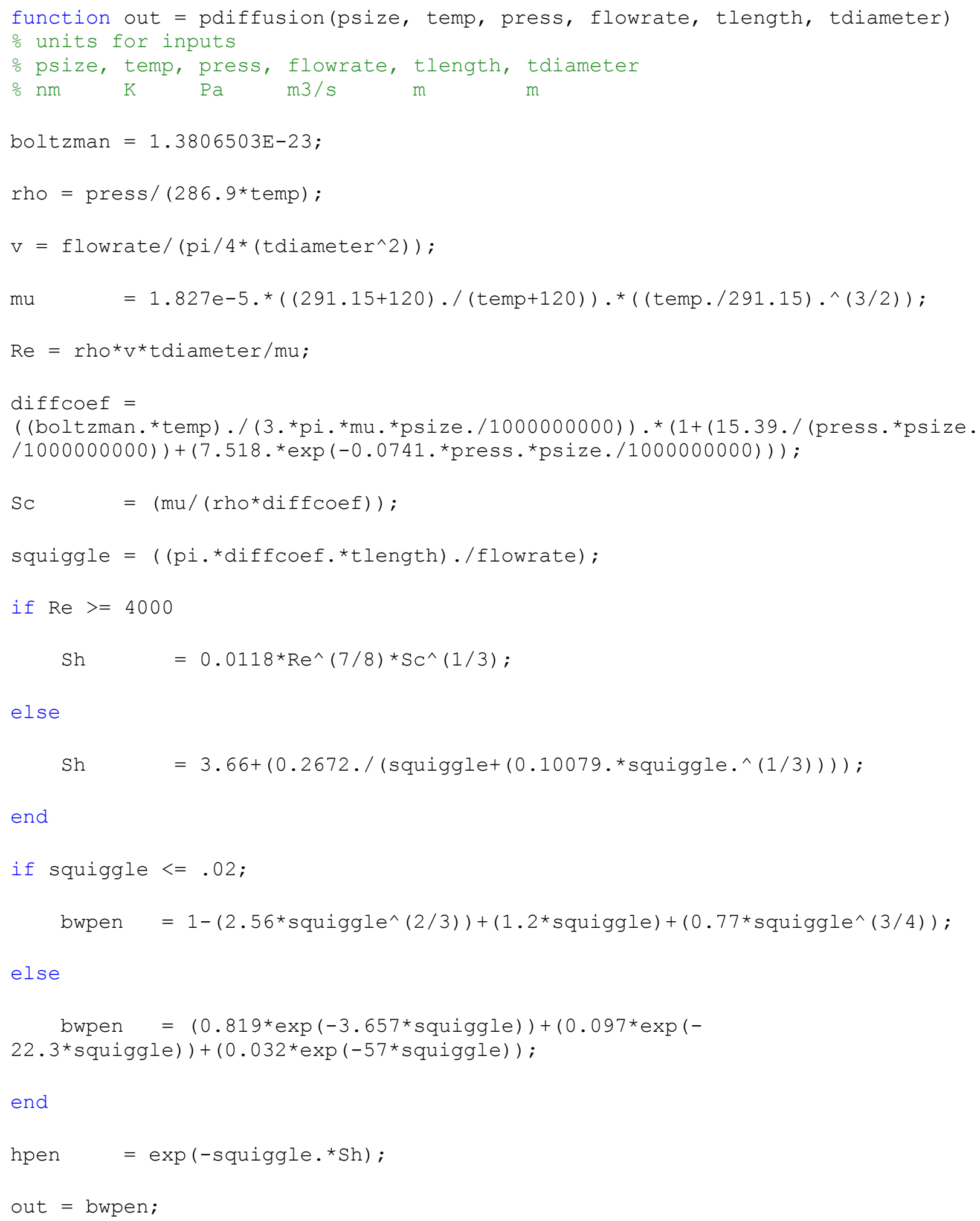




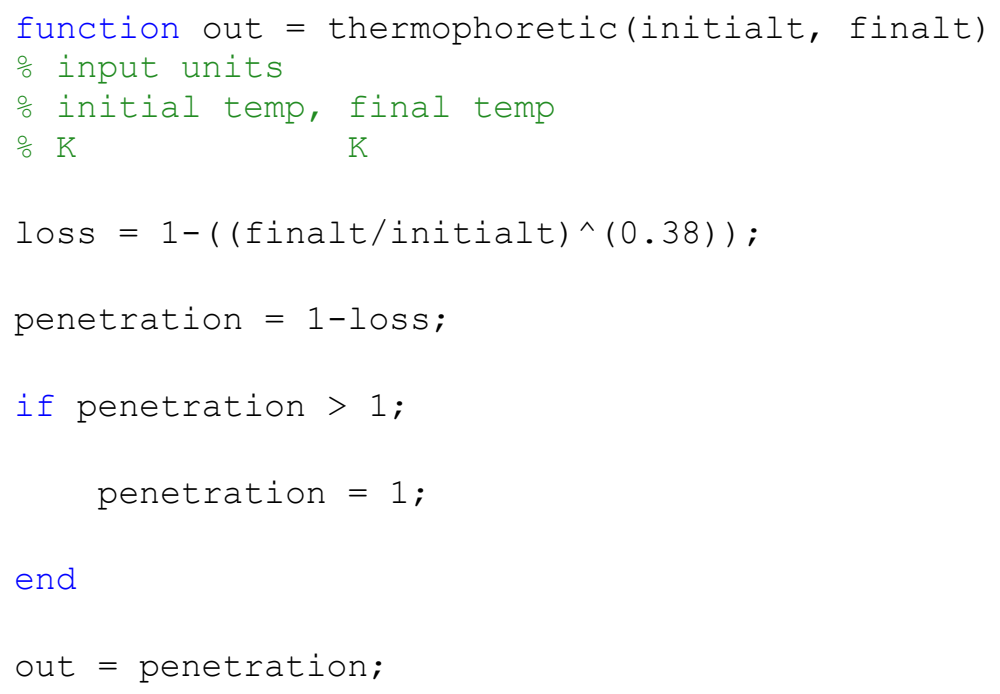




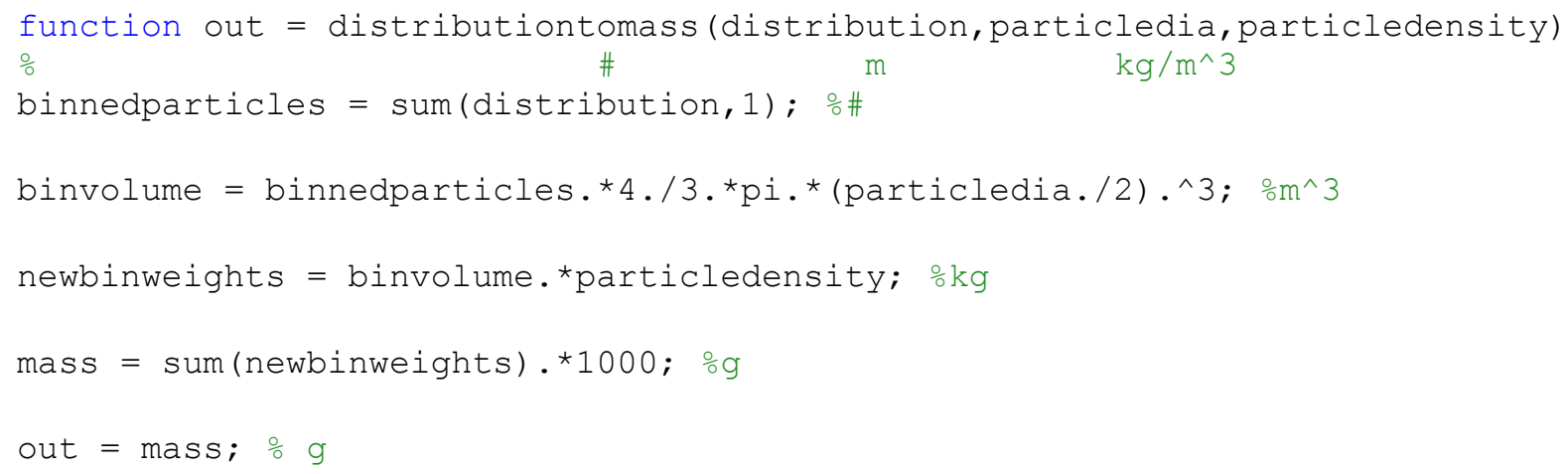




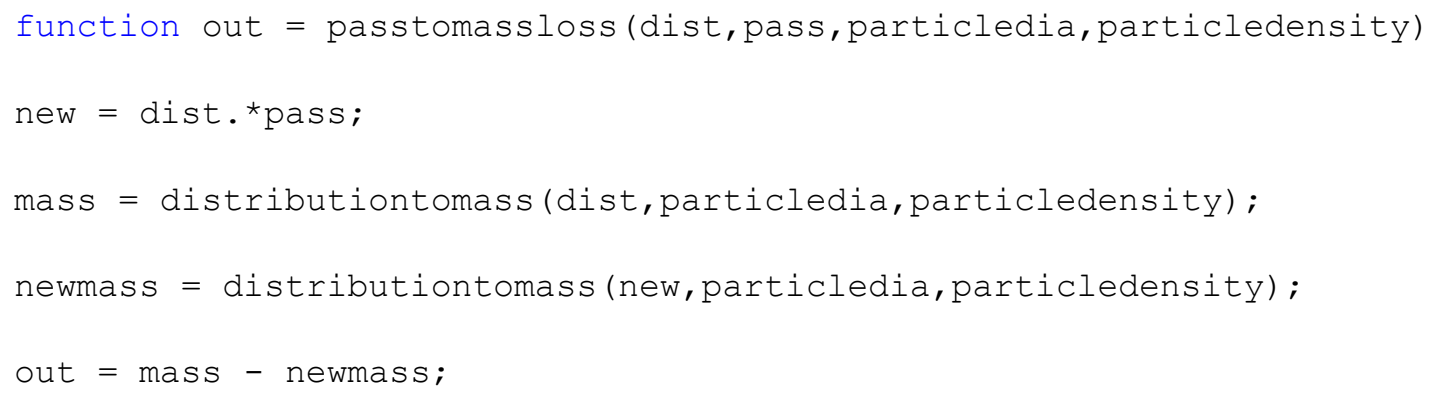

